$$
\begin{gathered}
\text { UNIVERSIDADE DE SÃO PAULO } \\
\text { ESCOLA DE COMUNICAÇÕES E ARTES } \\
\text { PROGRAMA DE PÓS-GRADUAÇÃO EM CIÊNCIA DA INFORMAÇÃo }
\end{gathered}
$$

DENYSSON AXEL RIBEIRO MOTA

REPRESENTAÇÃO E RECUPERAÇÃO DE INFORMAÇÃO EM ACERVOS DIGITAIS NOS CONTEXTOS DA WEB SEMÂNTICA E WEB PRAGMÁTICA: UM ESTUDO CRÍTICO 


\section{REPRESENTAÇÃO E RECUPERAÇÃO DE INFORMAÇÃO EM ACERVOS DIGITAIS NOS CONTEXTOS DA WEB SEMÂNTICA E WEB PRAGMÁTICA: UM ESTUDO CRÍTICO}

Tese apresentada ao Programa de PósGraduação em Ciência da Informação da Escola de Comunicações e Artes da Universidade de São Paulo - Área de Concentração: Cultura e Informação; Linha de Pesquisa "Organização da informação e do conhecimento", para fins de obtenção do título de Doutor em Ciência da Informação.

Orientadora: Prof. Dra. Nair Yumiko Kobashi 


\section{DENYSSON AXEL RIBEIRO MOTA}

\section{REPRESENTAÇÃO E RECUPERAÇÃO DE INFORMAÇÃO EM ACERVOS DIGITAIS NOS CONTEXTOS DA WEB SEMÂNTICA E WEB PRAGMÁTICA: UM ESTUDO CRÍTICO}

Tese apresentada ao Programa de PósGraduação em Ciência da Informação da Escola de Comunicações e Artes da Universidade de São Paulo - Área de Concentração: Cultura e Informação; Linha de Pesquisa "Organização da informação e do conhecimento", para fins de obtenção do título de Doutor em Ciência da Informação.

APROVADA EM: 24 / 09 / 2015

BANCA EXAMINADORA:

Profa. Dra. Nair Yumiko Kobashi - PPGCI/USP

Orientadora

Profa. Dra. Leilah Santiago Bufrem

Examinadora Externa

Prof. Dr. Maurício Barcellos Almeida

Examinador Externo

Profa. Dra. Marilda Lopes Ginez de Lara - PPGCI/USP Examinadora Interna

Prof. Dr. Marcelo dos Santos - PPGCI/USP

Examinador Interno 
Este trabalho é dedicado a amigos e familiares, que sempre me apoiaram durante todo este processo, tanto nos momentos de alegria quanto de agonia. 


\section{AGRADECIMENTOS}

Agradeço neste instante àqueles que a memória permite lembrar, sem fazer destes exclusivos nesse momento de gratidão, pois a memória é falha.

A meus pais: Ieda Ribeiro e Jael Costa Mota. Tudo que sou devo a eles;

A Professora Nair Kobashi, por toda a paciência com minhas "teimosias" e sabedoria ao me guiar nesta pesquisa;

A Gracy Martins, pelo apoio, carinho e companheirismo presentes em todo momento;

A Henry e Marcos, que me recebiam com carinho em Marília, junto com Aline e Luciana que nos acompanhavam nesta linda cidade;

Aos grandes amigos Everton Dias e André Anderson, sempre presentes mesmo distantes, e à Milca Ramos, em especial, sem a qual este trabalho não seria entregue;

Aos Colegas do PPGCI/USP, que compartilharam este processo e que com as conversas muitas vezes traziam iluminações para os caminhos deste trabalho;

Aos professores da USP, pelos ensinamentos e amizade;

E um agradecimento especial aos Professores Marcelo dos Santos, Marilda Lopes Ginez de Lara, Leilah Santiago Bufrem e Maurício Barcellos Almeida, membros da Banca de defesa. 
For millions of years, mankind lived just like the animals. Then something happened which unleashed the power of our imagination. We learned to talk. [...]

-Stephen W. Hawking, British Telecom advertisement, 


\section{RESUMO}

Estudo comparativo das propostas da Web Semântica e da Web Pragmática, com base nas teorias da organização e recuperação de informações, com o objetivo de propor uma modelagem de representação de dados, que inclua contextos, para melhorar a qualidade dos processos informacionais. Dirige-se o foco da pesquisa aos problemas da representação e recuperação de informações em acervos bibliográficos, principalmente com o uso de RDF e Topic Maps. Para isso, são apresentadas as origens da Web Semântica e da Web Pragmática e os conceitos fundamentais relacionados a esse ambiente, tais como linguagem, representação e recuperação da informação e do conhecimento; termos e terminologia; semântica e pragmática. A metodologia do trabalho foi construída a partir da análise e discussão dos conceitos fundamentais, a modelagem em Diagrama Entidade-Relacionamento e a codificação em RDF e XTM para representar contextos, aplicados a um repositório de textos científicos. Com base na análise crítica das propostas de organização e recuperação de informação das Web Semântica e Web Pragmática, apresenta-se uma proposta de representação de informações com contexto que poderá contribuir para melhorar a relevância dos resultados da recuperação de informações na WWW. Os contextos representados são: Citações, Domínio de Origem do Documento, Domínio da Palavra-Chave, Áreas de Formação do Indivíduo, Âreas de Publicação do Indivíduo, Áreas de Publicação da Revista e Interesses do Indivíduo. A pesquisa permitiu observar que há limites para introduzir contextos em sistemas de informação e compreender, também, que termos como semântica e pragmática requerem abordagem crítica. De fato, a operacionalização de conceitos semânticos e pragmáticos ainda está longe de ser realidade nos sistemas de informação contemporâneos no contexto da www. É importante ressaltar que a presente pesquisa tem cunho interdisciplinar por abordar problemas discutidos tanto na Ciência da Computação como na Ciência da Informação. Esta abordagem interdisciplinar ocorre, em primeiro lugar, porque o objeto de pesquisa, embora tenha origem na Ciência da Computação, requer as teorias e métodos da representação da informação estudados na Ciência da Informação para ser desenvolvido de forma adequada.

Palavras-chave: Acervos Digitais de Textos Científicos. Organização do Conhecimento. Recuperação da Informação. Representação de Contexto. Web Semântica. Web Pragmática. 


\begin{abstract}
Comparative study of the proposals of the Semantic Web and Pragmatic Web, based on the information organization and retrieval studies, in order to propose a model that includes contexts to improve the quality of information retrieval processes. Information representation and retrieval in library collections are the focus of the approach, especially with the use of RDF and Topic Maps. For the development of this research, the origins of the Semantic Web and Pragmatic Web and its fundamental concepts such as language, information and knowledge representation and retrieval; terms and terminology; semantics and pragmatics were discussed. The methodology of this work consisted of the analysis and discussion of key concepts, such as Entity-Relationship Diagram modeling and encoding in RDF and XTM to represent contexts, applied to a repository of scientific texts. Based on the critical analysis of proposed information organization and retrieval from the Semantic Web and Pragmatic Web, it is proposed an information representation with context that could improve the of relevance of the results of information retrieval processes in WWW. The contexts represented were: Quotation, Document Source Domain, Keyword Domain, Person's Education Areas, Person's Publication Areas, Journal's Publication Areas and Person's Interests. This research allowed to undestand that there are limits to introduce contexts in information systems and that terms such as semantic and pragmatic require critical approach. Indeed, the operationalization of semantic and pragmatic concepts is still far from reality in contemporary information systems in the context of www. This research has interdisciplinary nature by addressing problems discussed both in Computer Science and in Information Science. The interdisciplinary approach was adopted because the object of research, although originated in Computer Science requires the to be appropriately developed, theories and methods of information representation studied in Information Science.
\end{abstract}

Keywords: Digital Collections of Scientific Texts. Knowledge Organization. Information Retrieval. Context Representation. Semantic Web. Pragmatic Web. 


\section{TABELA DE FIGURAS}

Figura 1 - Sintaxe, semântica e pragmática............................................................................ 14

Figura 2 - Diagrama de um Sistema de Recuperação da Informação. ................... 15

Figura 3 - Exemplo de valores de vetor para termos de busca em três textos ....... 17

Figura 4 - Relação entre gramática, léxico e léxicos de especialidade ...................... 30

Figura 5 - Possibilidade de sobreposição de contextos ................................................... 46

Figura 6 - Tipos de Relevância e suas relações..................................................................... 48

Figura 7 -Relevância vs Pertinência .......................................................................... 50

Figura 8 - A Web como recursos interligados ...................................................... 52

Figura 9 - A Web como objetos inter-relacionados .............................................. 53

Figura 10 - Tecnologias envolvidas na Web Semântica ........................................... 67

Figura 11 - Exemplo de RDF em formato gráfico ..................................................... 69

Figura 12 - Diagrama Entidade-Relacionamento da BRAPCI ................................... 84

Figura 13 - Relacionamento de Citação entre Artigos ............................................ 91

Figura 14 - Relacionamento de Citação entre Artigo e Obra ....................................... 91

Figura 15 - Tipos de Citação da Ontologia CiTO ......................................................... 92

Figura 16 - Relacionamento entre Área de Conhecimento e Artigo ....................... 93

Figura 17 - Área de Conhecimento e Titulação para o Autor ................................. 94

Figura 18 - Área de Conhecimento e Titulação para o Usuário ................................ 94

Figura 19 - Tipos de Citação da Ontologia CiTO ...................................................... 95

Figura 20 - Áreas de Publicação do Autor na Base Atual........................................... 96

Figura 21 - Áreas de Publicação do Autor Sugerida .............................................. 96

Figura 22 - Área de Publicação da Revista..................................................................... 97

Figura 23 - Áreas de Publicação do Autor Sugerida ...................................................... 97

Figura 24 - Propriedades do Vocabulário FOAF ................................................. 109 


\section{TABELA DE CÓDIGOS}

Código 1 - Exemplo de código RDF.......................................................................68

Código 2 - Exemplo de código OWL .............................................................................. 70

Código 3 - Exemplo de código SparQL Simples ................................................................ 71

Código 4 - Exemplo de código SparQL ............................................................................. 71

Código 5 - Exemplo de tópicos abstratos em XTM...................................................... 73

Código 6 - Exemplo de tópico concreto (instancia) em XTM ....................................... 74

Código 7 - Exemplo de relacionamento (Association) em XTM ................................... 74

Código 8 - Exemplo de tópico de instância com ocorrência em XTM ....................... 75

Código 9 - Exemplo de definição de escopo em XTM..................................................... 76

Código 10 - Exemplo de definição de palavras-chave em RDF .................................... 78

Código 11 - Exemplo de reificação em RDF ..................................................................... 78

Código 12 - Exemplo de associação em XTM.................................................................. 79

Código 13 - Exemplo de citação em RDF ......................................................................... 98

Código 14 - Exemplo de citação com reificação em RDF............................................... 99

Código 15 - Exemplo de várias citações com reificação em RDF ............................... 100

Código 16 - Exemplo de citação em XTM ....................................................................... 100

Código 17 - Domínio do Artigo em RDF........................................................................ 101

Código 18 - Domínio do Artigo em XTM ....................................................................... 102

Código 19 - Área de Formação em RDF ...................................................................... 102

Código 20 - Área de Formação com reificação em RDF ............................................. 103

Código 21 - Área de Formação em XTM........................................................................ 104

Código 22 - Domínio Terminológico em RDF Reificado.............................................. 105

Código 23 - Domínio Terminológico em XTM.............................................................. 106

Código 24 - Áreas de Publicação da Revista em RDF Simples.................................. 106

Código 25 - Áreas de Publicação da Revista em XTM................................................ 107 
Código 26 - Áreas de Publicação do Indivíduo em RDF 107

Código 27 - Áreas de Publicação do Indivíduo em XTM. 108

Código 28 - Interesse do Indivíduo em RDF 110

Código 29 - Interesse do Indivíduo em XTM 110 


\section{TABELA DE QUADROS}

Quadro 1 - Tabela-verdade para uma busca booleana usando dois termos 16

Quadro 2 - Exemplo de valores de vetor para três termos em três textos................ 17

Quadro 3 - Visão condensada das características das abordagens de RI................ 19

Quadro 4 - Conhecimento Público vs Conhecimento Privado .................................. 50

Quadro 5 - Matriz das Categorias Centrais da Ontologia de Sowa .......................... 65

Quadro 6 - Contextos Representados e Autores Utilizados ..................................... 111 


\section{SUMÁRIO}

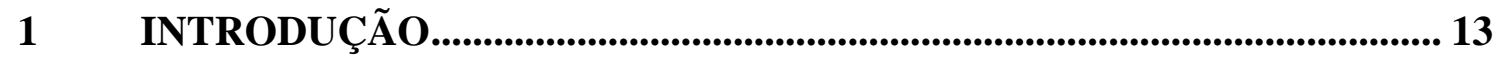

$1.1 \quad 0$ problema da pesquisa .............................................................................................. 20

$1.2 \quad$ Hipótese de trabalho.................................................................................................. 21

1.3 Objetivos......................................................................................................... 22

1.4 Motivação e resultados esperados ......................................................................... 22

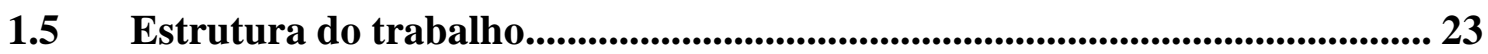

2 REPRESENTAÇÃ̃ E RECUPERAÇÃO DA INFORMAÇÃO................... 25

$2.1 \quad$ Linguagem .......................................................................................................................... 26

2.2 Termo, Terminologia e Conceito ................................................................................ 27

2.2.1 Termo …............................................................................................................... 27

2.2.2 Terminologia ………................................................................................................... 29

2.2.3 Conceito ................................................................................................................... 30

2.3 Semântica e Pragmática .................................................................................................. 33

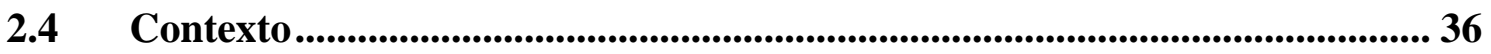

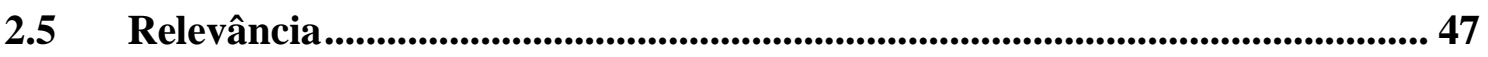

3 WEB SEMÂnTICA E WEB PRAgMáticA: Aspectos Históricos, Conceituais, Empíricos e Formais ............................................................................. 52

3.1 Web Pragmática: origem e objetivos ...................................................................... 54

3.1.1 A Ciência como Contexto, ou O Contexto da Ciência......................................... 55

3.1.2 Web Pragmática vs Pragmática Virtual: estudo crítico das versões da web ... 58

3.2 Web Semântica e Web Pragmática: limites conceituais ................................... 61

$3.3 \quad$ Ferramentas e procedimentos .................................................................................. 63

3.3.1 Ontologias ......................................................................................................................... 63 


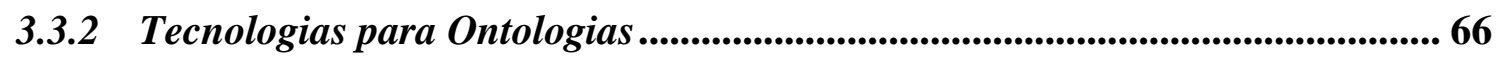

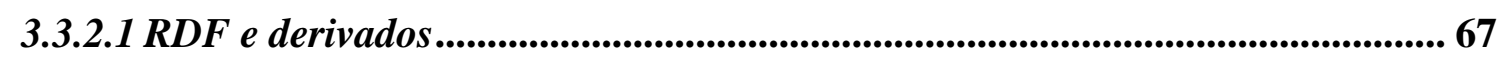

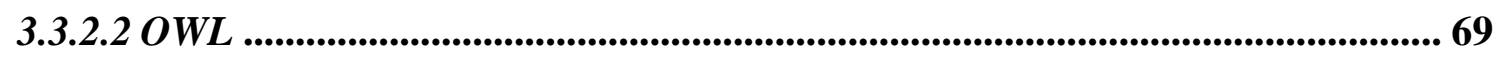

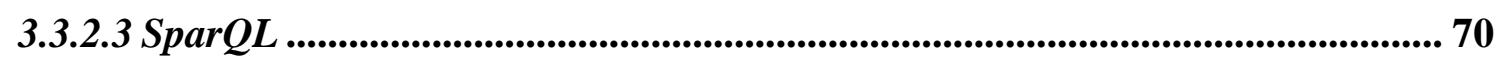

3.3.3 Topic Maps ....................................................................................................... 71

3.3.4 Semelhanças e diferenças entre RDF e Topic Maps: em busca da Web Pragmática ............................................................................................................... 76

4. PERCURSO METOdOLÓGICO PARA A CONSTRUÇÃO DE UM MODELO DE REPRESENTAÇÃO E RECUPERAÇÃO DA INFORMAÇÃO PARA A WEB PRAGMÁTICA....................................... 80

4. 1 Procedimentos Metodológicos da Pesquisa ............................................... 80

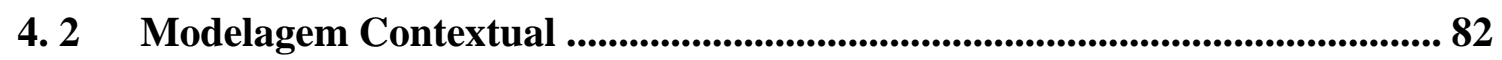

5. MODELAGEM CONTEXTUAL: representação de contexto para a web

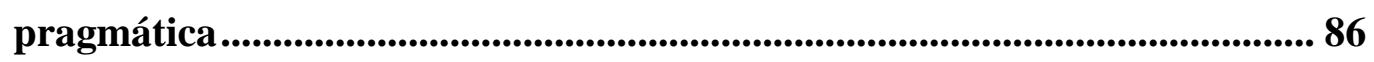

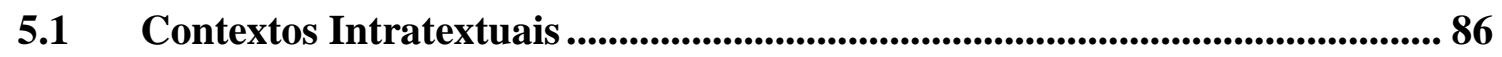

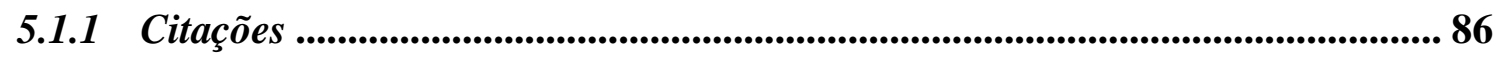

5.1.2 Domínio de Origem do Documento................................................................ 87

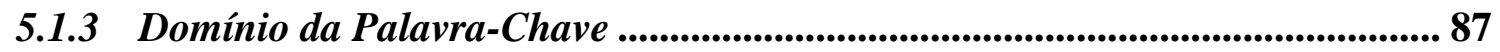

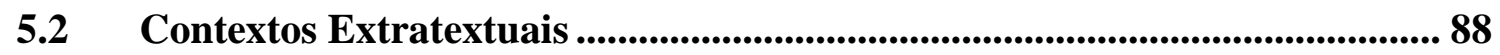

5.2.1 Áreas de Formação do Indivíduo ................................................................... 88

5.2.2 Áreas de Publicação do Indivíduo e da Revista .................................................. 89

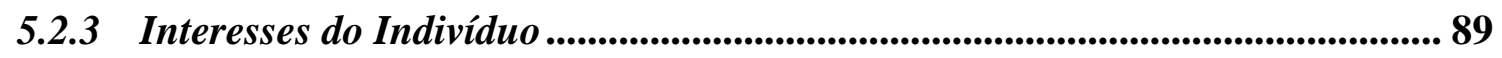

5.3 Representações Contextual em Ambientes Informacionais Digitais............. 90

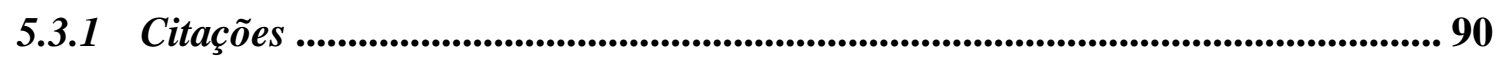

5.3.2 Domínios de Origem do Documento ............................................................. 93

5.3.3 Áreas de Formação do Indivíduo ........................................................................... 93 


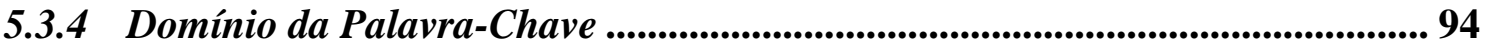

5.3.5 Áreas de Publicação do Indivíduo ...................................................................... 95

5.3.6 Área de Publicação da Revista .............................................................. 96

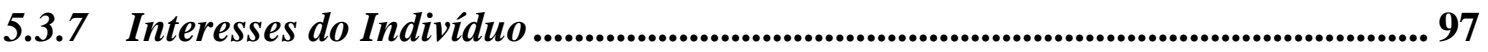

5.4 Representações Contextuais na Web Pragmática............................................ 97

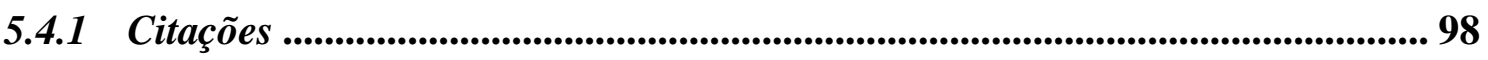

5.4.2 Domínio-base do Documento .................................................................... 101

5.4.3 Área de Formação do Indivíduo ................................................................. 102

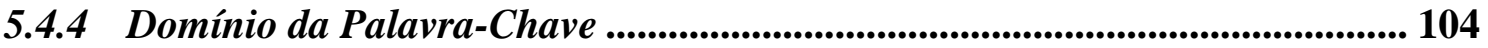

5.4.5 Área de Publicação da Revista ......................................................................... 106

5.4.6 Áreas de Publicação do Indivíduo ........................................................... 107

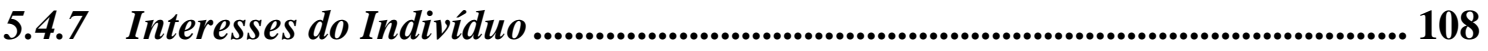

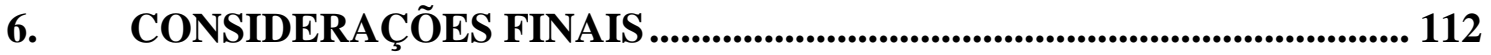

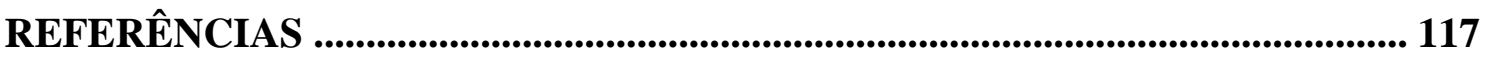




\section{INTRODUÇÃO}

A linguagem está inexoravelmente relacionada aos seres humanos, que utilizam sistemas de signos para representar e realizar trocas de conhecimentos entre si. Os signos, na linguagem natural, podem e são utilizados com diferentes significados. Porém, as múltiplas possibilidades de significar afetam negativamente as condições de recuperar informações precisas para fins determinados em sistemas de recuperação de informação (SRI). Por essa razão, duas áreas do conhecimento - Ciência da Informação e Ciências da Computação -, têm investido historicamente na elaboração de teorias, métodos e técnicas para aprimorar os dispositivos informacionais para que estes possam responder, de forma cada vez mais otimizada, às demandas sociais de informação. Nesses domínios, têm recebido especial atenção os estudos sobre a estruturação e a representação da forma e do conteúdo dos objetos informacionais que, de acordo com Floridi (2002), são entidades que possuem propriedades e características interpretáveis por seres humanos. O atributo mais importante desses objetos, na presente pesquisa, é que eles não são necessariamente físicos: requer-se apenas que seus traços possam ser percebidos, identificados. Os objetos informacionais considerados limitam-se àqueles armazenados em bibliotecas digitais e em outros tipos de repositórios digitais acadêmicos. Nesses dispositivos, as informações estão estruturadas e armazenadas em um ambiente controlado, cujo público-alvo é previamente definido, apresentando, portanto, perfis passíveis de identificação e codificação para os objetivos da recuperação de informações.

Um aspecto importante dos estudos de representação e recuperação de informações é a compreensão da linguagem. As investigações sistemáticas sobre a linguagem, são desenvolvidas em diferentes domínios: Filosofia da Linguagem, Semiologia, Semiótica, entre outros. Dentre os estudos da linguagem pode-se citar, em uma primeira abordagem, a perspectiva de Morris (1985), para quem, há três elementos essenciais que definem o significado das palavras: a sintaxe, a semântica e a pragmática (Figura 1). 
Figura 1 - Sintaxe, semântica e pragmática

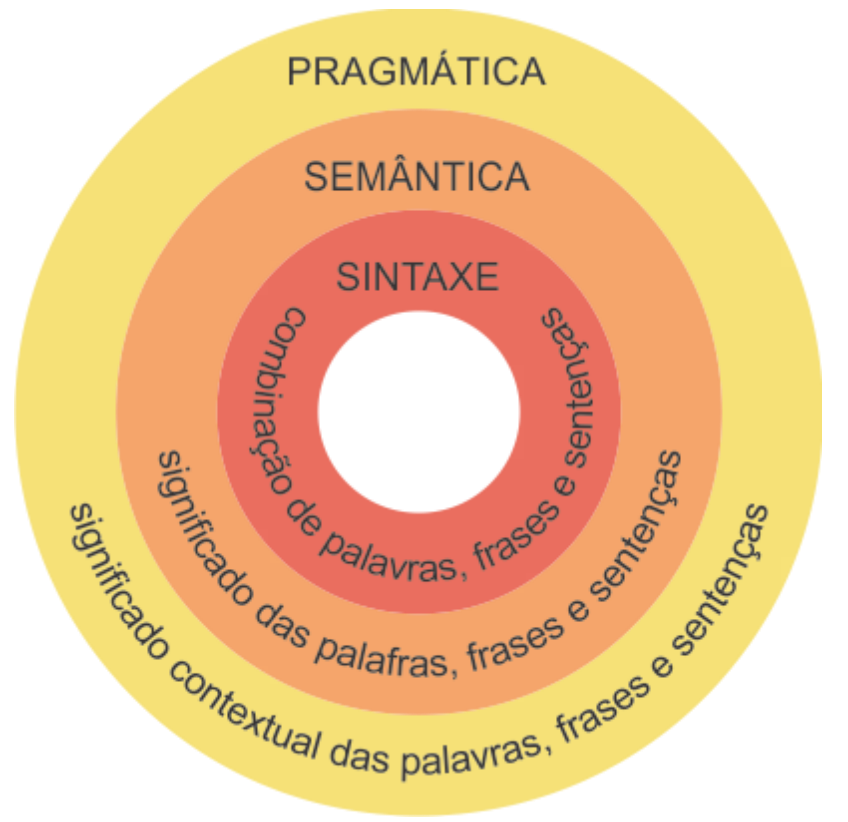

Fonte: Elaborado pelo autor, 2014 Modificado de Boundless, 201X.

A Sintaxe estuda as estruturas combinatórias entre as palavras para formar frases e sentenças, desconsiderando-se, nessas análises, a relação entre conceito e intérprete (MORRIS, 1985).

A Semântica, por sua vez, estuda o significado das palavras e sentenças e a relação dessas palavras, ou signos, com os objetos que eles representam ou significam (MORRIS, 1985). Porém, o estudo puramente semântico das expressões humanas, ou seja, dos elementos que dependem apenas do sistema da língua, desconsiderando o contexto de uso das palavras e dos indivíduos envolvidos no processo comunicacional, é considerado insuficiente para compreender a linguagem como um todo e, principalmente, o significado das palavras em enunciados concretos (CANÇADO, 2008).

O campo que estuda o uso da língua em contextos é a Pragmática. Nessa perspectiva, levam-se em conta o ambiente físico, a entonação, as expressões faciais, o histórico e experiências do emissor e receptor, além de outros elementos extralinguísticos presentes no processo de significação. Isso permite analisar não apenas os vocábulos utilizados, mas também a intencionalidade do emissor e as relações entre signos e usuários (MORRIS, 1985). Com os estudos da Pragmática é possível identificar, por exemplo, se o emissor está sendo irônico, sinalizando isso com gestos ou tom de voz, para expressar um significado não usual das palavras de sua mensagem (PALMER, 1981). 
No campo da Recuperação da Informação (RI) são igualmente importantes os estudos relacionados à linguagem e à significação. Para Ingwersen (1992), a recuperação da informações está fundamentada em processos de representação, armazenamento, busca e descoberta de informações relevantes. Para o autor, a RI, o principal campo de estudos da Ciência da Informação (INGWERSEN, 1992; JÄRVELIN; VAKKARI, 1992), tem como um de seus objetivos projetar, construir e testar Sistemas de Recuperação de Informação (SRI), ou seja, sistemas que, ao serem interrogados, retornam informações para o usuário. São, nessa medida, dispositivos em que as informações se encontram estruturadas, codificadas de forma padronizada, que podem ser acessadas por meio de interfaces de busca. Dito de outro modo, são sistemas que envolvem a relação entre o criador e o consumidor de informações por meio da linguagem (Figura 2).

Figura 2 - Diagrama de um Sistema de Recuperação da Informação.

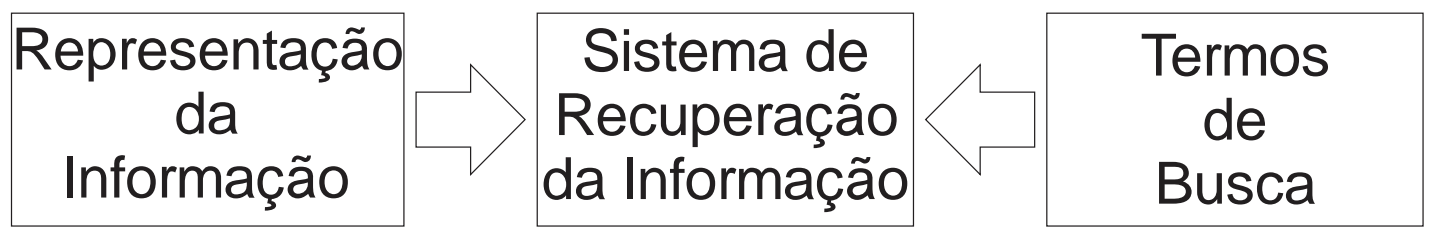

Fonte: Elaborado pelo autor, 2014. Adaptado de Ingwersen (1992).

A representação de informações, sob a ótica dos SRI, é geralmente composta pelos seguintes elementos: os documentos propriamente ditos, como no caso de dispositivos que integram textos completos; os termos de indexação atribuídos automaticamente ou por indexadores humanos; as estruturas gráficas (imagens, quadros e tabelas) presentes nos documentos; os dados de catalogação, ou dados formais (dados de pesquisa anexados e/ou apresentados no texto de forma estruturada) (INGWERSEN, 1992).

Os problemas principais da representação da informação nos SRI são: definir o conteúdo informacional dos documentos e determinar sua relevância nas buscas (LANCASTER, 2004). Tendo em vista o crescimento incessante da produção de documentos, no mundo contemporâneo, e o tempo necessário para indexá-los, procurase, cada vez mais, automatizar esses processos. É uma tarefa complexa porque devem ser considerados os problemas da linguagem, tal como expostos por Morris e outros filósofos da linguagem, tanto quanto por semiólogos e semioticistas. 
A determinação da relevância envolve operações de entrelaçamento do conteúdo dos documentos com os termos de indexação atribuídos e os termos usados nas buscas. A relevância não é algo simples de ser identificado ou calculado pois envolve, além dos termos de indexação atribuídos aos textos e das estratégias utilizadas em buscas, diversos elementos cognitivos e situacionais que não são facilmente externalizáveis. Estas situações serão discutidas mais adiante, mas, neste momento, é propício abordar alguns aspectos da relevância em SRI.

A determinação de relevância da recuperação em SRIs é comumente expressa por três métodos: o booleano, o vetorial e o probabilístico, também tratados como métodos clássicos de recuperação da informação (CARDOSO, 2008). O primeiro deles, baseado na teoria dos conjuntos e na álgebra booleana (GERSTING, 1995), é considerado o mais simples dos três. Esse método permite comparar a coincidência, ou ausência, dos termos utilizados em uma estratégia de busca, em documentos, ou em sua representação por descritores, de acordo com os critérios de verdadeiro ou falso, e uso dos operadores lógicos "e", "ou" e "não", de forma a obter resultados verdadeiros ou falsos, conforme exemplo de tabela-verdade exemplificada no Quadro 1.

Quadro 1 - Tabela-verdade para uma busca booleana usando dois termos

\begin{tabular}{|c|c|c|c|c|c|}
\hline Termo 1 (t1) & Termo 2 (t2) & t1 e t2 & t1 ou t2 & não t1 & t1 e não t2 \\
\hline V & V & V & V & F & F \\
\hline V & F & F & V & F & V \\
\hline F & V & F & V & V & F \\
\hline F & F & F & F & V & F \\
\hline
\end{tabular}

Fonte: Elaborado pelo autor, 2015.

O método vetorial (BONFIM, 2006) atribui pesos aos termos, de acordo com a avaliação de sua frequência, tanto em um determinado documento, quanto na base de dados como um todo e pontua, em forma de vetor, a relação entre documentos e termos de busca em valores entre 0 e 1 (Quadro 2). Este método é interessante por considerar a relevância como algo não-binário, diferente, portanto, do booleano. Para o método vetorial não existe informação totalmente relevante ou totalmente irrelevante; ao contrário, a possibilidade de relevância ou irrelevância é calculada e exposta em valores percentuais. 
Quadro 2 - Exemplo de valores de vetor para três termos em três textos

\begin{tabular}{|c|c|c|c|}
\hline Termo & SaS & PaP & WH \\
\hline Afeto & 0,996 & 0,993 & 0,847 \\
\hline Ciúme & 0,087 & 0,120 & 0,466 \\
\hline Murmúrio & 0,017 & 0 & 0,254 \\
\hline
\end{tabular}

Fonte: Elaborado pelo autor, 2014. Adaptado de Manning Raghavan e Schütze (2008)

Desta forma, os documentos retornados em uma busca são aqueles que têm um vetor, chamado de $\vec{v}\left(d_{x}\right)$ - sendo $x$ o número do documento analisado -, que mais se aproxima do vetor gerado para os termos da busca, denominado $\vec{v}(b)$, como ilustrado na Figura 3. Este método permite classificar os resultados, assim como retornar documentos considerados relevantes, mesmo que estes não tenham sido indexados com todos os termos utilizados em uma busca.

Figura 3 - Exemplo de valores de vetor para termos de busca em três textos

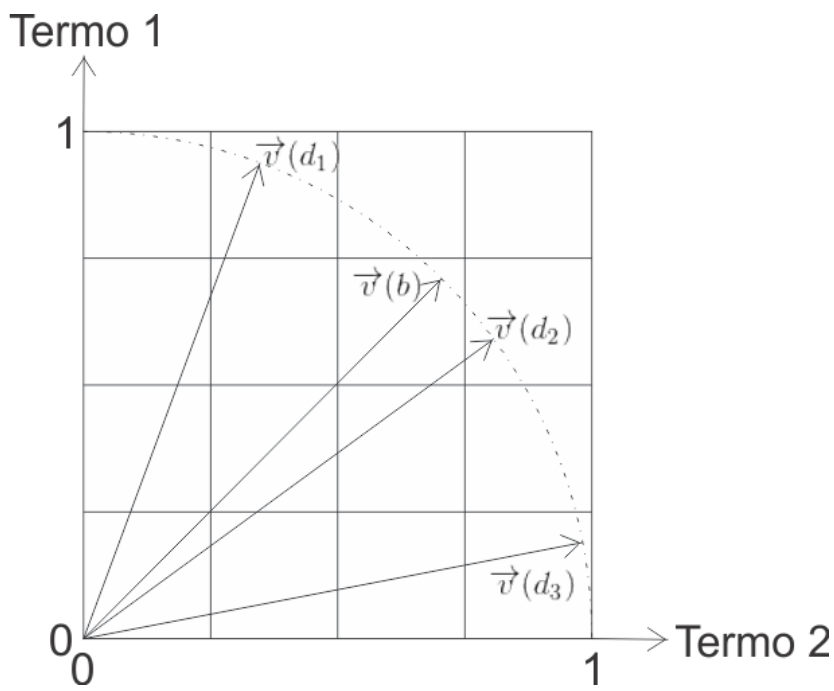

Fonte: Elaborado pelo autor, 2015. Adaptado de Manning, Raghavan e Schütze (2008)

O método probabilístico, por sua vez, utiliza diferentes fórmulas matemáticas de cálculo de probabilidades que variam de acordo com sua implementação em um SRI. Essas fórmulas são utilizadas para atribuir valores de relevância para cada documento e, em sua forma mais comum, utiliza os resultados de buscas anteriores, que sinalizaram 
documentos relevantes ou irrelevantes, e calculam a aproximação da busca atual com as prévias. Dessa forma, calculam-se as probabilidades de relevância e de não-relevância de um documento. Este método é o mais complexo dos três para ser implementado dada a necessidade de referências reais de relevância, ou a criação de estimativas confiáveis, para que o SRI tenha parâmetros de comparação de resultados (MANNING; RAGHAVAN; SCHÜTZE, 2008).

Os estudos sobre as teorias e métodos de recuperação de informação podem ser feitos sob diferentes pontos de vista. As abordagens mais conhecidas são a vertente tradicional, a orientada para o usuário e a cognitiva. A primeira tem como foco a representação de informações e de consultas conforme representado no lado esquerdo da Figura 2 (Representação das relações da RI, p.15). Utiliza, em suas técnicas e procedimentos a correspondência entre os termos da consulta e as representações das informações. Os problemas da significação não são objeto de preocupação na abordagem tradicional.

A segunda, a orientada para o usuário, procura modelar os usuários e suas necessidades e comportamentos informacionais. Nesta abordagem, os processos de busca são dinâmicos porque os indivíduos aprendem nos eventos de busca, podendo, no processo, haver modificações em suas necessidades de informação.

A terceira, a abordagem cognitiva, baseia-se na psicologia cognitiva, em particular nos estudos de aprendizagem. Considera a representação e a recuperação de informações como processos cognitivos que podem ser simulados, mesmo que rudimentarmente, por computador. O Quadro 3 sumariza as abordagens dessas três perspectivas, conforme proposto por Ingwersen (1992). 
Quadro 3 - Visão condensada das características das abordagens de RI

\begin{tabular}{|c|c|c|c|}
\hline & Tradicional & Orientada ao Usuário & Cognitiva \\
\hline $\begin{array}{l}\text { Objetivo e } \\
\text { Foco }\end{array}$ & $\begin{array}{l}\text { Refinamento de técnicas de } \\
\text { RI; } \\
\text { Métodos de representação; } \\
\text { Testes cientificamente } \\
\text { controlados; } \\
\text { Problemas de relevância; } \\
\text { Requisição igual à consulta. }\end{array}$ & $\begin{array}{l}\text { Compreende o } \\
\text { comportamento do usuário } \\
\text { e suas necessidades de } \\
\text { informação; } \\
\text { Investigação de vida real; } \\
\text { Modelagem de usuários. }\end{array}$ & $\begin{array}{l}\text { RI como processo que } \\
\text { envolve estados } \\
\text { cognitivos; } \\
\text { Interações complexas; } \\
\text { Domínio cognitivo e } \\
\text { modelagem de tarefas; } \\
\text { RI baseadas em } \\
\text { conhecimento. }\end{array}$ \\
\hline $\begin{array}{l}\text { Resultados, } \\
\text { Consequências }\end{array}$ & $\begin{array}{l}\text { Soluções ad hoc; } \\
\text { Técnicas de } \\
\text { correspondência parcial; } \\
\text { Falhas de classificação } \\
\text { automática; } \\
\text { Algoritmos de parsing em } \\
\text { análise de texto; } \\
\text { Aplicações de Multi e } \\
\text { Hipermídia. }\end{array}$ & $\begin{array}{l}\text { Modelos e tipos de } \\
\text { usuários; } \\
\text { Interação intermediada pelo } \\
\text { usuário; } \\
\text { Projetos de interfaces } \\
\text { simples; } \\
\text { Modelos de busca por } \\
\text { entrevistas; } \\
\text { Hipótese ASK; } \\
\text { Modelo Monstrat. }\end{array}$ & $\begin{array}{l}\text { RI inteligente; } \\
\text { RI adaptada para suporte; } \\
\text { Teoria unificadora de RI; } \\
\text { Valores semânticos, } \\
\text { inferências plausíveis } \\
\text { Modelos de mediador. }\end{array}$ \\
\hline $\begin{array}{l}\text { Compreensão } \\
\text { de informação }\end{array}$ & $\begin{array}{l}\text { Somente informação } \\
\text { científica; } \\
\text { Usuários cientistas; }\end{array}$ & $\begin{array}{l}\text { Informação entendida como } \\
\text { vital para a sociedade, } \\
\text { inclusive ficção; } \\
\text { Usuários de todos os níveis } \\
\text { sociais. }\end{array}$ & $\begin{array}{l}\text { Informação suplementar } \\
\text { para a compreensão de } \\
\text { mundo do usuário; } \\
\text { Variação individual. }\end{array}$ \\
\hline Suportes & $\begin{array}{l}\text { Matemática, linguística, } \\
\text { ciência da computação, IA. }\end{array}$ & $\begin{array}{l}\text { Psicologia cognitiva, } \\
\text { psicolinguística; } \\
\text { Sociologia. }\end{array}$ & $\begin{array}{l}\text { Ciências cognitivas; } \\
\text { Sociologia. } \\
\text { IA < - > RI }\end{array}$ \\
\hline
\end{tabular}

Fonte: Elaborado pelo autor, 2015. Adaptado de Ingwersen (1992)

Os três métodos acima expostos são baseados em sintaxes de buscas com poucos questionamentos sobre a significação (Figura 1, p. 14), sendo ignorados, por exemplo, os elementos complexos que modificam os significados das palavras. Para superar essas limitações, e já considerando o ambiente da internet, Tim Berners-Lee propôs a inclusão de elementos semânticos às páginas e documentos da Web, proposta conhecida por Web semântica (BERNERS-LEE; HENDLER; LASSILA, 2001). Esta web baseia-se no uso de metadados específicos para representar informação, sob a forma de enunciados lógicos estruturados em triplas, que permitem fazer inferências simples com base nos termos de busca e nas relações semânticas apresentadas nas representações.

$\mathrm{Na}$ padronização proposta, os metadados seguem sempre a estrutura [sujeito] <predicado> [objeto]. Exemplificando: para afirmar que o autor do livro Foundations of the theory of signs é Charles Morris, o enunciado seria marcado como: 
[Foundations of the theory of signs] <tem como criador> [Charles W. Morris]

A representação para URL ${ }^{1}$, com o uso de identificadores persistentes e permanentes para o sujeito e o objeto, e marcadores específicos para o predicado das triplas, seria sinalizado como:

http://lccn.loc.gov/a41002443 dc:creator http://dbpedia.org/page/Charles_W._Morris

Esta estrutura de metadados será explicada, de forma detalhada, mais adiante.

A significação requer contextualização para ser claramente compreendida, como referido anteriormente. Alguns autores perceberam essa ausência na Web Semântica, tendo destacado que ela não poderá atingir o nível de significado necessário se não considerar o contexto de uso das palavras (SINGH, 2002b; DE MOOR, KEELER e RICHMOND, 2002; DI MAIO, 2008).

São os problemas acima, referentes à recuperação de informações, tematizados nos estudos da Web semântica e da Web Pragmática, que propomos estudar, cujo recorte é apresentado a seguir.

\subsection{O problema da pesquisa}

A representação de informações, para posterior recuperação, requer elementos descritivos que permitam identificar os conteúdos dos documentos de forma precisa e avaliar sua relevância para uma dada necessidade de informação. A Web Semântica já avançou nesta questão adicionando elementos que podem identificar semanticamente os dados armazenados na rede. Mas é possível, e necessário, ir além. A representação de contextos, para a interpretação pragmática de informações, é o passo mais natural a seguir, com base nas questões já colocadas por Morris (1985) e por aqueles que lidam com a Pragmática.

Mesmo que diferentes tecnologias criadas pelo ser humano permitam ir além dos usos previstos, as tecnologias da Web Semântica não apenas não previram, como não permitem a inclusão de contextos. É necessário, portanto, pensar em novas

\footnotetext{
${ }^{1}$ Acrônimo para: Uniform Resource Identifier - Identificador Uniforme de Recurso.
} 
possibilidades teóricas, metodológicas e tecnológicas para modelar SRIs que possam integrar contextos aos metadados.

O problema principal da presente pesquisa é, desse modo, explorar as possibilidades de modelagem de sistemas de RI que incorporem diferentes tipos de contextos, com o objetivo de tornar as respostas dos sistemas mais adequadas às expectativas dos usuários. Assim, as questões para as quais desejamos buscar respostas podem ser resumidas em duas perguntas: 1) É possível incluir contextos em representações de objetos informacionais? 2) Quais são os caminhos para se chegar a isso?

\subsection{Hipóteses de trabalho}

Às indagações acima, podem ser propostas as seguintes hipóteses de trabalho:

- os acervos informacionais digitais, nas bases de recursos informacionais de texto completo ou de representações desses recursos (dados bibliográficos, resumos e palavras-chave), se enquadram nas características essenciais da Web Semântica. Apesar dos avanços já alcançados nas pesquisas sobre recuperação de informações, pode-se avançar, ainda mais, incorporando-se as questões pragmáticas aos ambientes informacionais digitais;

- é possível potencializar a capacidade de recuperação de informações, nesses espaços, com a adoção de critérios pragmáticos de representação de informações;

- as teorias pragmáticas podem fundamentar a inclusão de contexto aos metadados de ambientes digitais.

- a representação de elementos contextuais, a definição de perfis de usuários preferenciais de acervos de domínios especializados, assim como a publicação de conteúdos realizada em um domínio científico delimitado e supervisionado, possibilitará modelar um SRI aderente aos princípios da Web Pragmática.

- os Topic Maps e as Ontologias podem ser pensados como instrumentos de modelagem de dados contextuais em acervos de ambientes digitais.

São estas as hipóteses operacionais que orientam a modelagem de uma Web Pragmática, que pode ser expressa na forma de objetivos de pesquisa, como segue: 


\subsection{Objetivos}

O principal objetivo deste trabalho é propor uma abordagem teóricometodológica para representação de contextos em acervos informacionais digitais, de modo a avançar em direção à Web Pragmática.

Para alcançar este objetivo geral, enumeram-se os seguintes objetivos específicos:

- Estudar criticamente os conceitos gerais que guiam a representação e recuperação de informações e de conhecimentos;

- Estudar os conceitos fundamentais da Web Semântica e Web Pragmática e discuti-los sob a ótica da Ciência da Informação;

- Estudar os possíveis contextos que podem ser representados em acervos informacionais digitais e em bases de dados de periódicos científicos;

- Explorar alternativas de modelagem de representação de contextos, em acervos digitais, utilizando os Topic Maps e RDF.

\subsection{Motivação e resultados esperados}

Esta pesquisa foi motivada em estudos realizados anteriormente durante o Curso de Graduação em Sistemas de Informação e de Especialização em Análise de Testes de Software, realizadas na Ciência da Computação; no mestrado em Ciência da Informação, foram feitos estudos sobre os modelos de Gestão do Conhecimento e sua adequação às Micro e Pequenas Empresas, fundamentados na interface entre Ciência da Computação e Ciência da Informação. Estas experiências forneceram as bases teóricas e metodológicas para desenvolver a presente pesquisa sobre a estruturação de informações em ambientes digitais.

Busca-se, neste trabalho, apresentar uma proposta teórico-metodológica para implantação das tecnologias da Web Pragmática, fundamentadas em conceitos desenvolvidos na Ciência da Informação e na Ciência da Computação. Para isso, será feita a definição teórica do que são a Web Semântica e a Web Pragmática, além de 
representações de informações para verificar sua viabilidade sob a ótica da Ciência da Informação.

Com os resultados obtidos, espera-se melhorar a representação dos acervos de informações, descrevendo-os não apenas em termos semânticos, mas acrescentando-lhes relações contextuais, em perspectiva pragmática. Desta forma, são apresentadas e discutidas as possibilidades de ir além das propostas da Web Semântica, portanto, em direção a uma Web Pragmática, de modo a serem obtidos melhores resultados na avaliação de relevância em eventos de recuperação de informações.

Espera-se que os resultados desta pesquisa contribuam tanto para o avanço tecnológico, na perspectiva da Ciência da Computação, quanto para o aprofundamento das questões da representação e recuperação de informação estudadas na Ciência da Informação.

\subsection{Estrutura do trabalho}

Os resultados desta pesquisa estão estruturados em seis capítulos.

O primeiro capítulo é introdutório, no qual se encontram expostos a motivação na escolha do tema, o problema da pesquisa, as hipóteses de trabalho e os objetivos.

No segundo capítulo é apresentado e discutido o marco teórico da pesquisa, no qual são apresentados e discutidos os conceitos de representação e recuperação da informação, com especial destaque para o contexto de interpretação e usos da linguagem.

O terceiro capítulo aborda conceitualmente a Web Semântica e a Web Pragmática, apresenta as tecnologias nelas envolvidas e suas especificidades em relação às demais abordagens sobre a pragmática na web.

O quarto capítulo detalha os procedimentos metodológicos, descreve a construção e delineamento da pesquisa empírica, os critérios de seleção do recorte investigado e os aspectos técnicos da pesquisa.

O capítulo cinco apresenta os procedimentos de modelagem contextual, com considerações e percepções sobre o processo de investigação e discussão dos resultados obtidos.

Finaliza-se a pesquisa com as considerações sobre a proposta de um modelo de representação de contexto em metadados de informações digitais, as possíveis 
contribuições desta pesquisa ao campo da Ciência da Informação. São igualmente discutidas as limitações da pesquisa e as possibilidades de trabalhos futuros oriundas desta tese. 


\section{REPRESENTAÇÃO E RECUPERAÇÃO DA INFORMAÇÃO}

O que diferencia os seres humanos dos outros seres vivos é a capacidade única, dos primeiros, de elaborar e utilizar linguagens complexas para representar, expressar e trocar informações e conhecimentos (CARSTAIRS-MCCARTHY, 2008).

Sob essa ótica, a comunicação, a representação e a recepção de informações são usualmente expressas pelo esquema: emissor, receptor, mensagem, canal e um contexto compartilhado (INGWERSEN, JÄRVELIN, 2005). Esse esquema envolve necessariamente uma linguagem que, caso não seja compartilhada, afeta a compreensão das mensagens ou informações.

Capurro (1991) concebe a comunicação como processo que ocorre em duas etapas consecutivas: primeiro, existe a percepção da realidade, uma representação mental do que é observado e, posteriormente, essa representação mental pode ser codificada e inscrita em suportes físicos, ou comunicada verbalmente para outros indivíduos, que a reinterpretam e a assimilam também mediante representações mentais.

As informações documentárias são também um tipo de representação codificada, expressas com base em padrões. Este tipo de representação resulta de processos de catalogação e de indexação que permitem, respectivamente, a identificação dos aspectos individuais dos documentos e a condensação de seu conteúdo informacional (KOBASHI, 1994). Os produtos desses processos, as informações documentárias, são uma forma de representação simbólica, não de objetos abstratos, mas "uma representação construída a partir de um objeto efetivamente presente”, representação "que mesmo sendo diferente do original, é equivalente a ele, do ponto de vista do conteúdo" (KOBASHI, 1994, p. 50).

A recuperação da informação, por sua vez, é o processo, ou método, pelo qual um (possível) usuário recebe, a uma indagação, uma lista de informações (provavelmente) relevantes (MOOERS, 1951). Este processo é de natureza linguística pois, para que ocorra, é necessário expressar a pergunta por meio de uma linguagem, geralmente linguagem natural, e posteriormente verificar sua correspondência com a descrição dos objetos informacionais disponíveis em sistemas, descrição também expressa mediante uma linguagem (BLAIR, 2003; 2006). Dessa forma, para que ocorra o processo de recuperação de informações relevantes é necessário que, antes disso, tenha sido feita a adequada representação das informações dos objetos informacionais armazenados em sistemas. 
Como pode ser percebido, tanto os processos de representação quanto os de recuperação de informações são expressos pela linguagem. Estes conceitos, e suas aplicações para a representação e recuperação de informações, serão abordados a seguir.

\subsection{Linguagem}

Para a Linguística, a linguagem é considerada uma faculdade humana, universal, sendo as línguas realizações da linguagem. Na história da Linguística, distinguem-se claramente as diferentes etapas de desenvolvimento dos estudos dos idiomas em relação à sua origem e a busca de seus elementos comuns. O desenvolvimento da Linguística incorpora aspectos sociais, abordagem que vê a linguagem como um fato social humano, elemento de interação entre indivíduos e, ao mesmo tempo, instrumento dessa interação (BENVENISTE, 1976).

A língua é um sistema constituído de signos que permite realizar um grande número de combinações. Conjuntos de signos, sonoros ou visuais podem ser interconectados segundo regras ou padrões, de forma que as mensagens assim construídas façam sentido (MORRIS, 1985).

No sistema linguístico saussureano, o signo apresenta dois planos: significante e significado. Saussure (2008, p. 80) afirma que o signo linguístico é "uma entidade psíquica de duas faces" que relaciona uma imagem acústica (significante), ou sua correspondência gráfica, a um conceito (significado), sendo esta relação arbitrária, construída mediante convenção.

Essa arbitrariedade, explica Saussure (2008), permite que os sons de "m", "a" e "r", ou "mar", representem a ideia do mar sem que exista relação direta do som com o conceito, a não ser por convenção. Assim, o ser humano tem a capacidade de "representar o real por um "signo", e de compreender o "signo" como representante do real" (BENVENISTE, 1976, p. 27, grifos do autor).

É possível separar, ou classificar, as linguagens em dois tipos: naturais e artificiais. As primeiras são as línguas que indivíduos de diferentes nacionalidades e culturas utilizam para se comunicar no dia-a-dia, ou seja, os idiomas falados nas diferentes regiões do planeta (BENVENISTE, 1976).

As linguagens artificiais, por outro lado, são subsistemas recortados da linguagem natural para uso em contextos específicos, não apenas para facilitar a 
comunicação entre os indivíduos que compartilham contextos, mas também para diminuir a ambiguidade própria da linguagem natural. Dentro de uma área de conhecimento, seu sistema terminológico é chamado de linguagem de especialidade, constituído de conceitos pertinentes a esse domínio. Porém, a linguagem natural é sempre o ponto de partida das linguagens de especialidade. Por mais que as linguagens artificiais, com suas notações e restrições, tentem (e eventualmente consigam) evitar a ambiguidade, as definições sempre serão realizadas em linguagem natural, voltando, de certa forma, ao problema inicial (SOWA, 2000a).

\subsection{Termo, Terminologia e Conceito}

\subsubsection{Termo}

O termo, enquanto elemento de representação e significação, já havia sido estudado na antiguidade, por Aristóteles, especificamente no que se refere à função simbólica das palavras.

As palavras faladas são símbolos da experiência mental e as palavras escritas são os símbolos das palavras faladas. Assim como todos os homens não têm a mesma escrita, para todos os homens não há os mesmos sons da fala, mas as experiências mentais, que simbolizam estas diretamente, são as mesmas para todos (ARISTÓTELES, 2005, p. 2).

De acordo com as Normas ISO 704; ISO 1087-1 (2000 apud LARA, 2004) o termo é uma designação que corresponde a um conceito em uma linguagem de especialidade. O termo é um signo linguístico que se distingue da palavra, sendo esta última uma unidade da língua geral. Sendo signo, o termo, ao ser qualificado, ou definido no interior de um discurso de especialidade, designa "conceitos próprios das disciplinas e atividades da especialidade"2 (CABRÉ, 1993, p. 169, tradução nossa). Assim, "A definição terminológica busca definir o conceito, e não um significado, estabelecendo um jogo de conceito a conceito que determina as relações que os unem" (LARA, 2004, p. 94).

\footnotetext{
${ }^{2}$ No original: los conceptos propios de las disciplinas y actividades de especialidad.
} 
Abbagnano (1998) afirma que, na lógica terminista, a função do termo, seja este universal ou particular, é definida pela noção de suposição, de que os termos estão no lugar da coisa suposta, do conceito que indicam. São, assim, unidades usadas na comunicação especializada para designar os conceitos ou objetos de uma realidade específica e preexistente (CABRÉ, 1993).

Os termos diferenciam-se das palavras, também, por suas relações. Os termos se relacionam de forma muito mais estreita com os outros termos do seu domínio de origem do que com os de outros domínios do conhecimento ou com as palavras do léxico comum, formando assim um subsistema linguístico com elementos próprios, mas que ainda se submetem às normas e regras de formação de frases da língua (CABRÉ, 1993).

Os termos podem ser visualizados ou analisados linguisticamente a partir de três pontos de vista: formal, semântico e funcional. Cabré (1993, p. 171) explica estes três pontos de vista da seguinte forma:

Desde una perspectiva formal, los términos son conjuntos fonológicos susceptibles de ser articulados fonéticamente $-\mathrm{y}$ de ser representados gráficamente - con una estructura interna constituida por morfemas. Desde un punto de vista semántico, los términos son unidades de referencia a una realidad, y por lo tanto están dotados de un significado que puede describirse como un conjunto de rasgos distintivos. Desde una perspectiva funcional, los términos son unidades distribucionales que requieren un entorno lingüístico determinado, y que en el discurso se encuentran frecuentemente combinados con otros términos específicos (la fraseología).

Dentro do escopo desta pesquisa, importa considerar duas perspectivas: a semântica e a funcional. A perspectiva semântica permite perceber os termos como pertencentes a uma realidade; com isso, a utilização de um termo, em detrimento de outro, para representar o assunto de um texto mostra, também, a referência a uma realidade em detrimento de outra, indicando o(s) domínio(s) do conhecimento ao qual pertence um dado texto. A perspectiva funcional corrobora a perspectiva semântica. A perspectiva semântica e funcional da Teoria Comunicativa da Terminologia (TCT) pode, portanto, ser identificada com as questões semânticas e pragmáticas da representação da informação por meio de linguagens documentárias. 


\subsubsection{Terminologia}

A Teoria da Terminologia (TGT) nasceu na década de 1930, desenvolvida pelo engenheiro austríaco Eugene Wüester, patrocinada pela Organisation for Economic Cooperations and Development (OECD) da Organização das Nações Unidas (ONU). A TGT surgiu da necessidade de organização terminológica da área da eletrotécnica, tendo servido como modelo para outros dicionários técnicos. Wüester sistematizou princípios terminológicos que deram a essa atividade um caráter científico.

A palavra terminologia é relativamente genérica, mas Wüester propõe quatro significados distintos para ela: "uma lista de termos e significados; a nomenclatura técnica de uma área; os termos de uma área de especialidade; e um conjunto de princípios teóricos" (CAMPOS, 2001, p. 71). A terminologia, como visualizada por Wüester, era inicialmente uma ramificação da linguística aplicada, mas, posteriormente, ganhou o estatuto de uma disciplina autônoma. É importante citar que Wüester nunca designou seu trabalho terminológico como uma "Theorie", no alemão, mas sempre se referiu a ele como "Lehre", que indica um guia prático. Assim, em vez de uma abordagem puramente teórica, atuou de forma prática, propondo "leis" em vez de “teorias” (CABRÉ, 1993).

Para Cabré (1999), no entanto, a TGT é insuficiente para abordar cientificamente as questões terminológicas, entre outros motivos, por ser reducionista, ter finalidade normativa e metodológica, e por considerar a terminologia apenas como uma ferramenta de trabalho. À TGT, Cabré propõe a TCT, caracterizada como uma revisão dos fundamentos da terminologia wüsteriana, levando em conta as funções da terminologia na comunicação especializada.

Com a TCT, Cabré (1999) visa traçar uma teoria de base linguística que analisa as unidades terminológicas - os termos - em sua dimensão textual e discursiva. Segundo Cabré (1999), a TCT não considera os termos como unidades isoladas que constituem seu próprio sistema; ao contrário, os termos são unidades que se incorporam ao léxico de um falante no momento em que este adquire um conhecimento especializado.

A autora ilustra essa ideia por meio de um gráfico de Venn, que mostra os termos como um subconjunto ou subsistema do léxico comum, que por sua vez é um elemento da gramática (Figura 4) 
Figura 4 - Relação entre gramática, léxico e léxicos de especialidade

\section{Gramática}

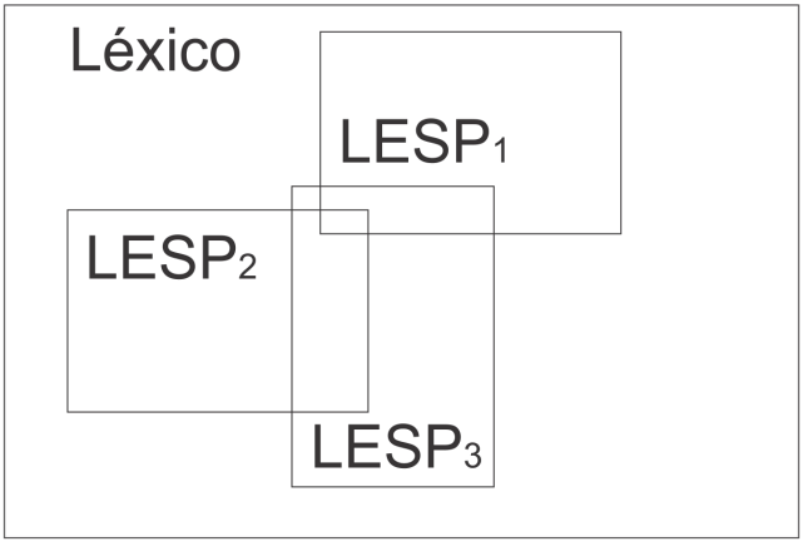

Fonte: Adaptado de Cabré (1993).

Tendo em vista a proximidade semântica entre as formas de expressão "palavra" e "termo", que se associam igualmente à forma de expressão "conceito", apresentamos, a seguir, as características do conceito.

\subsubsection{Conceito}

Sobre o conceito, Japiassú e Marcondes (2006) afirmam que o termo tem origem no latim conceptum, utilizado para indicar um pensamento ou ideia, sejam eles abstratos, amplos, específicos, ou mesmo um objeto ou uma classe de objetos. Para Aristóteles, o conceito é a essência maior das coisas. Cada coisa possui um conjunto de características e propriedades, que são os elementos dos conceitos e traduzem os atributos das coisas (ARISTÓTELES, 2005). Os conceitos são, então, ferramentas para que se possa falar sobre ou comunicar as coisas que nos rodeiam.

Abbagnano (2007, p. 164), descreve o conceito como "qualquer espécie de sinal ou procedimento semântico" que designa um objeto, seja este "abstrato ou concreto, próximo ou distante, universal ou individual, etc.”. Martins (2010, pp. 27-28), com base em Abbagnano (1998), afirma que o conceito tem quatro funções:

a primeira função dos conceitos é a de descrever os objetos da experiência para permitir o seu reconhecimento; a segunda função tem 
caráter classificador, pois o homem define e classifica objetos, fatos e funções por meio de conceitos; a terceira função é a de organizar os dados da experiência de modo que se estabeleçam entre eles conexões de natureza lógica; a quarta função diz respeito à previsão que o objetivo de um signo era prever, antecipar ou projetar a solução de um problema exatamente formulado.

Peirce (1977), por outro lado, afirma que o conceito não é necessariamente algo concreto ou particular, mas pode ser um conjunto de coisas, um local, evento ou ocorrência, ou uma ideia ou abstração de natureza universal.

Os conceitos, segundo Hjørland (2009), podem ser analisados ou definidos com base em quatro teorias: empirismo, racionalismo, historicismo e pragmatismo. $\mathrm{O}$ empirismo define os conceitos mediante o agrupamento de objetos semelhantes, considerando as características e propriedades que podem ser "objetivamente" observadas; na perspectiva racionalista, os conceitos são primitivos ou fundamentais, ou seja, são conhecidos universalmente; o historicismo define os conceitos de forma genealógica, relacionando-os a teorias e discursos; no pragmatismo, os conceitos são classes, expressos por meio de signos, fixados ao se definir as classes de coisas que melhor alcançam um propósito determinado.

Wittgenstein volta-se para os conceitos e seus usos. Para ele, "Os conceitos nos conduzem às investigações. Eles são a expressão de nosso interesse, e conduzem o nosso interesse" (WITTGENSTEIN, 2009, p.203, §570). Wittgenstein diferencia o conceito das palavras que o denominam, mas ao mesmo tempo mostra que não é possível desassociá-los completamente pois "Não analisamos um fenômeno (p. ex. o pensar), mas um conceito (p. ex. o conceito de pensar), portanto o emprego de uma palavra” (WITTGENSTEIN, 2009, p.160, §383).

Francelin (2010, p. 17), com base em Wittggeinstein, afirma que "Nessa medida, um conceito é aprendido com a linguagem, no uso da linguagem, e não com o fenômeno". Fazendo um paralelo com o conceito de "dor", afirma: todo ser humano aprende que a sensação que sente é denominada "dor", e aprende também que "dor" pode ser usado em diversas situações, como saudade, amor não correspondido, ver as pessoas sofrendo, entre outros. Dessa forma, ao entender o que significa a palavra "dor" os sujeitos conseguem aplicar o conceito a outras sensações semelhantes, denominandoas com a mesma palavra.

Observa-se, do dito acima, que não é possível desassociar os conceitos das palavras. Para a própria definição e compreensão do que ocorre na realidade, ou para 
explicar um novo conceito, utilizam-se palavras e conceitos previamente conhecidos. Para Hjørland (2009, p. 1521, tradução livre), há um claro problema quando se necessita definir um conceito. $\mathrm{O}$ autor exemplifica essa ideia afirmando que "Um dicionário é inútil a menos que saibamos os significados de várias palavras”3; mostra, desse modo, que há interdependência entre conceitos, no sentido de que é impossível definir um conceito sem usar palavras que apontam para outros conceitos. Isso pode se tornar um problema cíclico, sendo necessário sempre definir conceitos usando outros conceitos que, por sua vez, podem não ser entendidos e necessitam de novas definições. Encerra-se este ciclo apenas quando, na definição, todos os conceitos utilizados são conhecidos.

Hjørland (2009) afirma, além disso, que um engano comum é achar que os conceitos não mudam, ou que as palavras apontam eternamente apenas para um conceito. Assim, é necessário observar a sociedade e como suas ações mudam ao longo do tempo para perceber como os conceitos também variam. $\mathrm{O}$ autor cita o exemplo das escolas e igrejas, mostrando que são atividades estabilizadas na sociedade, para as quais se usam os signos "escola" para indicar um local onde se ensina e "hino" para se referir o que se canta na igreja, mas que à medida que esses objetos, atividades ou ações sofrem modificações, os conceitos também mudam, mesmo que o signo permaneça o mesmo. Hjørland (2009) aborda também os estudos históricos para mostrar que os dicionários históricos registram como uma determinada palavra esteve associada a diferentes significados, ao longo do tempo.

Para Hjørland (2009), uma das funções do conceito é criar certa estabilidade, um padrão para que seja possível comunicar o que se pensa, e que mesmo que este objeto mental sofra transformações (como uma pessoa que envelhece ao longo do tempo, ou um rio cujas águas nunca são as mesmas), é o conceito que permite que ignoremos essas variações para que a comunicação seja bem estabelecida. Com isso, da mesma forma que é possível afirmar que não se entra duas vezes no mesmo rio (considerando que a água em que se entra, no nível molecular, não é a mesma nas duas vezes), também é possível afirmar que é possível, sim, entrar no mesmo rio duas vezes (ao se ignorar a alteração molecular da água e denominar o rio com um nome próprio ou localização, por exemplo).

\footnotetext{
${ }^{3}$ No original: A dictionary is useless unless we already know the meanings of many words.
} 
No entanto, as considerações sobre a alteração ou não dos significados dos conceitos é completamente contextual, como já foi observado por diversos autores. Francelin (2010, p. 18), por exemplo, afirma que "No universo da Filosofia pragmática da linguagem, de Wittgenstein, o processo de significação (dos conceitos) é sempre contextual", fenômeno que será abordado no item a seguir.

\subsection{Semântica e Pragmática}

Como exposto anteriormente, nos estudos linguístico-semióticos de Morris (1985) há três elementos que influenciam o significado das palavras: a sintaxe, a semântica e a pragmática (Figura 1, p.10). Os estudos de Morris, e de outros pesquisadores da área, se baseiam nos trabalhos semióticos de Peirce (1977), principalmente na tríade representâmen-objeto-interpretante. Para Morris (1985) a sintaxe é apenas a verificação da composição sígnica das palavras, a junção de letras que indicam o significado, fato que permite, por exemplo, diferenciar "pula" de "mula".

A semântica adiciona à composição da palavra sua posição em uma frase, no aspecto lógico-linguístico e sua relação com seu denotatum, no aspecto semióticofilosófico (TAMBA-MECZ, 2006; MORRIS, 1985). Para Morris (1985, p. 55, tradução nossa), a semântica é o estudo da "relação dos signos com seus designata e, com isso, com os objetos que podem denotar ou que, de fato, denotam"4. Esta visão é puramente semiótica e relaciona cada palavra ou termo com a imagem mental do objeto ideal que este designa, independentemente de outros elementos que possam influenciar a designação.

A semântica, no aspecto lógico-linguístico, concentra-se “apenas nas características linguísticas das significações, sem preocupação com seus demais aspectos, filosóficos ou psicológicos" (TAMBA-MECZ, 2006, p. 11). Busca-se aqui o significado literal das palavras e frases. Os estudos semânticos se constituíram de diferentes formas, de acordo com a época em que foram realizados ou com a base teórica adotada, porém, a forma mais clara e diferenciada das outras formas de estudo dos sentidos (sintático ou pragmático) é a que explora o significado derivado das regras de composição das sentenças, segundo estruturas, de certa forma pré-definidas para a

\footnotetext{
${ }^{4}$ No original: "relación de los signos con sus designata y, por ello, con los objetos que pueden denotar o que, de hecho, denotan".
} 
construção de diferentes frases, independentemente do contexto de seu uso (TAMBAMECZ, 2006).

Para Bréal (1900), o significado não apenas deriva de regras impostas sobre as palavras, mas outros elementos, como a posição das palavras em uma frase, podem modificar o significado. Esta ordem, por exemplo, está definida nas regras de formação das frases, chamadas pelo autor de lógica da linguagem. Segundo Bréal, são essas regras que, entre outras coisas, não permitem que um adjetivo esteja numa flexão de gênero diferente da do substantivo.

Um alerta, porém, é feito por Cançado (2008) para o fato de que o estudo semântico das expressões, seja sob a visão linguística ou semiótica, que ignora o contexto de uso das expressões, é insuficiente para compreender de forma mais ampla como ocorre o processo de interpretação. Bréal (1900, p. 106) já apontava para o aspecto contextual da interpretação quando afirmou que a "expressão se adapta à coisa através das circunstâncias, o lugar, o momento, e a óbvia intenção do discurso"5.

O campo que estuda o uso da língua dentro de contextos é a Pragmática. Na Pragmática, elementos extralinguísticos são utilizados para complementar o significado das palavras, de modo a explicitar a intencionalidade do emissor e do receptor, dando maior importância à relação dos signos com seus usuários (MORRIS, 1985). Para Bréal (1900), o receptor tem metade da responsabilidade na interpretação (sendo a outra metade do autor) e denomina de subjective-element o fator de interpretação derivado de elementos contextuais. Com os estudos do campo da Pragmática é possível identificar a intenção do emissor da mensagem, mesmo que as palavras, isoladamente, indiquem o contrário (PALMER, 1981).

Para Armengaud (2006), Morris é o primeiro autor a usar especificamente o termo Pragmática, embora os estudos deste campo já ocorressem desde a década de 40, com Bar-Hillel, com especial destaque para o ano de 1950, quando foi publicado o artigo de Strawson On Referring, que abordava o uso de expressões dentro de contextos. Armengaud (2006) afirma que não há um único fundador da Pragmática, mas há vários, com diferentes influências: Peirce e Morris, como fundadores diretos; Frege e Wittgenstein, como fundadores indiretos, graças à contribuição para a Semântica, do primeiro, e o estabelecimento do Paradigma da Comunicabilidade, do segundo; Carnap

\footnotetext{
${ }^{5}$ No original: "expression adapt itself to the thing through the circumstances, the place, the moment, and the obvious intention of the discourse".
} 
e Bar-Hillel, como fundadores intermediários, devido à influência exercida nos trabalhos posteriores.

Todo sistema de interpretação é baseado no signo e, assim, a Linguística está dentro do escopo da semiótica (PEIRCE, 1977). Para este autor, o sentido é função do uso, e quando as frases são analisadas sem considerar a ocorrência dela, haverá um sentido oriundo apenas das palavras e de seu encadeamento, mas, quando consideradas a identidade ou situações do falante e do ouvinte, o sentido é modificado, enriquecido (ARMENGAUD, 2006).

Morris (1985), por sua vez, parte dos estudos de Peirce e estabelece os níveis de semiose, de interpretação do signo e suas relações. O primeiro é o nível sintático, que aborda a relação dos signos entre si, o segundo é o nível semântico, que relaciona os signos com os objetos e, o terceiro, o nível pragmático, que relaciona os signos com seus intérpretes. Para Morris, este último nível tem os seres vivos como intérpretes, e por isso, caracteriza também os aspectos bióticos da semiose, sejam eles psicológicos, biológicos ou sociológicos (ARMENGAUD, 2006).

Segundo Armengaud (2006), é Frege (2009) quem introduz a diferenciação entre sentido e referência. A diferença entre esses dois conceitos está diretamente relacionada aos planos em que atuam: o sentido está no plano interpretativo e, a referência, no plano extralinguístico. O exemplo clássico exposto por Armengaud (2006) é o caso das frases "a estrela da tarde" e "a estrela da manhã", que têm sentidos diferentes, embora tenham a mesma referência: Vênus. Frege (2009) também determina que o fato de ser possível inferir sentido de uma frase não indica que sua referência tenha sido identificada. Cita como exemplo "o corpo celeste mais distante da terra" (p. 133) para mostrar que, apesar desta frase ter sentido, não há objeto de referência para ela.

Para determinar o sentido, então, não basta conhecer a referência - se é que ela existe -, mas sim compreender o contexto de uso da palavra e a isto Frege denomina de princípio da contextualidade (ARMENGAUD, 2006). Outra contribuição de Frege, segundo Armengaud (2006), é a diferenciação entre linguagem científica e linguagem natural, em que a primeira tem a necessidade funcional de ser unívoca, marcando com precisão suas articulações, mas, a segunda, precisa da equivocidade para ter, em sua riqueza e ambiguidade, maior poder afetivo e retórico.

Wittgenstein (1968, p. 41), de certa forma, relativiza as fundamentações semânticas ao dizer que "Você não pode prescrever a um símbolo o que lhe é permitido 
expressar. Tudo o que um símbolo pode expressar lhe é permitido" (grifos no original), afirmando com isso que a relação entre o signo e o seu significado não seria fixa ou prédeterminada. Posteriormente, ele será mais brando, afirmando que "toda palavra tem um significado. Este significado é atribuído à palavra. Ele é o objeto que a palavra designa" (WITTGENSTEIN, 2009, p. 15), e afirma que essa construção ou atribuição de significado às palavras é feita pelo uso da linguagem.

Para Blair, um estudioso da pragmática na Ciência da Informação, Wittgenstein é um dos principais responsáveis (ou o principal responsável) pela "virada linguística" ocorrida no século XX (BLAIR 2003, p. 9). Segundo este autor, os trabalhos de Wittgenstein evidenciaram que não se trabalha com ideias, mas com a descrição delas, e que muitos dos problemas filosóficos não eram realmente filosóficos, mas apenas decorrentes do uso inadequado da linguagem. Wittgenstein, conforme Blair (2003), mudou a forma de percebermos o pensamento ao mostrar que não pensamos em "ideias" ou "significados" e depois traduzimos isso em palavras, mas que são as próprias palavras que vêm à mente, e que a linguagem é o próprio "veículo do pensamento" (WITTGENSTEIN, 2009, p. 146). Portanto, para Blair (2003), o ser humano não utiliza a linguagem apenas para expressar a ideia pensada, para traduzir o conhecimento, mas a utiliza para pensar.

O uso da linguagem e a construção de significados aconteceria, segundo Wittgenstein (2009), de forma social, entre pelo menos dois indivíduos: um instrutor e um instruído, um mestre e um discípulo. Dessa forma, a construção do significado ocorre de forma prática, isto é, é no uso da palavra que ela adquire significado. Toda interpretação seria um processo vinculado à ação, denominada de ação comunicativa. As diferentes ocasiões e propósitos guiam a construção de sentido dado às frases enunciadas, processo que o autor denomina de "jogo de linguagem" (WITTGENSTEIN, 2009), por se tratar de uma atividade social, partilhada e regulada. Esses “jogos de linguagem" seriam ilimitados, assim como os contextos de interpretação, questão abordada no próximo item.

\subsection{Contexto}

O principal aspecto que diferencia a Semântica da Pragmática é o estudo das expressões linguísticas em seu contexto de uso que, de acordo com as variações 
situacionais, pode ter seu significado modificado. São estas situações que são denominadas de contexto de uso ou apenas de contexto.

O contexto é o cerne da Pragmática, um objeto de pesquisa intrigante para as diferentes áreas do conhecimento. O significado de contexto tem um histórico de divergências entre diversas áreas (VALLET et al, 2006), não havendo, portanto, um único significado global aceito para toda situação ou tipo de informação veiculada (EDMONDS, 1999). Devido a essa diversidade, busca-se aqui reunir definições oriundas de diferentes áreas para identificar uma perspectiva adequada às propostas da Web Pragmática.

De forma geral, e no campo específico da Linguística, o contexto é composto por vários elementos (sociais, situacionais e/ou pessoais), que interferem no comportamento linguístico dos indivíduos. As possibilidades contextuais são, de certa forma, infinitas, principalmente se forem considerados os sujeitos em situações que envolvem diferentes idiomas, domínios do saber e formação. Nessa mesma perspectiva, Armengaud (2006) define contexto como as situações comunicativas concretas que ocorrem em situações determinadas por lugar, tempo e identidade dos falantes. Tudo o que for necessário para avaliar o significado das elocuções é, então, contexto. O sentido das palavras deve ser apreendido a partir do sentido das frases onde elas figuram e das frases dentro de um parágrafo, e assim consecutivamente. Para compreender, então, o que o enunciatário deseja informar, há que situar a palavra em seu contexto de uso na frase.

O contexto, para Lyons (1979) pode ser definido a partir de quatro elementos:

[...] situação espaciotemporal que inclui o falante e ouvinte, as ações que eles realizam no momento e vários objetos e eventos externo. [...] O ouvinte [...] interpreta esses [...] elementos corretamente mediante referência às características relevantes da situação. [...] 0 conhecimento partilhado pelo falante e pelo ouvinte do que se disse antes, na medida em que isso seja pertinente para a compreensão do enunciado. [...] a aceitação tácita pelo falante e ouvinte de todas as convenções, crenças e pressuposições relevantes 'dadas como certas' pelos membros da comunidade linguística a que o falante e o ouvinte pertencem (LYONS, 1975, p. 413, grifos no original) ${ }^{6}$.

\footnotetext{
${ }^{6}$ No original: [...] spatiotemporal situation which includes the speaker and hearer, the actions they are performing at the time and various external objects and events. [...] The hearer [...] interprets these $[. .$.$] elements correctly by reference to the relevant features of the situation. [...]$ the knowledge shared by the speaker and hearer of what has been said earlier, in so far as this is
} 
Percebe-se que as possibilidades de uso das expressões é bastante intricado sendo, em geral, pouco consideradas nos processos de recuperação de informações não por ser algo ignorado ou desconhecido, mas porque sua adequada representação implica levar em conta elementos que muitos desenvolvedores de sistemas de informações julgam demasiado complexos para serem operacionalizados.

É importante ressaltar que o conceito de contexto pode ser considerado ambíguo ou demasiado amplo e, por isso, alguns autores utilizam outros termos para designar o conjunto de circunstâncias em que o sujeito se encontra durante o processo de busca de informações. Alguns exemplos dessas delimitações são as de Julien e Michels (2002), que utilizam o conceito de "situação", e Allen and Kim (2001), que preferem utilizar o termo "tarefa". Por outro lado, Ingwersen e Järvelin tratam o contexto como um conjunto de fatores, uma série de elementos determinados por itens como "a tarefa de uma pessoa, sua fase e situação" (INGWERSEN; JÄRVELIN, 2005, p. 1, tradução livre). Além disso, outros indivíduos e componentes também podem influenciar o processo.

Armengaud (2006, p. 82) afirma que o "conceito de contexto adquire vigor e consistência ao se aproximar da noção de mundo possível”, restringindo-se, assim, as possibilidades contextuais a um conjunto de situações, denominado de conjuntocontexto, que são as mais prováveis de ocorrer. O conceito de mundos possíveis é compartilhado por Eco (2000), que exemplifica com a palavra baleia. Para Eco, existem dois mundos possíveis: um onde 'baleia' é interpretado como um peixe, e outro onde é interpretado como mamífero. Ambas as interpretações podem estar corretas porque podem pertencer a diferentes concepções de mundo.

Considerando essas variações, e a forma com que os autores abordam a questão do contexto, é perceptível que alguns elementos podem ser representados de forma relativamente fácil e outros não, sendo este um dos principais problemas presentes em estudos de usuários. Porém, para avaliar inicialmente as várias possibilidades de pesquisa, será considerado aqui o contexto de forma mais ampla, com seus vários

pertinent to the understanding of the utterance. [...] the tacit acceptance by the speaker and hearer of all the relevant conventions, beliefs and presuppositions 'taken for granted' by the members of the speech-community to which the speaker and hearer belong. 
possíveis elementos, de acordo com as definições de Armengaud (2006) e de Ingwersen e Järvelin (2005).

Na perspectiva pragmática, Teun Van Dijk (1977b) trabalha com a noção de frame. Este é definido como um conjunto de conhecimentos de mundo (sejam eles conhecimento técnico, de idioma, posicional, situacional etc.) que possibilita elaborar diferentes interpretações das sentenças. Assim, diferentes frames permitem interpretar uma mesma frase de diferentes formas.

Eco (1987) aborda os frames como uma "estrutura de dados que serve para representar uma situação estereotipada" ${ }^{7}$ (p. 114, tradução nossa). Essas estruturas conteriam um conjunto de informações que ditam as ações e reações do sujeito na situação em que este se encontra. Dessa forma, se as informações do frame se confirmam, o sujeito sabe como deve agir, porém, caso existam informações divergentes no frame, o sujeito entra em um estado ou condição em que é necessário adaptar-se à situação para agir de acordo com as equivalências situacionais armazenadas como conhecimento prévio. Nestas situações, o sujeito modifica o frame em que ocorreram as divergências ou cria um novo para a situação específica.

A representação de contextos em forma de frames pode ser considerada como puramente representação do conhecimento, pois, ao contrário do que ocorre com as representações de registros informacionais, o que se busca explicitar aqui são os diferentes conhecimentos situacionais que influenciam a interpretação textual. $\mathrm{O}$ autor afirma que já houve iniciativas para explicitar o conhecimento de mundo, porém, o sucesso dessas experiências foi limitado devido à complexidade e variação dos contextos possíveis de ocorrer.

Edmonds (1999), em consonância com Van Dijk (1977a, 1977b) e Eco (1987), afirma que, nos sistemas naturais, um único efeito pode ter várias causas e que, para sua adequada representação, é mister ignorar alguns elementos para que a ampla quantidade de fatores não gere demasiada complexidade ao realizar a modelagem do mundo possível, ou do domínio desejado. Considerando o efeito como a interpretação de uma palavra ou sentença, as causas podem ser várias, e elas variarão de acordo com elementos psicológicos e sociais construídos desde a infância. Assim, no âmbito dos sistemas de informação, para a adequada representação de informações contextualizadas, é necessário delimitar os contextos, considerando apenas os mais

\footnotetext{
${ }^{7}$ No original: "estructura de datos que sirve para representar una situación estereotipada".
} 
plausíveis ou prováveis. Dito de outro modo, os conceitos de mundo-possível, frame e conjunto-contexto tornam operacionalizável a inclusão de contextos em sistemas de informação.

Para Borlund (2003), o contexto é a percepção do usuário em situação de busca de informação, portanto, nada mais é que um construto psicológico que representa, internamente, o conhecimento e as suposições sobre o mundo em um determinado momento e sua necessidade informacional dentro desse mundo. De forma semelhante, um autor também tem seu contexto, pois, ao representar seu conhecimento, ele expõe ali uma série de elementos de contexto que o circundam, começando pelo tema escolhido e a forma de representação.

Edmonds (1999) classifica os contextos em interno e externo (físico, social e biológico). No primeiro, o contexto interno é o próprio conhecimento do indivíduo (ou grupo social), utilizado no processo de aprendizagem mediante a (re)lembrança e o reconhecimento de diferentes situações para melhor se adequar ao presente; já o contexto externo é caracterizado pelo ambiente compartilhado por um grupo, chamado também pelo autor de "context-as-a-resource" ${ }^{8}$ " context-we-inhabit", que pode ser, por exemplo, um contexto temporal. Mas sua delimitação sem considerar o contexto interno é complexa, principalmente porque o contexto interno pode ser de um grupo de pessoas, e separar o que seria interno e externo para esse grupo traz claras dificuldades.

$\mathrm{Na}$ segunda classificação, o contexto físico é constituído pelos elementos espaciais e temporais que um grupo de pessoas pode compartilhar, e, para o autor, são os mais simples ou claros de serem analisados; o contexto social é o que gera, segundo Edmonds (1999), a maior quantidade de elementos em comum entre os indivíduos, principalmente por serem oriundos da cultura e da linguagem, mas que ao mesmo tempo é demasiado rico, ou complexo, para ser analisado; já o contexto biológico são as experiências emocionais, de consciência ou de conhecimento compartilhado que um grupo de indivíduos pode ter. Eles são extremamente importantes no processo de aprendizagem, mas seu estudo é complexo pois, muitas vezes, são confundidos ou ocultos pelos contratos sociais.

Por outro lado, Armengaud (2006) comenta que Carnap faz distinção entre dois tipos de dependências entre palavra e significado: uma dependência não-essencial,

\footnotetext{
${ }^{8}$ Tradução livre: contexto como um recurso.

${ }^{9}$ Tradução livre: contexto que habitamos.
} 
quando o significado de uma palavra ou frase é constituído pelas palavras/frases que a precedem (um contexto interno ao texto); a outra, chamada de essencial, quando o significado varia de acordo com elementos extralinguísticos (um contexto externo ao texto). São semelhantes aos “ditos e não ditos” de Eco (1984, p. 97).

Nesses estudos, a dependência não-essencial é completamente voltada para o texto, sendo realizada pelo leitor no momento de uso da informação. Estes aspectos têm sido utilizados em sistemas de recuperação de informações e de indexação/catalogação semi-automáticas, como na identificação de palavras relevantes dentro de frases e de frases dentro de parágrafos. Essa identificação ainda não é perfeita (LANCASTER, 1993), porém, é realizada com grande velocidade e tem resultados considerados aceitáveis.

Mesmo que Armengaud (2006) afirme que a primeira dependência se preocupa apenas com o texto, é possível perceber que ela também se relaciona com o contexto extralinguístico do autor. As escolhas das palavras para expressar as ideias, autores para citar ou, até mesmo, o uso de voz passiva ou ativa é uma influência de elementos extralinguísticos.

A segunda, a dependência essencial, no entanto, é mais complexa, pois é dependente dos indivíduos que interagem com o texto e o contexto da interação, sejam eles histórico, acadêmico ou social. Essa dependência é especialmente relevante quando considerados os processos de recuperação de informações, em que a leitura ocorre de forma superficial, visto que se procura apenas identificar palavras/frases que indiquem relevância, ou por consulta ao resumo do texto. Neste caso, o contexto é, especificamente, a necessidade de informações, influenciada pelo histórico acadêmico do indivíduo.

Como dito anteriormente, Julien e Michels (2002), Allen and Kim (2001) e Ingwersen e Järvelin (2005), abordam essa dependência de perspectivas variadas, cada um com diferentes objetivos e resultados, o que mostra a complexidade dos estudos de contextos nas ações humanas.

Cortina (2000), em sua obra sobre a leitura e a recepção de textos, categoriza os contextos em interior e exterior, porém de forma específica. Para o autor, o contexto interior é relacionado ao significado da palavra dentro de um enunciado, de forma semelhante à analise semântica do significado, conforme também expõe Morris (1985). O contexto exterior, por sua vez, refere-se à necessidade de "localizar as condições 
sócio-históricas e de produção do enunciado" e, nesta situação, é "necessário que se busquem essas informações em outros textos" (CORTINA, 2000, p. 25), portanto, em um contexto intertextual.

Retomando Lyons (1975), citado acima, Cortina afirma que o contexto é construído à medida que o enunciado é desenvolvido e pressupõe que o significado deste depende do conteúdo dos enunciados anteriores. Cita como exemplo uma conversa entre duas pessoas em que os enunciados se encadeiam para darem sentido uns aos outros. Este é o chamado "contexto situacional". Outro contexto é chamado de "contexto restrito", e neste, os elementos linguísticos sequenciais não são considerados para a criação de significado, mas considera-se que este é dependente de "um conhecimento sociocultural dos sujeitos em interação" (CORTINA, 2000, p. 27).

Ainda na discussão do conceito de contexto, Cortina (2000) se apóia em Greimas e Courtés (1983) para afirmar que o contexto é construído pela relação estabelecida entre um determinado texto e outros que o precedem e é dessa relação que ocorre a significação dos enunciados de um texto. Nesta proposta, Greimas e Courtés (1983) categorizam o contexto em dois tipos: um contexto linguístico e um contexto extralinguístico ou situacional. O primeiro é explícito no texto, construído com as frases e textos que precedem a enunciação em questão e, o segundo, é implícito, e está relacionado aos elementos externos ao texto que precisam ser conhecidos pelo leitor para melhor compreender o texto. Esta categorização é semelhante àquela apresentada por Armengaud (2006).

Segundo Van Dijk (1992), o contexto envolve elementos como "crenças, desejos, preferências, normas e valores" ${ }^{10}$ (VAN DIJK, 1977a, p. 212, tradução nossa) tanto do interlocutor quanto do ouvinte/leitor, assim como um conhecimento convencional ou compartilhado. Qualquer que seja a teoria pragmática, seu objetivo deve ser unir as sentenças (em sua forma gramatical) e as interações (relações sociais). Para o autor, portanto, independe na comunicação o que o interlocutor realmente sabe, pensa ou deseja se estes elementos não estão expressos, se seu comportamento não demonstra esses estados internos (VAN DIJK, 1977b)

Fica claro que os estados mentais dos criadores de informações são apenas relevantes se os consumidores não apenas têm conhecimento sobre esses estados, mas se sabem usá-los e estabelecem a relação destes com suas próprias interpretações de

\footnotetext{
${ }^{10}$ No original: "beliefs, wants, wishes, preferences, norms and values".
} 
mensagens, dentro de um contexto social. A relação do que é interno, e sua externalização, é destacada quando o autor afirma que é necessária a "ligação direta entre o que é pensado, etc. e o que é demonstrado"11 (VAN DIJK, 1977a, p. p. 213, tradução nossa, grifo no original).

Eco (1987) desenvolve a noção de contexto sob uma perspectiva interna ao texto. Para o autor, o significado de um determinado termo está diretamente relacionado à aparição deste junto de outros termos pertencentes ao mesmo sistema de significação, e que, juntos, apontam para o significado adequado ou preciso. Quando isto ocorre temse o co-texto, um contexto delimitado pelo próprio texto. Para o autor, as "seleções contextuais preveem possíveis contextos: quando estes se realizam, se realizam em um co-texto"12 (ECO, 1987, p. 29, tradução nossa).

Os elementos contextuais são parte de um amplo sistema semiótico, mas que, dentro de um texto, devem ser expressos para que sejam, no momento de sua leitura, adequadamente interpretados. Assim, em textos narrativos, somente quando os elementos circunstanciais são verbalmente descritos é que podem ser considerados como contexto, mas sem o esclarecimento ou registro dessas circunstâncias não poderiam ser considerados desta forma (ECO, 1987).

Fica claro que o co-texto ocorre apenas dentro do texto que está sendo lido, mas o processo de interpretação também é influenciado por elementos externos. Eco (1987) afirma que o leitor não lê o texto de forma isolada, mas é influenciado por outros textos que leu anteriormente. Essa competência extra e intertextual envolve não apenas o texto em uso, mas "abarca todos os sistemas semióticos com que o leitor está familiarizado"13 (ECO, 1987, p. 116, tradução nossa, grifo no original), e aí entram não apenas os outros textos que o leitor conhece, mas também os elementos extralinguísticos.

Há, no entanto, dois outros contextos extralinguísticos no processo de leitura: o de criação e o de consumo. O primeiro deles envolve os elementos que influenciaram o autor da obra no processo de criação, tais como como a imagem do receptor a quem é dirigida a obra, os dados sobre a situação cultural, o que já foi dito anteriormente, entre outros (LEVINSON, 1983).

\footnotetext{
${ }^{11}$ No original: "direct link between what is thought, etc. and what is shown".

${ }^{12}$ No original: "selecciones contextúales prevén posibles contextos: cuando éstos se realizan, se realizan en un cotexto".

${ }^{13}$ No original: "abarca todos los sistemas semióticos con que el lector está familiarizado".
} 
Sobre o segundo, Rothe (1987) afirma que devem ser tratados e considerados não somente os elementos contextuais de criação do texto, mas, principalmente, de que forma e em que condições ocorrem a recepção e seu consumo. Para o autor "o texto é, pois, a resposta a uma pergunta"14 (ROTHE, 1987, p. 16, tradução livre), pergunta que varia de leitor para leitor, e daí, consequentemente, variam também as respostas (interpretações).

Esta última dependência contextual vai ao encontro do que Eco (1960) afirma sobre a interpretação, como "uma pluralidade de significados que convivem num só significante" (p. 22), possibilitando diversas formas de leitura e de interpretação de um mesmo texto, de acordo com o número de mundos possíveis existentes. No entanto, Eco (2000) afirma também que, mesmo sendo admissível a existência de diferentes leituras, há leituras não aceitáveis, interpretações que fogem demasiado da intenção do autor e que, por isso, podem ser consideradas como leituras erradas.

Seguindo a ilustração de Eco (1987, p. 30) sobre as possibilidades de interpretação dentro de um contexto, seria plausível, então, formalizar o conjunto de significados possíveis em expressões matemáticas. Assim, considerando " $f$ " como a função de interpretação sobre uma palavra ou enunciado “ $x$ ”, obtêm-se diversos significados, denotados com “s”, segundo a expressão abaixo:

$$
f(x)=\left\{s_{1}, s_{2}, s_{3}, \ldots, s_{n}\right\}
$$

Como descrito, a quantidade de significados possíveis é indefinida, pois o significado de uma palavra não é determinado apenas por ela, mas depende de outros fatores. Assim, a função de interpretação não ocorre apenas sobre o enunciado, mas deve levar em conta outros elementos, como o contexto. Ao considerar que dentro de um determinado contexto a palavra ou enunciado tem apenas um significado, para todo contexto "c $c_{i}$ " que esteja dentro do conjunto de mundos possíveis "MP", tem-se a expressão:

$$
f\left(x, c_{i}\right)=s_{i} \quad \forall c_{i} \in \mathrm{MP}
$$

\footnotetext{
${ }^{14}$ No original: "el texto es, pues, la respuesta a una pregunta".
} 
Onde " $i$ " é o identificador do contexto, e, mudando o contexto, muda-se também o significado. Usando o exemplo das baleias de Eco (2000), e alterando os contextos de acordo com os mundos possíveis descritos por ele, percebem-se as seguintes situações:

$$
\begin{gathered}
f(\text { baleia }, \text { biblia })=\text { peixe } \\
f(\text { baleia }, \text { biologia })=\text { mamifero }
\end{gathered}
$$

De modo semelhante, e usando outro exemplo de Eco (1987, p. 30), é possível interpretar um contexto com diferentes significados, como é o caso do leão e seu local de observação:

$$
\begin{gathered}
f(\text { leão, selva })=\text { liberdade, ferocidade, etc. } \\
f(\text { leão, circo })=\text { adestramento, espetáculo, etc. } \\
f(\text { leão, zoológico })=\text { cativeiro, estudo, controle, etc. }
\end{gathered}
$$

E seria possível também pensar em um contexto que não permite interpretações imediatas ou possíveis. Neste caso, o resultado seria inconcluso, ou vazio:

$$
f\left(x, c_{i}\right)=\varnothing
$$

Essas relações de significação variam de acordo com o número de mundos possíveis. Obviamente a relação não é tão simples e a palavra pode estar relacionada com mais de um contexto por vez, indicando significados diferentes não apenas para os contextos individualmente, mas também para diferentes combinações dos mesmos, e a sobreposição desses contextos configura um outro contexto (Figura 5). 
Figura 5 - Possibilidade de sobreposição de contextos

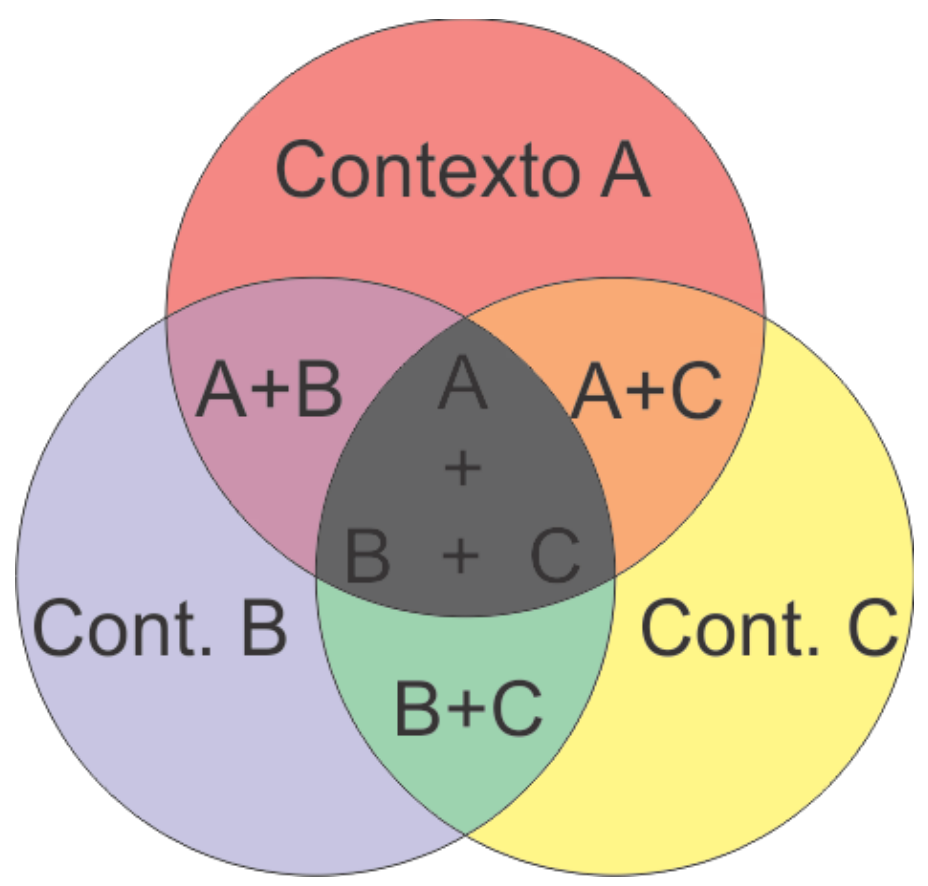

Fonte: Elaborado pelo autor, 2015.

Dessa forma, é possível visualizar uma expressão complexa, que envolva maior quantidade de contextos para definição do significado. Sejam dois contextos, como os contextos $\mathrm{A}+\mathrm{B}, \mathrm{B}+\mathrm{C}$ e $\mathrm{A}+\mathrm{C}$ acima ilustrados:

$$
f\left(x, c_{A}, c_{B}\right)=s_{A B}
$$

No caso de um conjunto variado de contextos, a definição dos significados pode ser expressa como segue:

$$
f\left(x,\left\{c_{1}, \ldots, c_{n}\right\}\right)=s_{1 \ldots n}
$$

Em repositórios tradicionais, a recuperação de informação, principalmente de recursos bibliográficos, supõe a representação do assunto ou tema do documento (KOBASHI, 1994). Pode-se supor que a representação poderá tornar-se mais rica e frutífera, nos processos de recuperação, se ao assunto do documento forem adicionados elementos contextuais. Dito de outro modo, pode-se dar mais sentido à representação temática se ela for enriquecida semântica e pragmaticamente, por meio de dados contextuais. 
É importante ressaltar que outros trabalhos abordaram a recuperação de informação com o uso de contextos, sem, no entanto, representá-los formalmente, tal como no trabalho de Shen, Tan e Zhai (2005) que utilizam o feedback implícito dos usuários para identificar e melhorar os resultados das buscas.

Esse modo de abordagem indireta de contextos é, de certa forma, uma visão alinhada com as de Ingwersen e Järvelin (2005) e Allen e Kim (2001), que consideram a necessidade de informação como algo mutável ao longo do processo de busca, que se molda de acordo com os resultados intermediários obtidos até chegar ao resultado desejado.

No entanto, pode-se melhorar a qualidade dos resultados dos processos de recuperação se algum contexto for representado formalmente e incorporado aos SRI para avaliação no processo de identificação das informações. Por meio da representação de contextos seria possível, portanto, melhorar a identificação da relevância das informações em eventos de busca.

\subsection{Relevância}

A relevância é definida de diversas formas: como a avaliação de pertinência ou utilidade de fontes de informação em comparação a uma necessidade de informação de um indivíduo (INGWERSEN; JÄRVELIN, 2005); como a medida da eficácia do contato ou relação entre uma fonte e um destinatário no processo comunicacional (SARACEVIC, 1975); ou como a relação entre a requisição de busca e o conteúdo de uma coleção de documentos, seja um texto completo ou uma representação do original (CASE, 2007). Para Saracevic (2007), a relevância é um dos principais, se não o conceito-chave da Recuperação da Informação. A avaliação de relevância pode ser realizada tanto por indivíduos (ex. bibliotecários) como por mecanismos automatizados (ex. SRI).

Saracevic (1975) aborda os diferentes conceitos e tipos de relevância que podem ser encontrados na literatura, afirmando que a Ciência da Informação surge como o terceiro campo a lidar com este conceito de forma mais concreta, ao lado da Lógica e da Filosofia. Já Case (2007) comenta que é notória a quantidade de pesquisas e publicações voltadas para este tópico na Ciência da Informação, assim como a visão de que os estudos de relevância poderiam ser a principal abordagem para compreender e definir o conceito de informação. Segundo Saracevic (1975), na Filosofia, e principalmente nos 
estudos de Schutz, a relevância é vista como o princípio fundamental que relaciona as diferentes realidades do mundo social. Para Schutz, segundo Saracevic (1975), existem três tipos de relevância: a relevância tópica, a relevância motivacional e a relevância interpretativa $^{15}$.

A relevância tópica refere-se à avaliação do assunto ou tema da informação (o tópico) e como este se relaciona com os critérios de busca, de forma semelhante a como os SRI mais simples a verificam. Esta definição de relevância, compartilhada por muitos autores, é a mais comum dentro da Ciência da Informação (CASE, 2007).

A relevância interpretativa, que ocorre no momento da leitura ou consumo da informação, situação em que o leitor verifica a adequação da informação retornada pelo sistema em relação aos seus critérios, é também chamada por Case (2007) de relevância subjetiva $^{16}$. A relevância motivacional, por sua vez, é influenciada por elementos contextuais e situacionais, que podem transformar uma informação irrelevante em relevante, ou vice-versa, relevância esta que vai ao encontro do que autores como Ingwersen e Järvelin (2005) consideram importante considerar. Todos estes tipos de relevância estão, na verdade, inter-relacionados e não isolados, como se pode ver na Figura 6.

Figura 6 - Tipos de Relevância e suas relações

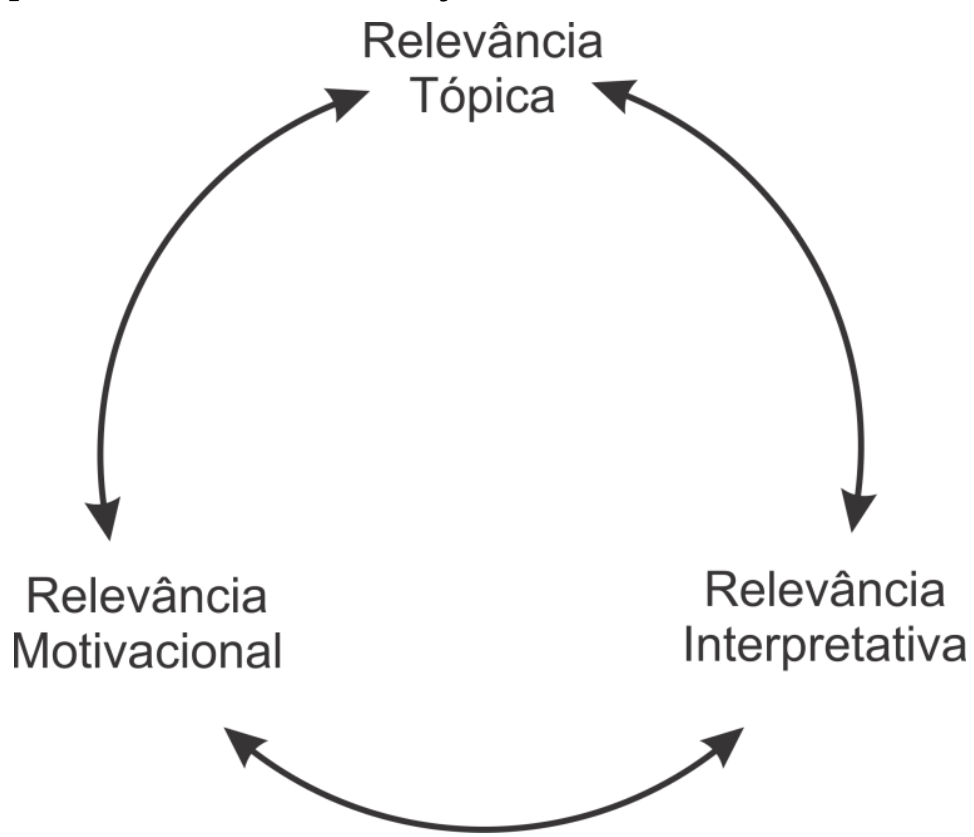

Fonte: Adaptado de Saracevic (1975)

\footnotetext{
${ }^{15}$ No original: "topical relevances, motivational relevances and interpretational relevances".

${ }^{16}$ No original: "subjective relevance".
} 
A avaliação da relevância, como se pode perceber, é algo relativo: o que é relevante para um usuário, em um dado momento, pode deixar de sê-lo em outro momento, da mesma forma que o que não era relevante poderá passar a sê-lo em outro contexto de pesquisa; além disso, duas coisas relevantes podem ter "níveis" de relevância distintos (SARACEVIC, 1975). Nesse sentido, o autor lista algumas coisas que podem afetar o julgamento da relevância de uma informação: o que já se conhece sobre um assunto, o que se pensa que é desejado e como foi requisitado, o que se entende da requisição, a diferença entre o que se deseja e o que é necessário, quem está requisitando, qual a situação da requisição, entre outros.

Nesta linha, Ingwersen e Järvelin (2005) afirmam ser possível identificar ou perceber outros tipos de relevância, dependendo do ponto de vista utilizado: do ponto de vista humano têm-se a relevância cognitiva e a relevância situacional; do ponto de vista dos SRI têm-se a relevância algorítmica e a relevância binária. Para estes autores, as pessoas julgam a relevância da informação de forma subjetiva e dinâmica, diferentemente dos sistemas que a realizam de forma simplista, o que afeta diretamente o processo de recuperação da informação. $\mathrm{O}$ julgamento humano não apenas amplia as possibilidades de obtenção de melhores resultados na recuperação, mas, por outro lado, adiciona uma nova camada de complexidade ao planejamento e ao processamento das informações em sistemas.

Saracevic (1975) diferencia a relevância da pertinência: a relevância é a propriedade que relaciona os resultados da busca à pergunta ou requisição realizada, enquanto a pertinência relaciona os resultados à necessidade de informação (Figura 7). Nesta definição, resultados relevantes podem ser também pertinentes, mas há também resultados relevantes que não são pertinentes e resultados não relevantes que são pertinentes. Do ponto de vista humano, no momento da avaliação da informação, o que se deseja são, na verdade, resultados pertinentes (CASE, 2007). Os SRI, porém, não são capazes de avaliar a pertinência dos resultados. Eles podem, apenas responder as perguntas postas pelo usuário calculando o grau de aderência entre pergunta do usuário e dados acumulados no sistema. 
Figura 7 -Relevância vs Pertinência

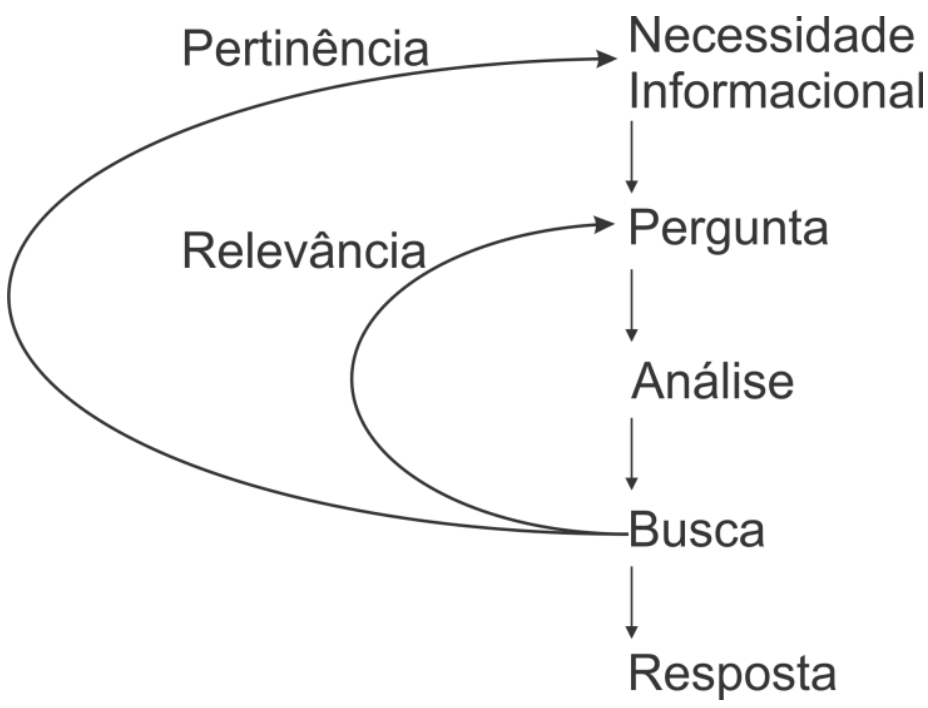

Fonte: Adaptado de Saracevic (1975)

Saracevic (1975) cita Kemp (1974) para mostrar que a diferença entre relevância e pertinência é, também, uma diferenciação entre verificação objetiva e subjetiva, entre conhecimento público e conhecimento privado. Saracevic sistematiza essa concepção (aqui reproduzido no Quadro 4) para mostrar que a diferenciação entre conhecimento público e privado também ocorre em outras áreas do conhecimento, como na Psicologia e na Linguística, e faz um paralelo entre a relevância e a pertinência, com base nos estudos de Schutz (1970), já citados, e os de Kemp (1974). Para Saracevic (1975), a relevância tópica de Schutz está diretamente relacionada à noção de relevância e ao conhecimento público de Kemp, enquanto a relevância interpretativa está relacionada à pertinência e ao conhecimento privado.

Quadro 4 - Conhecimento Público vs Conhecimento Privado

\begin{tabular}{|l|l|l|}
\hline \multicolumn{1}{|c|}{ Campo } & \multicolumn{1}{c|}{ Público } & \multicolumn{1}{c|}{ Privado } \\
\hline Ciência da informação & Relevância & Pertinência \\
\hline Filosofia da ciência & Conhecimento público & Conhecimento privado \\
\hline Psicologia & Denotação & Conotação \\
\hline Linguística & Semântica & Pragmática \\
\hline Sociologia do conhecimento & Comunicação formal & Comunicação informal \\
\hline
\end{tabular}

Fonte: Adaptado de Saracevic (1975)

Para os objetivos de recuperação, no entanto, é possível apenas operar com o que já foi explicitamente representado, levado do privado para o público, mesmo que sejam elementos intrinsicamente privados, como os contextos de produção ou de busca de informações. Por essas razões, procura-se operacionalizar a relevância e não a 
pertinência. Pode-se pensar que a Pertinência, colocada no âmbito Privado, no Quadro 4, é mais dependente de informação pragmática do que a Relevância. Nessa medida, a Pertinência é mais difícil de ser avaliada por ter características mais subjetivas. Certamente, a Relevância e a Pertinência devem ser objeto de aprofundamento, em outras pesquisas. Mesmo com as diferentes possibilidades de definir relevância, para os objetivos deste trabalho, será adotada a de Saracevic (2007, p. 1918, tradução nossa) que define a relevância como a

[...] relação entre informação ou objetos informacionais (o Ps) de um lado e os contextos, que incluem estados cognitivos e afetivos e situações (necessidade informacional, intenção, tópico, problema, tarefa; o Qs) por outro lado, baseado em alguma propriedade que reflete uma manifestação desejada de relevância (tematicidade, utilidade, comparação cognitiva; o Rs). ${ }^{17}$

É essa representação de elementos contextuais e situacionais, que Saracevic (2007) chama de Qs, e seus usos para a recuperação da informação, que se procurará modelar na proposta de materialização dos aspectos relativos à representação de contextos, na Web Pragmática, objetivo central da presente pesquisa.

\footnotetext{
${ }^{17}$ No original: "[...] relation between information or information objects (the Ps) on the one hand and contexts, which include cognitive and affective states and situations (information need, intent, topic, problem, task; the Qs) on the other hand, based on some property reflecting a desired manifestation of relevance (topicality, utility, cognitive match; the Rs)".
} 


\section{WEB SEMÂNTICA E WEB PRAGMÁtICA: Aspectos Históricos, Conceituais, Empíricos e Formais}

Na Web tradicional, também conhecida como Web Sintática, idealizada por Tim Berners-Lee (BERNERS-LEE; CAILLIAU, 1990), as páginas são estáticas, com predominância de documentos interligados por hyperlinks, não havendo nenhum outro dado ou informação extra que identifique ou descreva esses documentos ou seus componentes, como ilustrado na Figura 8.

Esta Web é denominada de Sintática, pois tudo o que está disponível pode ser descrito apenas utilizando-se a sintaxe, como definido por Morris (1985). Os elementos visuais apresentados nos navegadores são uma sequência de símbolos e caracteres, sem outro significado além do que for percebido pelo leitor. O computador, que realiza a requisição e exibição de conteúdo, não tem como distinguir ou atribuir significados aos conteúdos.

Figura 8 - A Web como recursos interligados

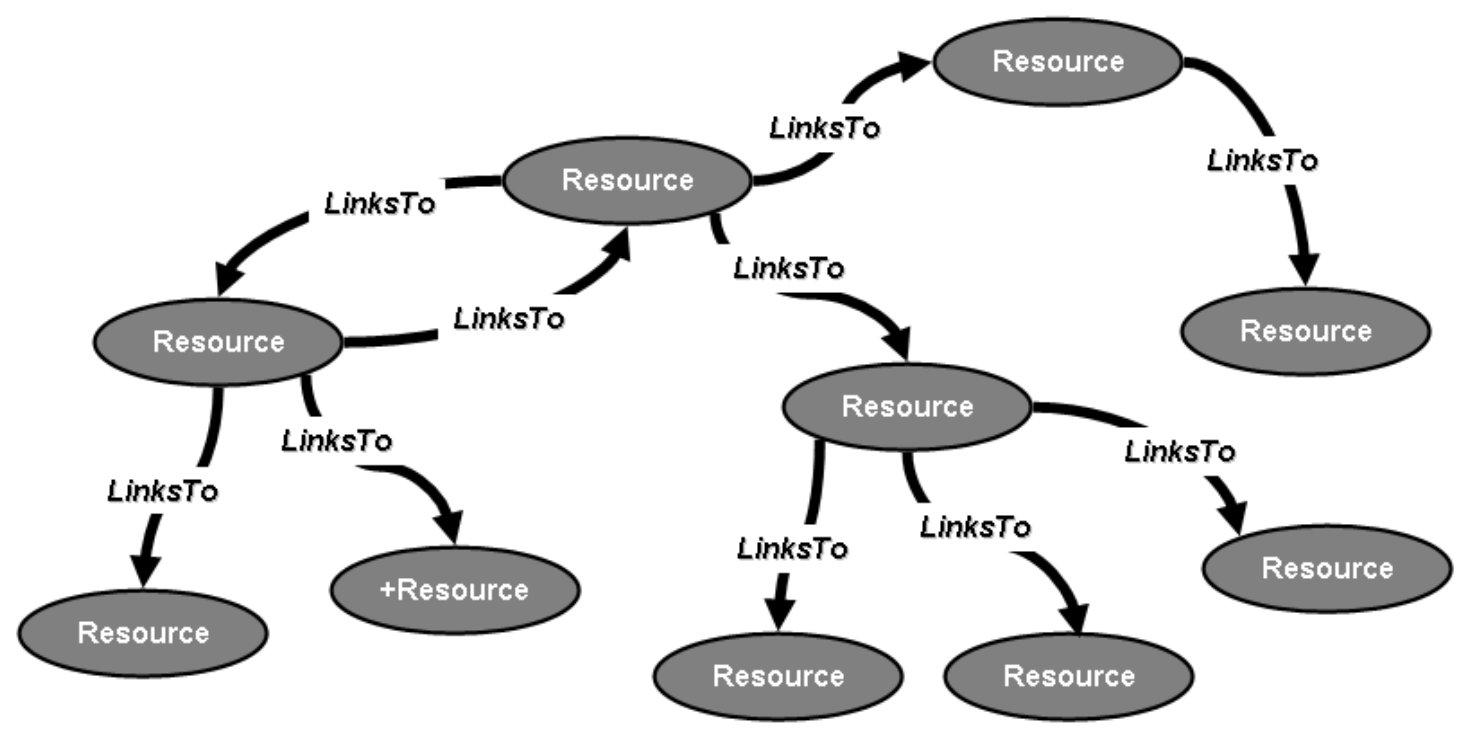

Fonte: BRATT, 2008.

Os conteúdos na Web são, via de regra, criados com o objetivo de disponibilizálos para leitores humanos (RAMALHO; VIDOTTI; FUJITA, 2007). Para Tim BernersLee (2005), o próximo passo seria transformar os computadores em leitores. Para permitir que as páginas sejam consultadas por máquinas e transformar a internet em um grande repositório, criou-se o conceito de Web Semântica. A ideia é que não somente pessoas sejam capazes de ler as páginas, mas outros computadores também consigam "compreender" o que as páginas contêm. 
O objetivo da Web Semântica é, nessa medida, explicitar as relações entre os signos e o que estes significam, de modo formal e explícito para que essas relações possam ser extraídas e processadas automaticamente, como ilustrado na Figura 9. Com isso, o computador poderá fazer inferências simples e recuperações mais precisas ao buscar elementos específicos e seus conteúdos, e não apenas pela sequência descrita. Assim, por exemplo, é possível diferenciar um texto de autoria de Stephen King de outro sobre Stephen King.

Figura 9 - A Web como objetos inter-relacionados

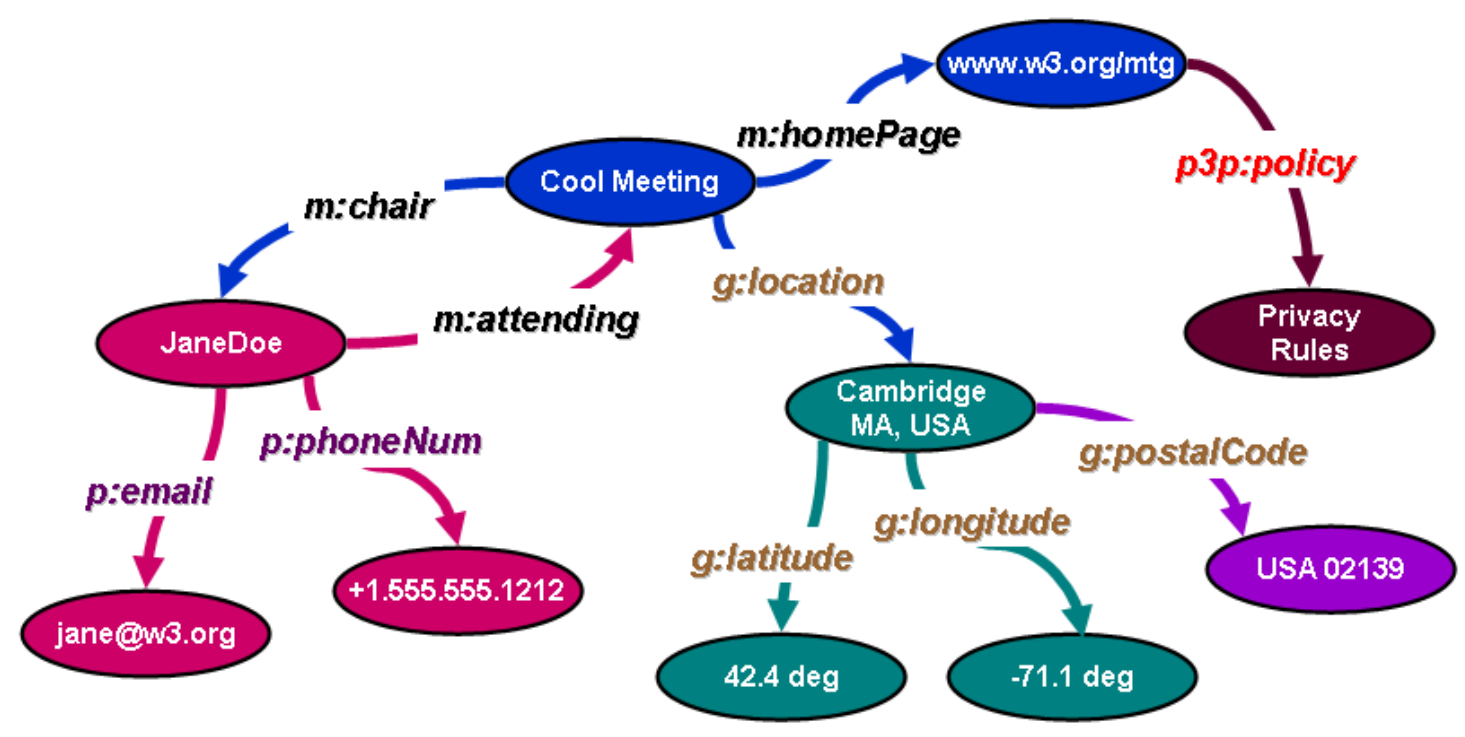

Fonte: BRATT, 2008.

Com estruturas de metadados específicos é possível incluir uma semântica leve, baseada em proposições lógicas, em forma de triplas, que permitem fazer inferências simples. É importante observar que, nesta proposta, os elementos lógico-semânticos não são pensados para serem utilizados por humanos porque estes são capazes de fazer essas inferências durante o processo de leitura. Todas as tecnologias, e principalmente o processo de inclusão desses metadados, são voltadas para os computadores. Nessa medida, os SRI operam como sistemas intermediários que realizam verificações e inferências com base em lógica formal.

Apesar de ser uma proposta interessante e amplamente aceita, não é isenta de problemas e críticas por parte da comunidade acadêmica. De Moor (2005) cita alguns aspectos problemáticos: a visão de que a atribuição de semântica por meio de sentenças triplas lógicas é suficiente para incluir significado em conteúdos Web, como se a semântica fosse o único elemento presente na significação; a Web Semântica exclui 
completamente o indivíduo do processo de interpretação e julgamentos de relevância no processo de recuperação da informação (DE MOOR, 2005; SINGH, 200X). Essas críticas, no entanto, não vieram vazias de conteúdo, contrapropostas ou sugestões de melhoria. Uma delas é a proposta de Web Pragmática, abordada a seguir.

\subsection{Web Pragmática: origem e objetivos}

A Web Pragmática surge da percepção de que algo faltaria à proposta da Web Semântica. Diversos autores (SINGH, 2002b; DE MOOR, KEELER e RICHMOND, 2002; DI MAIO, 2008) apontam o principal problema: a ausência de elementos que complementem os significados dos conteúdos publicados na Web, questionando, ainda, se a adição de elementos semânticos a esses conteúdos é suficiente para atingir o objetivo de criar uma Web significativa. Vale ressaltar que o termo semântica, utilizado no contexto da Web, remete à Semântica formal, que é o modo de garantir a realização de funções interpretativas por processos computacionais.

Para de Moor, Keeler e Richmond (2002), a Web Pragmática é uma Web em que processos pragmáticos essenciais são definidos e automatizados. A Pragmática é definida como o estudo da relação do signo com seus intérpretes, intérpretes estes inseridos em um contexto, que pode ser tanto situacional, como individual ou social, segundo Morris (1985) e Peirce (1977). Estes últimos são amplamente reconhecidos como os precursores conceituais da Web Pragmática (DE MOOR, KEELER e RICHMOND, 2002; DI MAIO, 2008). Dessa forma, é possível ver a Web Pragmática como uma tecnologia para criar representações de contextos na Web, de forma a aprimorar os processos de recuperação da informação. É importante comentar aqui que não há consenso no que se refere à completa adequação ou uso dos conceitos de Semântica e Pragmática nas Web Semântica e Web Pragmática, questão que será discutida mais à frente, no item 3.2.

A necessidade de se considerar os contextos na recuperação de informações não é uma novidade. Os estudos de relevância na recuperação, por meio da avaliação da relevância (ou não) dos resultados, já levavam em consideração os contextos. Ingwersen e Järvelin (2005) ressaltam que a recuperação de informações é um processo de busca que acontece dentro de um contexto determinado por diversos elementos: social, organizacional e cultural, assim como contextos sistêmicos. Para estes autores, toda 
informação é construída com base em dois elementos contextuais: o modelo de mundo do agente (seu contexto social e cognitivo) e a mensagem consumida em um contexto. Porém, deve-se pensar que a mensagem também foi construída dentro de um contexto, por um autor, com um modelo de mundo próprio. Quanto menos informação o agente tem sobre o contexto de produção e consumo da mensagem, maior a liberdade para interpretá-la. Isso ocorre de forma semelhante quando se considera a interpretação não apenas de uma fonte informacional, mas também de diferentes informações cujas fontes contextuais não estão acessíveis ao agente.

Enquanto em ambientes livres, lúdicos ou poéticos essa liberdade seja desejável, ela pode ser fonte de ruídos em ambientes informacionais de domínios científicos. Em outras palavras, a indeterminação dos significados pode resultar em menor acurácia no processo de recuperação. Porém a simples representação de contextos não soluciona os problemas; é imperativo determinar o que pode ser considerado como contexto suficiente para a interpretação (INGWERSEN; JÄRVELIN, 2005). Isso é necessário porque insuficiente informação de contexto de produção e consumo de mensagens pode levar, novamente, à ambiguidade e à necessidade de mais informação contextual, e assim indefinidamente.

Dentro dessa problemática, e com base na visão de contexto suficiente para a interpretação de mensagens, de Ingwersen e Järvelin (2005), pergunta-se: o que pode ser considerado informação contextual suficiente para representar trabalhos científicos? Para entender este problema e começar a delinear uma possível representação do contexto que envolve a produção e consumo de informações, no campo científico, primeiro é necessário realizar uma análise do domínio em que se enquadra a informação, fazendo-se paralelos com os contextos previamente citados.

\subsubsection{A Ciência como Contexto, ou O Contexto da Ciência}

Com base nos trabalhos de Kuhn (1970), Whitley (1974), ao abordar a institucionalização dos diferentes domínios de conhecimento, afirma que há, nas diferentes especialidades científicas, formas diversas de definir os grupos sociais e padrões de transferência de informação. Nessa perspectiva, Whitley (1974) classifica sua proposta de institucionalização em dois constituintes: institucionalização social e 
institucionalização cognitiva. O grau de consenso e padronização de elementos como ações, percepções e significados definirão o nível de institucionalização da área

Nessa direção, Whitley (1974) afirma também que não há como separar os aspectos cognitivos e sociais de forma absoluta, pois ao considerar que os pesquisadores, que realizam as atividades cognitivas, são indivíduos sociais, a ciência seria também uma atividade social, e todo o conhecimento científico é, então, uma expressão dessa atividade. Dessa forma, é possível ver a ciência como um conjunto de grupos sociais científicos regidos internamente por normas, relacionamentos, definições e terminologia próprias, de forma semelhante a outros grupos sociais.

Outros elementos que podem ser considerados para a avaliação da institucionalização são "os indicadores de produção científica, os indicadores de citação e os indicadores de cooperação" (KOBASHI; SANTOS, 2006, p. 29), que, dentro deste trabalho, se materializam em representações contextuais, assim como as áreas, subáreas e cursos institucionais do campo científico, como, no caso da Ciência da Informação, os cursos de Biblioteconomia, GI, Arquivologia e Museologia, por exemplo (ARBOIT; BUFREM; KOBASHI, 2011).

Os trabalhos científicos, por outro lado, são criados por esforços cognitivos de um ou mais pesquisadores que, por sua vez, pertencem a grupos sociais científicos. Os artigos são representações do conhecimento expressos por meio de teorias expressas por conceitos. Esses conceitos, ou abstrações, podem ter outros nomes - palavras, termos em diferentes grupos sociais científicos, ou os grupos podem utilizar o mesmo termo para representar conceitos distintos (CABRÉ, 1993). A identificação dos autores e a quais grupos sociais científicos eles pertencem são, em si mesmos, importantes informações contextuais para a interpretação de mensagens.

De modo semelhante, é possível que, no interior de uma única área, sejam utilizadas teorias, metodologias ou ferramentas que definem ambiguamente um determinado termo. É o caso do termo "pragmática”, que tem diferentes significados, de acordo com o autor escolhido: Wittgenstein, Habermas, Peirce, Morris etc.

Porém, não é possível considerar apenas a mensagem e seu(s) criador(es); é preciso considerar também o receptor, o intérprete da mensagem. Este está inserido, também, em um grupo social. Neste contexto, a definição dos termos tende a ser precisa. Ao realizar uma busca, portanto, não estão sendo indicadas apenas palavras: ao contrário, está presente a construção social de conceitos e são esses conceitos que são, 
via de regra, utilizados em buscas por informação especializada. Portanto, pode-se afirmar que um contexto social adequadamente representado promove recuperação de informação mais produtiva.

É importante notar que, se forem realizadas as adequadas representações conceituais dos diferentes grupos sociais acadêmicos, dentro do que é proposto para a Web Semântica, seria possível realizar uma equivalência computacional lógica entre diferentes termos que representam o mesmo conceito, assim como distinguir formas significantes iguais que apontam para diferentes conceitos e, assim, recuperar os itens mais relevantes, desde que as buscas sejam feitas por meio de conceitos inseridos em contextos.

Essas representações conceituais devem ser realizadas em conjunto entre os indivíduos. Não parece factível considerar todas as áreas de conhecimento para a criação de representações contextualizadas. É possível, porém, criar representações de grupos sociais científicos específicos. Essas representações, sendo realizadas para indivíduos de um mesmo grupo, vão ao encontro das propostas da Web Pragmática de Singh (2002a, 2002b) e Schoop, de Moor e Dietz (2006), de construção social do conhecimento.

Nesta perspectiva, alguns elementos ou aspectos contextuais extralinguísticos da Web Pragmática podem ser classificados em: tangíveis, como a localidade ou a instituição; idiomas dominados, filiação ou áreas de pesquisa; ou intangíveis, como a motivação e a necessidade que são de difíceis de serem descritos e formalizados.

Nesta etapa da pesquisa, o foco volta-se principalmente para os elementos linguísticos e a dois tipos de aspectos contextuais extralinguísticos. Alguns elementos de contexto que podem ser representados e podem ser encontrados em perfis acadêmicos são:

- Idiomas que o indivíduo domina e nível de domínio;

- Instituição(ões) a que o indivíduo está vinculado;

- Áreas de pesquisa;

- Cooperação com outros indivíduos (professores, pesquisadores, autores etc.);

- Vertentes teóricas adotadas;

- Conceitos adotados. 
Os três primeiros tipos de informações podem ser encontrados em diversas fontes, como a Plataforma Lattes ${ }^{18}$, ResearcherID, ORCID ou Google Scholar. Os outros três não são contemplados diretamente nestas plataformas, mas podem ser inferidos a partir deles, com certa facilidade, como no caso da cooperação, mas com maior dificuldade para as teorias e conceitos. Um exemplo de representação de cooperação está presente na Plataforma Lattes, onde é possível identificar, no perfil de cada autor, os coautores com que trabalha, assim como o Google Scholar que, além de identificar coautoria, também permite exibir quais perfis o autor acompanha e por quem é acompanhado.

Outro contexto possível de ser representado é o perfil cognitivo e social do buscador. Suas preferências, buscas anteriores, resultados informados como relevantes, e até mesmo o perfil acadêmico, podem ser utilizados para diferenciar um resultado de outro. Além do perfil do próprio buscador, os perfis de outros usuários podem ser utilizados para otimizar as buscas, identificando-se as pessoas que tenham preferências semelhantes às do buscador, e as buscas e resultados que estes preferiram.

Em um aspecto intermediário entre o linguístico e o extralinguístico há outros elementos que podem ser representados, como as características de citação. Neste caso, não apenas as referências seriam informadas, mas também de que forma elas são utilizadas. Algumas possibilidades são: concorda com, cita como autoridade, cita como fonte de dados, confirma, refuta, entre outras.

Obviamente, outros contextos podem ser identificados ou considerados. Não é intenção deste trabalho abarcar todos os possíveis contextos que influenciam a interpretação de informação científica, mas sim analisar as possibilidades de representar diferentes contextos e adicioná-los aos conteúdos da Web, com o objetivo de promover a recuperação de informações relevantes.

\subsubsection{Web Pragmática vs Pragmática Virtual: estudo crítico das versões da web}

Nesta seção serão discutidos os conceitos de Web Pragmática e Pragmática Virtual, mostrando suas diferenças e semelhanças, assim como o campo de aplicação de cada uma. É importante ressaltar que, em alguns casos, os dois conceitos são utilizados como sinônimos, quando na verdade abordam questões distintas.

\footnotetext{
${ }^{18}$ http://lattes.cnpq.br/
} 
Como dito anteriormente, a Web Pragmática busca definir e representar os elementos pragmáticos essenciais para a compreensão e interpretação de mensagens. Porém, por serem conceitos de uso recente, tais como Web Semântica e Web Pragmática, em conjunção com outros que podem ser abordados de diferentes formas, inclusive referentes à Semântica e à Pragmática, poderão ocorrer ambiguidades na compreensão desses termos. Um desses casos de ambiguidade ocorre nos estudos relativos à Pragmática em ambiente virtual.

Desde sua criação, a Web serve como uma plataforma de interação e comunicação entre indivíduos. Originalmente pensado para a comunicação entre bases militares, vem sendo utilizada efetivamente entre universidades e acadêmicos, tendo avançado para uso pela população em geral. Diante de seu contexto evolutivo, é possível afirmar que todos os elementos da comunicação escrita - Sintaxe, Semântica e Pragmática - já ocorrem na Web, desde seu surgimento. Os avanços tecnológicos também têm centrado suas pesquisas em projetos para adicionar elementos semânticos e pragmáticos aos conteúdos da Web para que os computadores possam realizar inferências e "compreender" melhor esses conteúdos, dando origem a duas novas áreas de estudo e aplicação: a Pragmática Virtual e a Web Pragmática.

Antes de aprofundar esta discussão terminológica, é necessário esclarecer os diferentes critérios que podem ser utilizados para caracterizar os tipos de Web. Um deles, definido por O’Reilly (2005), classifica a internet em estática ou interativa, esta última, chamada de Web 2.0. Isso foi afirmado em face da percepção da Web como uma plataforma de acesso a serviços e softwares, com características únicas, sendo citados como exemplos dessas características: o "eterno" beta, situações em que os aplicativos, por passarem por evoluções muito constantes não se tem uma versão considerada final ou completa; os pagamentos estilo self-service, diferentes dos modelos comerciais adotados em períodos anteriores; a identificação do aumento da interação que ocorre entre os indivíduos, sendo atenuada a diferenciação dos papéis de fornecedores e consumidores de conteúdos; a realização de atividades de forma descentralizada, eliminando-se, de certa forma, o papel centralizador de empresas fornecedoras de conteúdos, abarcando, ainda, as ações de indicação de erros, sugestões de melhorias, e até mesmo de correções, para os usuários.

Outra possibilidade de classificação da Web é oriunda das propostas de BernersLee, Hendler e Lassila (2001) que buscam adicionar significado aos conteúdos da Web. 
O significado, no entanto, não tem em vista, prioritariamente, o ser humano, mas a "compreensão" pelos computadores. Essa característica promove a diferenciação entre Web Sintática e Web Semântica: na primeira, o computador é capaz apenas de identificar os diferentes elementos que compõem o conteúdo, que são definidos como uma sequência ou conjunto de caracteres, ou signos; na segunda, é possível inferir significado dos diferentes elementos do conteúdo. A Web Pragmática tem origem nos princípios da Web Semântica.

Nesta discussão, é importante ressaltar algumas questões: primeiro, que as classificações acima são realizadas sob aspectos e perspectivas distintas: a de O'Reilly tem foco na comunicação humana mediada por computador, ampliada tecnologicamente, mas tem também a perspectiva mercadológica da Web; a de BernersLee, Hendler e Lassila é voltada para a interação do computador com os conteúdos disponíveis na Web, especificamente para as formas de representação de informações e de conhecimentos neste ambiente, e a introdução de novos conceitos e métodos para que o computador possa "entender" melhor os conteúdos e, assim, melhorar a recuperação de informações. Em segundo lugar, a proposta de O'Reilly foi apenas uma tentativa de dar nome a um fenômeno que já estava acontecendo, uma "simples" constatação da realidade, enquanto a de Berners-Lee, Hendler e Lassila cria uma nova Web, com novas possibilidades e ferramentas.

Por outro lado, ao considerar a Web desde seu surgimento como um ambiente não apenas propício, mas criado para a comunicação, há a possibilidade de serem estudados elementos sintáticos, semânticos e pragmáticos neste ambiente, como dito anteriormente. A Pragmática, enquanto domínio de estudos da construção social de significados, ganhou na Web um campo de pesquisas e aplicações frutíferas, sendo possível identificar e analisar diferentes formas de comunicação, dentro e entre os grupos sociais.

Um olhar mais atento sobre as perspectivas e conceitos próprios da Web Semântica e a Web Pragmática é importante para o desenvolvimento da proposta desta tese, de modelagem de contexto para as informações oferecidas na Web. Não é objetivo desta tese, no entanto, a análise ou avaliação dos processos pragmáticos no ambiente Web, tais como os jogos de linguagem, negociação de significados e ação comunicativa.

Estes processos são objeto de estudo da Pragmática Virtual, que com base nas teorias de Habermas (1981) tecem seus estudos de interação entre os atores e validade 
de sentenças. Estes estudos trabalham, principalmente, com a necessidade de compartilhamento de regras, que possam facilitar a comunicação e o entendimento das sentenças, por todos os participantes da ação de comunicação (GRACIOSO, 2010).

Considerando a Web como um grande ambiente comunicacional, que envolve pessoas de diferentes culturas, nacionalidades e ambientes sociais, a negociação de regras neste ambiente, embora exista, é algo difícil de visualizar, controlar e mensurar. Percebe-se então que 'temos de 'descobrir' quais são os critérios que validam a comunicação que se estabelecem e como se validam os conteúdos produzidos a partir dessa comunicação" (GONZÁLEZ DE GOMEZ; GRACIOSO, p. 11, grifos no original).

Este é o cerne das pesquisas da Pragmática Virtual, diferentes dos objetos da Web Pragmática, e neste trabalho, como dito anteriormente, não serão discutidos os objetos de pesquisa da Pragmática Virtual, mas os da Web Pragmática.

\subsection{Web Semântica e Web Pragmática: limites conceituais}

Ao discutir os conceitos de semântica, pragmática e suas aplicações no ambiente Web há, certamente, limites em relação ao que pode ser considerado, realmente, como semântico ou pragmático. Estas discussões não são novas, pois ocorrem desde o surgimento do conceito de Web Semântica. Porém, é necessário esclarecer alguns pontos que podem parecer conflitantes ou incompletos.

Ao abordar os conceitos e definições de Semântica e Pragmática, no item 2.3, foram apresentas as visões de diversos autores sobre as questões da linguagem humana; de forma semelhante, foram apresentados os conceitos de Web Semântica (início do capítulo 3) e Web Pragmática (item 3.1) como exposto na literatura consultada. O que é questionável é até que ponto a Web Semântica, e sua sucessora, a Web Pragmática, incorporam os conceitos das áreas da Semiologia e Semiótica sobre a semântica e a pragmática.

O que se percebe, ao serem analisados os exemplos e explicações presentes na literatura consultada, e nos dados abertos disponíveis na web, é que os dados considerados semânticos se resumem, via de regra, à inclusão de mais metadados padronizados para descrever os acervos informacionais; pode-se afirmar que não há, de fato, adição de significados, no sentido proposto pelos estudos semânticos, ou de adição 
de contextos de interpretação das informações, como sugere a Pragmática. Ao se considerar que os dados e, neste caso, os metadados, são expressos mediante sintaxe, então é possível afirmar que não se representam informações com elementos semânticos ou pragmáticos no ambiente Web, como propõem e afirmam as propostas da Web Semântica e da Web Pragmática, havendo, tão somente, adição de maior número de elementos sintáticos aos previamente existentes.

Não há, então, a possibilidade de encontrar elementos semântica ou pragmaticamente representados, em toda a amplitude desses conceitos, nas Web Semântica e na Web Pragmática, como afirma Gärdenfors (2004), que vai além, ao afirmar que a Web Semântica nem sequer seria ontológica, pois a descrição dos elementos é apenas parcial e não cobre todas as possibilidades que uma ontologia realmente poderia prover. O que se tem nas novas propostas para a Web são aplicações simplificadas de elementos de raciocínio, compreensão e comunicação humanas em um ambiente digital voltado para computadores.

Almeida, Souza e Fonseca (2011) apresentam um conjunto de definições sobre a Semântica, verificando a adequação dessas definições para a Web Semântica. Afirmam que, dentro deste escopo, a abordagem semântica que mais se aplica é a semântica formal. Os autores de textos da área, no entanto, não deixam isso claro, ou não a definem de forma adequada. Gärdenfors (2004), por sua vez, critica a visão da computação de que toda Semântica poderia ser reduzida à lógica de primeira ordem, ou teoria dos conjuntos. Para este autor, o raciocínio humano é complexo, não sendo possível formalizar essa complexidade por meio dos métodos da Semântica Lógica.

O que o computador realiza, nestes ambientes, são manipulações de símbolos e de proposições dadas como verdadeiras. Não é possível afirmar que o computador é dotado de inteligência ou que seja capaz de realizar inferências complexas, de forma semelhante ao Argumento da Sala Chinesa ${ }^{19}$, de Searle (1999), no qual se questiona se um processamento de dados ou símbolos realizado de forma predeterminada realmente indica inteligência ou autonomia por parte da entidade processadora.

É possível perceber, nos textos apresentados e discutidos acima, que dentro dos estudos e vertentes atuais da Semântica há muitos elementos passíveis de aplicação na Web Semântica, principalmente ao se considerar a forma como os seres humanos processam os signos e os compreendem. Da mesma forma, é possível pensar na

\footnotetext{
${ }^{19}$ No original: "Chinese Room Argument".
} 
ampliação e aprofundamento das propostas da Pragmática na Web Pragmática. Com efeito, a interação e a negociação de significados, como posto nos trabalhos de Wittgenstein $(1968,1994)$ e Morris (1985), não ocorrem no ambiente da Web Semântica e Web Pragmática.

Dito isto, é importante destacar que não se objetiva, nesta pesquisa, considerar todos os aspectos das teorias pragmáticas para aplicação no ambiente Web, por serem de operacionalização complexa para integração ao ambiente Web, com as tecnologias e métodos atualmente disponíveis.

Reitera-se, portanto, que neste trabalho se apresenta uma possibilidade de representação da informação com o uso de elementos específicos das teorias pragmáticas que possam promover o aprimoramento das formas de representação e recuperação de informações em ambientes informacionais digitais, cientes das limitações tecnológicas e conceituais que as abordagens atuais da Web Semântica e Web Pragmática implicam.

\subsection{Ferramentas e procedimentos}

Com a criação do conceito de Web Semântica, novas tecnologias e ferramentas foram criadas, assim como pensados novos usos para algumas já existentes, para dar suporte às propostas de promover melhor recuperação de informação. As ferramentas e procedimentos disponíveis serão descritos, a seguir, de forma a deixar claro seu funcionamento e como podem concretizar as propostas das Web Semântica e da Web Pragmática.

\subsubsection{Ontologias}

Ontologia é uma palavra derivada do grego: onto (ente, o ser, aquilo que é) e logos (teoria, palavra). O termo per se tem sua origem no trabalho Lexicon Philosophicum (1613) do filósofo alemão Rudolph Goclenius (JAPIASSU; MARCONDES, 2001), mas, como disciplina da Metafísica, já era utilizada por Aristóteles em estudos sobre a categorização das coisas existentes. Para evitar ambiguidades, doravante, a Ontologia como disciplina será grafada com inicial 
maiúscula, enquanto ontologia (em letras minúsculas) será utilizado para designar o dispositivo conceitual utilizado em sistemas de informação.

Para a Ontologia, tudo aquilo que é existente tem determinações necessárias do ser, ou seja, determinações que nenhuma forma de ser pode deixar de ter e essas determinações estão presentes em todas as formas e modos de ser (ABBAGNANO, 1998). Atualmente, a Ontologia é uma disciplina descritiva que busca observar e registrar os traços da existência e as características das diferentes entidades, abstratas ou concretas, que compõem a realidade (SOWA, 2000b).

$\mathrm{Na}$ Ciência da Informação e na Ciência da Computação, as ontologias, são definidas como especificações formais e explícitas de conceitualizações compartilhadas (GRUBER, 1994). Tal conceitualização é uma visão abstrata e simplificada do mundo, de uma área do conhecimento ou domínio, que se deseja representar para algum propósito.

As ontologias são, desse modo, sistemas de categorização da realidade observada, compostas de definições formais dos termos, e das relações entre os termos, utilizados na descrição e representação de uma área do conhecimento (GRUBER, 1993). Dentro da CI, a ontologia pode ser considerada como um tipo de representação de informações, da qual as outras como os tesauros, podem ser consideradas como subtipos ou especializações (HJORLAND, 2009). Também é possível visualizar as ontologias como modelagem dos conceitos e suas relações dentro de um mundo possível (INGWERSEN; JÄRVELIN, 2005).

As ontologias são, em geral, classificadas em 3 tipos: ontologia de fundamentação, ontologia de domínio, e ontologia híbrida. O primeiro tipo, também chamado, em inglês, de foundational ontology, foundation ontology, upper ontology ou top level ontology, é um modelo de objetos comuns, aplicáveis a uma grande gama de ontologias específicas, que classifica diferentes categorias de seres e objetos existentes no mundo. Opera como um vocabulário central que descreve termos de vários domínios, contendo noções gerais independentes de problema ou domínio. Como exemplo dessas ontologias é possível citar a de Aristóteles (2005), que classifica os elementos do mundo utilizando os conceitos de Substância, Quantidade, Qualidade, Relação, Lugar, Tempo, Estado, Hábito, Ação e Paixão, ou a de Sowa (2000a), que classifica o mundo segundo diversas categorias primitivas: Independente, Relativa ou Mediadora; Física ou Abstrata; Continuante e Ocorrente (No original: "Independent, 
Relative, or Mediating; Physical or Abstract; Continuant or Occurrent"). No Quadro 5, é possível observar 12 categorias, chamadas por Sowa de categorias centrais, oriundas de combinações das categorias primitivas. Estas categorias são denominadas: Objeto, Processo, Esquema, Script, Conjuntura, Participação, Descrição, História, Estrutura, Situação, Razão e Propósito.

Quadro 5 - Matriz das Categorias Centrais da Ontologia de Sowa

\begin{tabular}{|l|c|c|c|c|}
\hline & \multicolumn{2}{|c|}{ Physical } & \multicolumn{2}{c|}{ Abstract } \\
\hline & Continuant & Occurrent & Continuant & Occurrent \\
\hline Independent & Object & Process & Schema & Script \\
\hline Relative & Juncture & Participation & Description & History \\
\hline Mediating & Structure & Situation & Reason & Purpose \\
\hline
\end{tabular}

Fonte: Sowa (2001)

O segundo tipo, as ontologias de domínio, são representações conceituais de um determinado domínio de conhecimento ou área de estudo. O objetivo deste tipo de ontologia é conter uma listagem de termos utilizados dentro da especialidade escolhida, o que permite que sejam definidos termos, em princípio polissêmicos ou ambíguos, determinando seu escopo de uso. Assim, é possível representar diferentes definições, propriedades e relacionamentos entre, por exemplo, o termo "receita" do domínio da Farmacologia ou da Gastronomia. O terceiro tipo, as ontologias híbridas, têm representações de diferentes conceitos, tanto gerais ou abstratos, como também de objetos concretos ou reais dentro de um domínio.

O tipo de ontologia mais utilizado na Ciência da Informação e Ciência da Computação são as ontologias de domínio. Seus elementos são classes (categorias, classificações) dos vários domínios de interesse e relacionamentos entre essas classes e propriedades (ou atributos) que os entes das classes devem possuir. O primeiro elemento, as classes, são as categorias que foram identificadas nos entes do domínio representado. Essas classes são, em geral, abstrações dos conceitos em vez de objetos concretos, o que permite obter maior flexibilidade ao determinar sua definição, propriedades e relacionamentos.

O segundo elemento, os relacionamentos, podem ser definidos como as relações ou dependências entre objetos, que podem criar taxonomias, hierarquias ou relações de composição. As propriedades, o último elemento, são as características que todo objeto daquela classe possui. São semelhantes às determinações supracitadas, que todo ser ou 
ente deve possuir para ser classificado como existente e, neste caso, pertencente à categoria ou classe em questão.

Este método de classificar os objetos foi popularizado na Inteligência Artificial para melhorar a comunicação entre homens e máquinas (GONZÁLEZ, 2004). É amplamente utilizado para que os computadores "entendam" os conceitos, suas propriedades e suas relações com outros conceitos, possibilitando a criação de grandes bases de informação interoperáveis e melhor estruturadas, de modo a facilitar também a recuperação de informação.

Para a Web Semântica, as ontologias têm valor fundamental. Com elas é possível adicionar significado ou semântica aos diferentes campos e elementos dos conteúdos disponíveis na internet. Para realizar tal ação, as ontologias são representadas por meio de uma linguagem de programação criada especificamente para este objetivo, e, junto com outras tecnologias, permite que o conteúdo na internet passe, em princípio, a ser semanticamente rico. Essas tecnologias serão descritas a seguir.

\subsubsection{Tecnologias para Ontologias}

Dentro do escopo da Web Semântica, algumas tecnologias foram criadas e definidas como padrões, também chamadas de recomendações pela W3C. Essas tecnologias, em conjunto, permitem criar ontologias voltadas para o ambiente computacional para adicionar característica semânticas aos conteúdos disponibilizado na Web.

Grande parte dessas tecnologias, isoladamente, já existem ou têm sua fundamentação em outras tecnologias existentes há mais tempo. Exemplo disso são as $\mathrm{URI}^{20}$, que são identificadores únicos de recursos na web, cujo maior exemplo são as URLs que identificam univocamente um endereço de um recurso, e a XML ${ }^{21}$, uma linguagem que permite criar estruturas de dados flexíveis e de simples expansão. São "facilmente" lidas por seres humanos e permitem tanto o intercâmbio de dados entre diferentes bancos de dados como a integração de diversos programas. Seu funcionamento em conjunto permite recuperar as páginas da web como se fossem bancos de dados. Essas tecnologias são apresentadas na Figura 10 e descritas a seguir.

\footnotetext{
${ }^{20}$ Acrônimo para Uniform Resource Identifier, - Identificador Uniforme de Recurso.

${ }^{21}$ Acrônimo para eXtensible Markup Language - Linguagem de Marcação Extensível.
} 
Figura 10 - Tecnologias envolvidas na Web Semântica

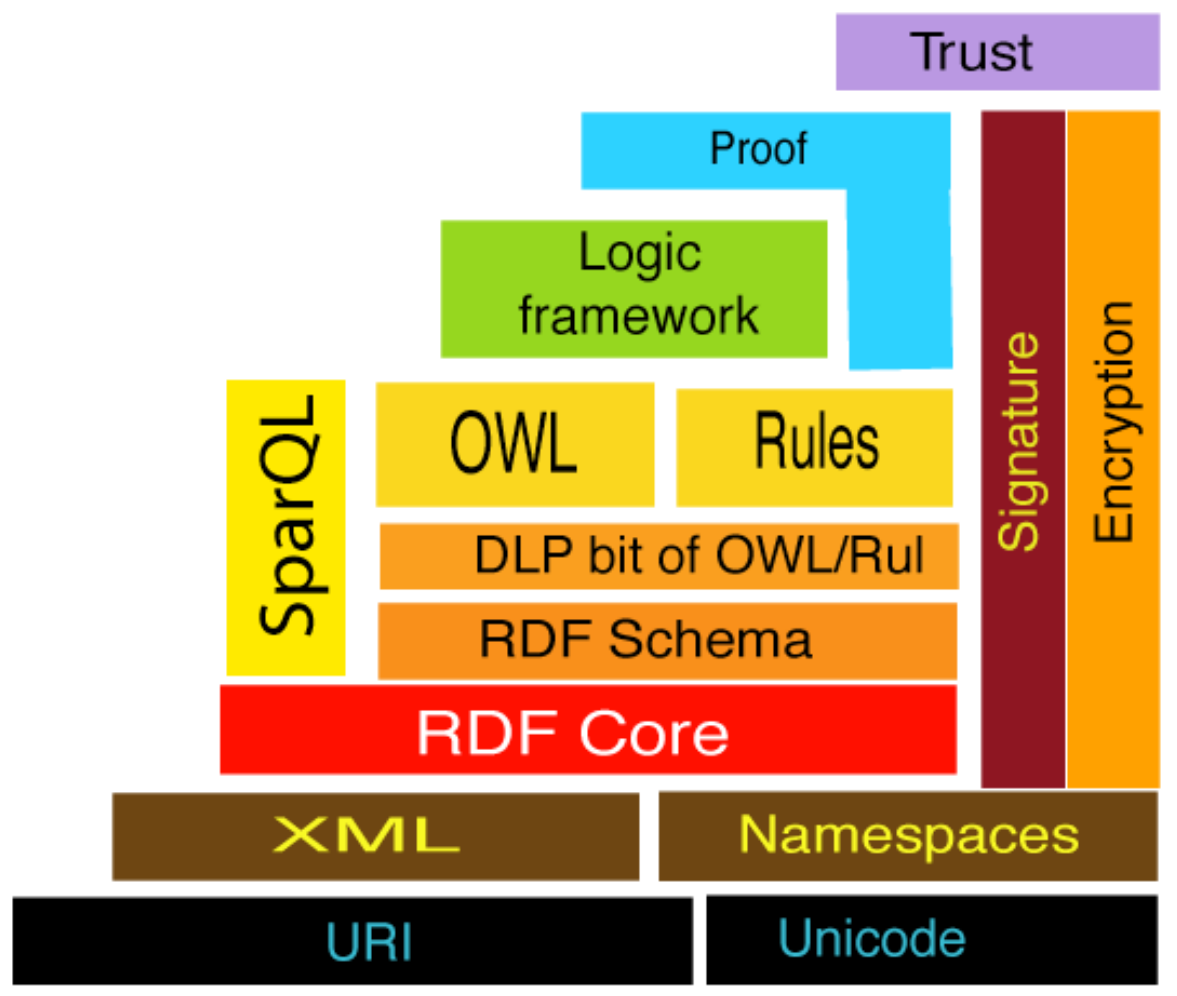

Fonte: BERNERS-LEE, 2005.

\subsubsection{RDF e derivados}

RDF, acrônimo para Resource Description Framework, é uma linguagem de marcação, proveniente da XML, que permite integrar uma variedade de aplicações: catálogos de bibliotecas, diretórios mundiais, distribuição e agregação de noticias, softwares e conteúdos para coleções pessoais de músicas, fotos e eventos, entre outros. A especificação RDF provê um sistema de ontologias leves para suportar o intercâmbio de conhecimento na internet e é uma linguagem simples para expressar modelos de dados que se referem a objetos (recursos) e suas relações.

Por ser baseado em XML, tem na simplicidade e na leveza suas principais características e vantagens. Forma sentenças tríádicas para formular a descrição dos elementos, sob o seguinte formato: um recurso (sujeito) tem uma propriedade (predicado) com um determinado valor (objeto). Como exemplo, é possível perceber, no 
Código $1^{22}$ que representa um registro da British Library, que o recurso bibliográfico identificado pela URI [http://bnb.data.bl.uk/id/resource/012875391] (sujeito) tem como <ISBN13> (predicado) o valor [9782067108844] (objeto).

Código 1 - Exemplo de código RDF

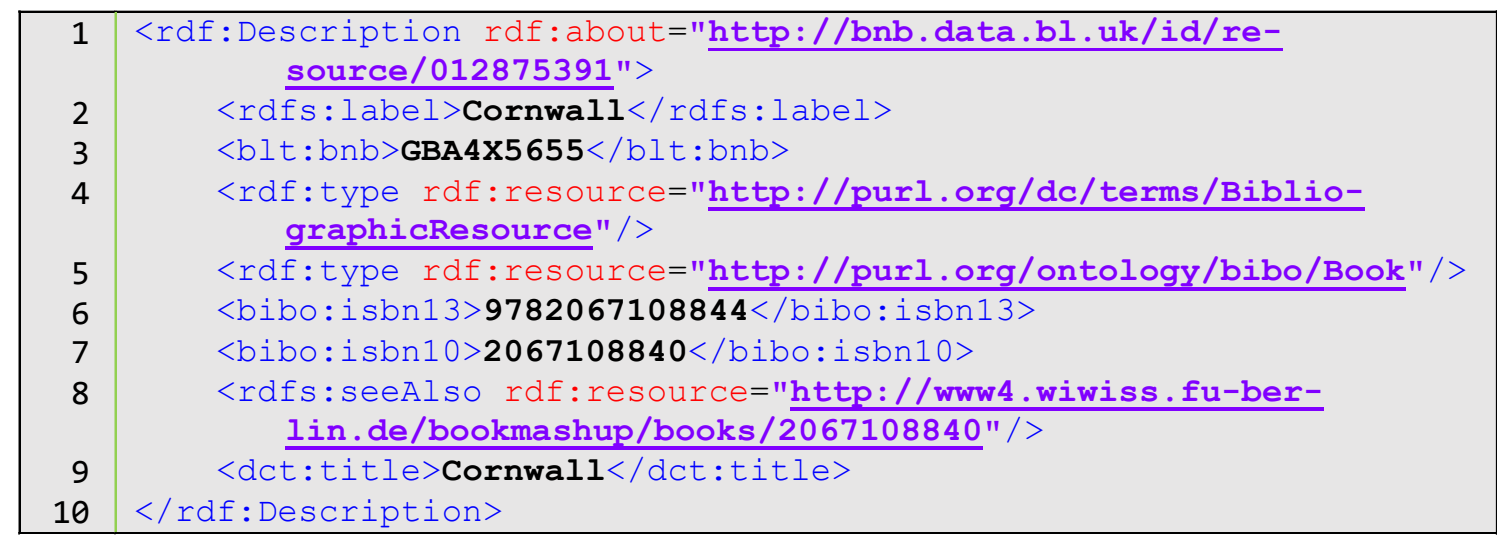

Fonte: adaptado de BRITISH LIBRARY, 2014.

O RDF permite também, por sua simplicidade, a integração com bancos de dados relacionais, relacionando o recurso (registro) e uma propriedade (coluna) com o valor. Dessa forma, com pequenas frases, se constrói uma grande rede de relacionamentos entre diferentes recursos, propriedades e valores (Figura 11). Essas redes permitem a extração de inferências e identificação de informações que, em uma base relacional, exigiria maior codificação específica. Em um repositório RDF, isso pode ser feito de forma transparente.

\footnotetext{
${ }^{22}$ Como dito anteriormente, há erros de sintaxe conhecidos em diversos Códigos aqui expostos como exemplos. Suas validações foram realizadas numa representação maior, e devem ser consideradas como trechos de código isolados, fora de contexto, ou pedaços desse código maior. Estes exemplos aqui apresentados foram retirados dessa representação completa para facilitar a leitura e mostrar, de forma simplificada, a possibilidade de representação nas diferentes linguagens de programação e sintaxes.
} 
Figura 11 - Exemplo de RDF em formato gráfico

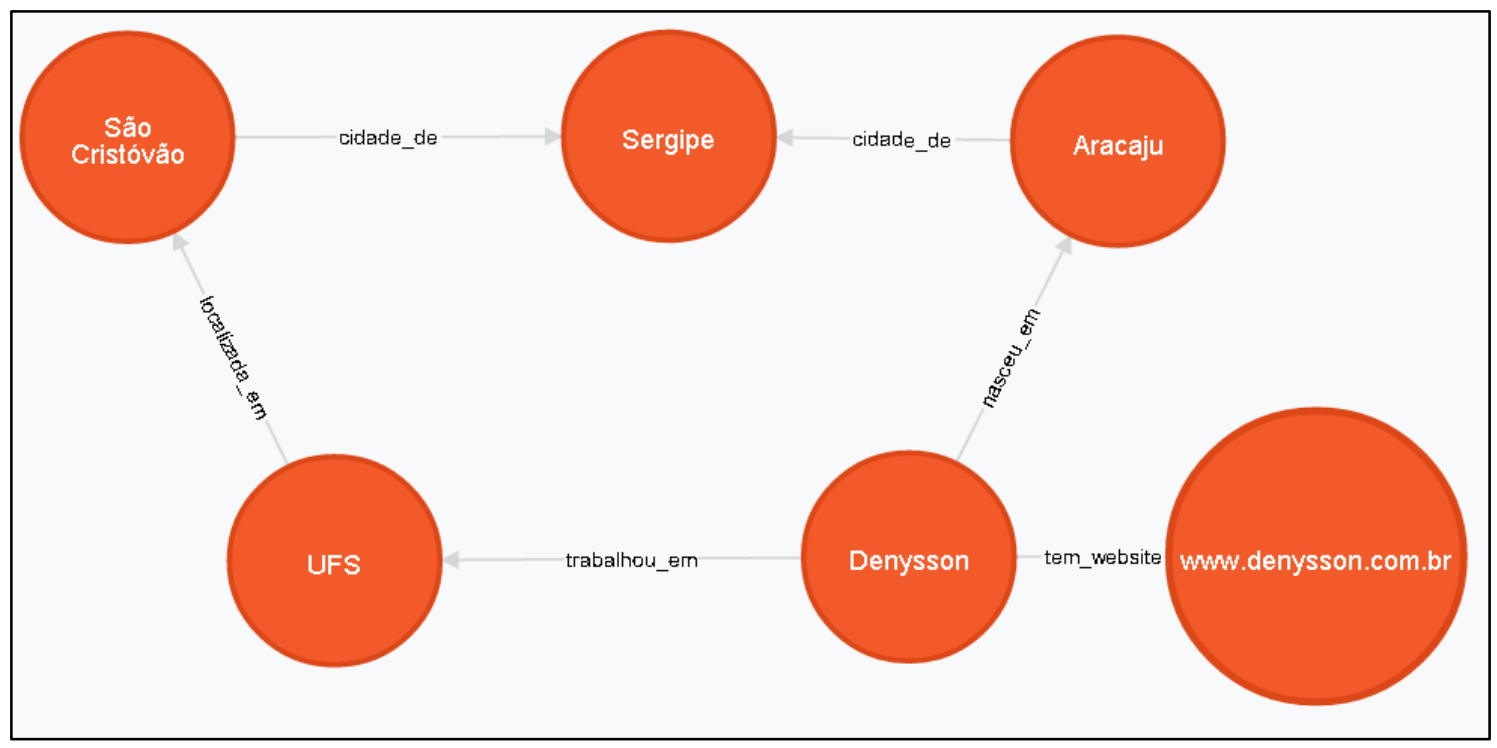

Fonte: Elaborado pelo autor, 2015.

\subsubsection{OWL}

Os dados em RDF são estruturados, mas por serem baseados em XML não há como garantir que sua estrutura está correta ou que os valores são adequados. Para resolver este problema criou-se outra linguagem, que permite definir as ontologias do domínio em questão e, com isso, definir restrições de relações entre entidades e os valores que as propriedades podem assumir. Essa linguagem é chamada de Web Ontology Language, mais conhecida por seu acrônimo OWL.

A OWL é, atualmente, reconhecida como um padrão W3C para a definição de ontologias na Web (W3C, 2012a). Seu uso é a fundamentação para que os computadores não apenas consigam recuperar dados, mas possam fazer as inferências necessárias para transformar a Web tradicional em uma mais inteligente: a Web Semântica. Sua estrutura foi projetada para facilitar a tradução e a representação de informações em estruturas semanticamente ricas, possibilitando a exploração dessas estruturas e o processamento, via computador, dos dados estruturados em RDF, de forma "inteligente".

Atualmente na versão 2 (a terceira versão, depois da 1 e da 1.1), a OWL permite formalizar as classes de um domínio e as relações entre as classes, assim como definir quais objetos são classes e quais são instâncias. Estas relações podem ter restrições hierárquicas, de equivalência e de disjunção, entre outras (W3C, 2012b). As 
propriedades também são expressas via OWL, que possibilita a criação de subpropriedades de forma hierárquica; as classes podem ser sujeito ou predicado das propriedades, ou tipos de valores que elas podem assumir (numérico, data, texto, etc), determinando restrições de dados em princípio semanticamente mais ricas (Código 2).

Código 2 - Exemplo de código OWL

\begin{tabular}{|c|c|}
\hline 1 & $\langle!--$ http://purl.org/spar/cito/cites --> \\
\hline 2 & \\
\hline 3 & 〈owl:ObjectProperty rdf:about="http://purl.org/spar/cito/cites"> \\
\hline 4 & $\langle$ rdfs:label xml:lang="en" >cites $\langle/$ rdfs:label $\rangle$ \\
\hline 5 & <rdfs:comment xml:lang="en">The citing entity cites the cited \\
\hline 6 & entity, either directly and explicitly (as in the reference \\
\hline 7 & list of a journal article), indirectly (e.g. by citing a more \\
\hline 8 & recent paper by the same group on the same topic), or \\
\hline 9 & implicitly (e.g. as in artistic quotations or parodies, or in \\
\hline 10 & cases of plagiarism). $\langle/$ rdfs: comment $\rangle$ \\
\hline 11 & <owl: inverseof rdf:resource="http://purl.org/spar/cito/isCitedBy"/> \\
\hline 12 & <rdfs:subPropertyOf rdf:resource="\&discourse- \\
\hline 13 & relationships;refersTo"/> \\
\hline 14 & $\langle/$ owl:ObjectProperty $\rangle$ \\
\hline
\end{tabular}

Fonte: adaptado de SHOTTON; PERONI, 2014.

\subsubsection{SparQL}

Para adequadamente recuperar os dados armazenados em RDF foi necessário criar uma linguagem capaz de selecionar e recuperar, dentro de um repositório específico, as triplas requisitadas. Esta é uma linguagem mais simples que as comumente usadas para a recuperação de dados em um repositório, pois, diferentemente das bases de dados comuns, cuja estrutura é variável, a estrutura simplificada do RDF, em triplas, permite a seleção, inferência e recuperação de dados de forma facilitada.

Com a SparQL, o que deve ser levado em consideração é a estrutura básica do RDF, [sujeito] <predicado> [objeto], informar alguns campos que são conhecidos e solicitar, com o prefixo ?, os dados que se desejam, como ilustrado no Código 3, que, informado o identificador do documento, recupera o título do mesmo. 
Código 3 - Exemplo de código SparQL Simples

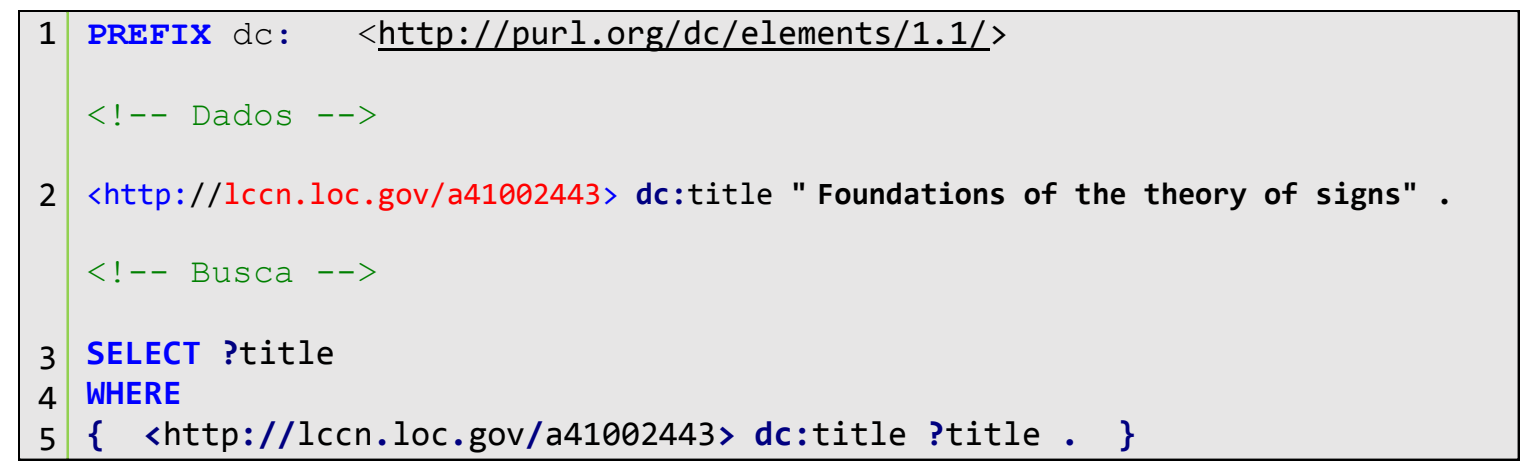

Fonte: Elaborado pelo autor, 2015.

É possível também retornar diferentes valores de um único registro, mediante o uso de substitutos para valores desconhecidos. Para isso, usa-se o prefixo ? porém sem ser recuperado após o comando SELECT, como ilustra o Código 4, que encontra e recupera, do repositório, os títulos dos livros (com ?title) e seus respectivos autores (com ?creator).

Código 4 - Exemplo de código SparQL

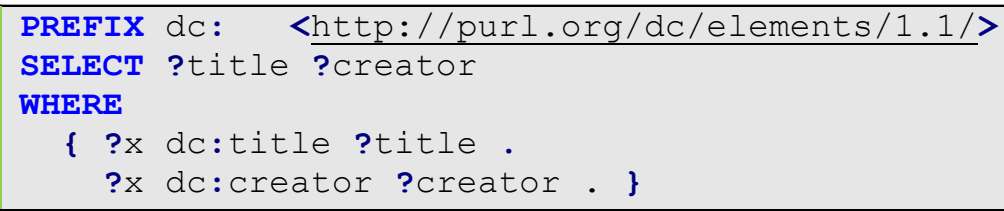

Fonte: Elaborado pelo autor, 2015.

Com esta estrutura básica, simples, é possível recuperar os registros dos repositórios e, se realizadas as buscas em sequência, utilizando-se elementos conhecidos em conjunto com elementos desconhecidos, é possível realizar inferências simples, extraindo dos registros RDF informações inicialmente escondidas, aparentemente desconhecidas. A SparQL é o fundamento da realização de inferências com RDF.

\subsubsection{Topic Maps}

Os Topic Maps são uma forma de representação de informação bibliográfica que pode ser utilizada na Web Semântica. Sua origem remonta à década de 1990, quando o grupo Davenport de produtores de livros eletrônicos buscava uma forma de organizar conteúdos publicados (ROVIRA, 2005). Esta tecnologia procurava representar as informações dos livros publicados simulando os índices remissivos de livros, apresentando ao leitor os textos em que um determinado conceito é abordado, sendo 
possível indicar não apenas o texto mas também a(s) página(s), de forma específica. Dessa forma, tinha como objetivo inicial armazenar e processar informação de livros eletrônicos, utilizando um formato padrão. Após alguns anos, os Topic Maps (doravante chamados pelo seu acrônimo TM) foram reconhecidos como um padrão de representação de informações bibliográficas, registrado sob a norma ISO/IEC 13250.

Os TM representam os conceitos e suas relações de forma semelhante às ontologias, previamente descritas, porém têm o diferencial de também adicionar ao conceito referências aos registros informacionais em que o conceito ocorre. Essas ocorrências podem ser documentos textuais, imagens, sons, vídeos, ou qualquer outro suporte de informação.

Sua estrutura básica é composta de Topic, Associations e Ocurrences. Além desses elementos, outros dão suporte e complementam as funcionalidades dos TM, que são os Roles, Names, Scope e Type/Instance. Esses elementos serão descritos a seguir, com base nos textos de González (2004), Pepper (2000) e Rovira (2005) e podem ser vistos compondo um exemplo em XML (em sua versão conhecida para os Topic Maps como XTM) no Código 5. 
Código 5 - Exemplo de tópicos abstratos em XTM

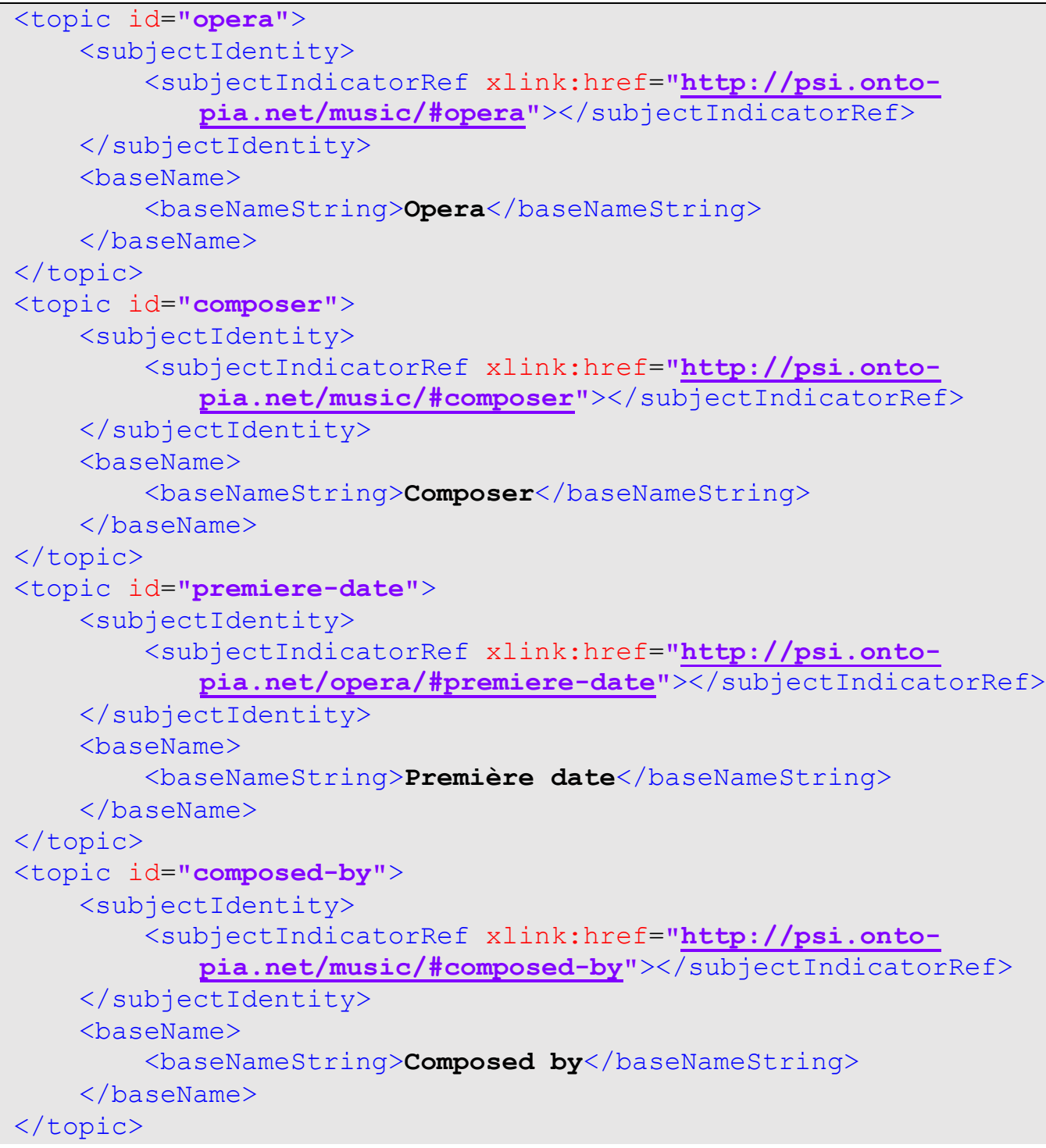

Fonte: adaptado de GESSA 2005.

Os Topic são os assuntos que necessitam ser representados dentro de um determinado domínio, de forma semelhantes às ontologias. A principal diferença em relação às ontologias é que, dentro dos TM, também são representados objetos concretos e não apenas um conceito abstrato, sendo todos eles considerados Topics, independentemente se abstratos ou concretos. Para diferenciar um do outro é utilizado o item Type/Instance, que identifica se um determinado Topic é considerado um objeto de tipo (Type), um conceito mais genérico ou abstrato, ou uma instância (Instance), como exemplificado abaixo (Código 6). 
Código 6 - Exemplo de tópico concreto (instancia) em XTM

\begin{tabular}{|c|c|}
\hline 1 & <topic id="puccini"> \\
\hline 2 & <instanceOf> \\
\hline 3 & <topicRef xlink:href="\#composer"></topicRef> \\
\hline 4 & $</$ instanceof $>$ \\
\hline 5 & $<$ subjectIdentity $>$ \\
\hline 6 & $\begin{array}{c}\text { <subjectIndicatorRef xlink:href="http://en.wikipe- } \\
\text { dia.org/wiki/Puccini"></subjectIndicatorRef }>\end{array}$ \\
\hline 7 & $</$ subjectIdentity $>$ \\
\hline 8 & $<$ baseName $>$ \\
\hline 9 & <baseNameString $>$ Giacomo Puccini $</$ baseNameString $>$ \\
\hline 10 & $</$ baseName $>$ \\
\hline 11 & $</$ topic $>$ \\
\hline
\end{tabular}

Fonte: adaptado de GESSA, 2005.

As Associations são as relações entre os Topic, que ocorrem em qualquer direção e sentido. Para dar suporte a essas associações bilaterais utilizam-se os Role. Cada Association relaciona dois Topic mediante dois Role. Esse Role identifica o papel de cada um dos elementos na associação. Por exemplo, uma associação (Association) de <autoria> entre dois itens (Topic) [Alexandre Dumas] e [O Conde de Monte Cristo] há os papéis (Role) de "autor" e o de "obra” (Código 7).

\section{Código 7 - Exemplo de relacionamento (Association) em XTM}

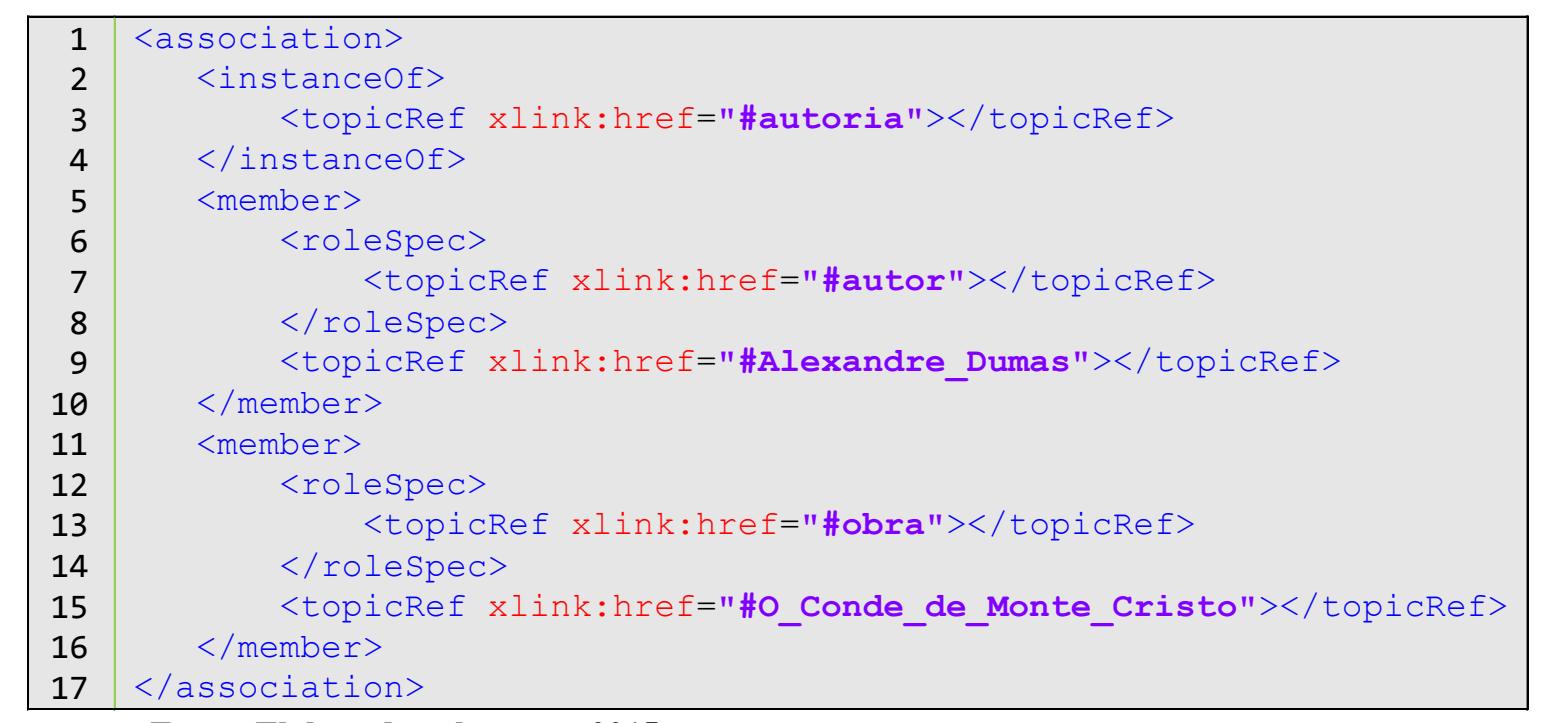

Fonte: Elaborado pelo autor, 2015.

As Ocurrences são os recursos em que podem ser encontradas informações ou descrições dos Topics; elas podem indicar um capítulo de livro, um vídeo numa base de dados, ou uma fotografia física ou digital (Código 8). 
Código 8 - Exemplo de tópico de instância com ocorrência em XTM

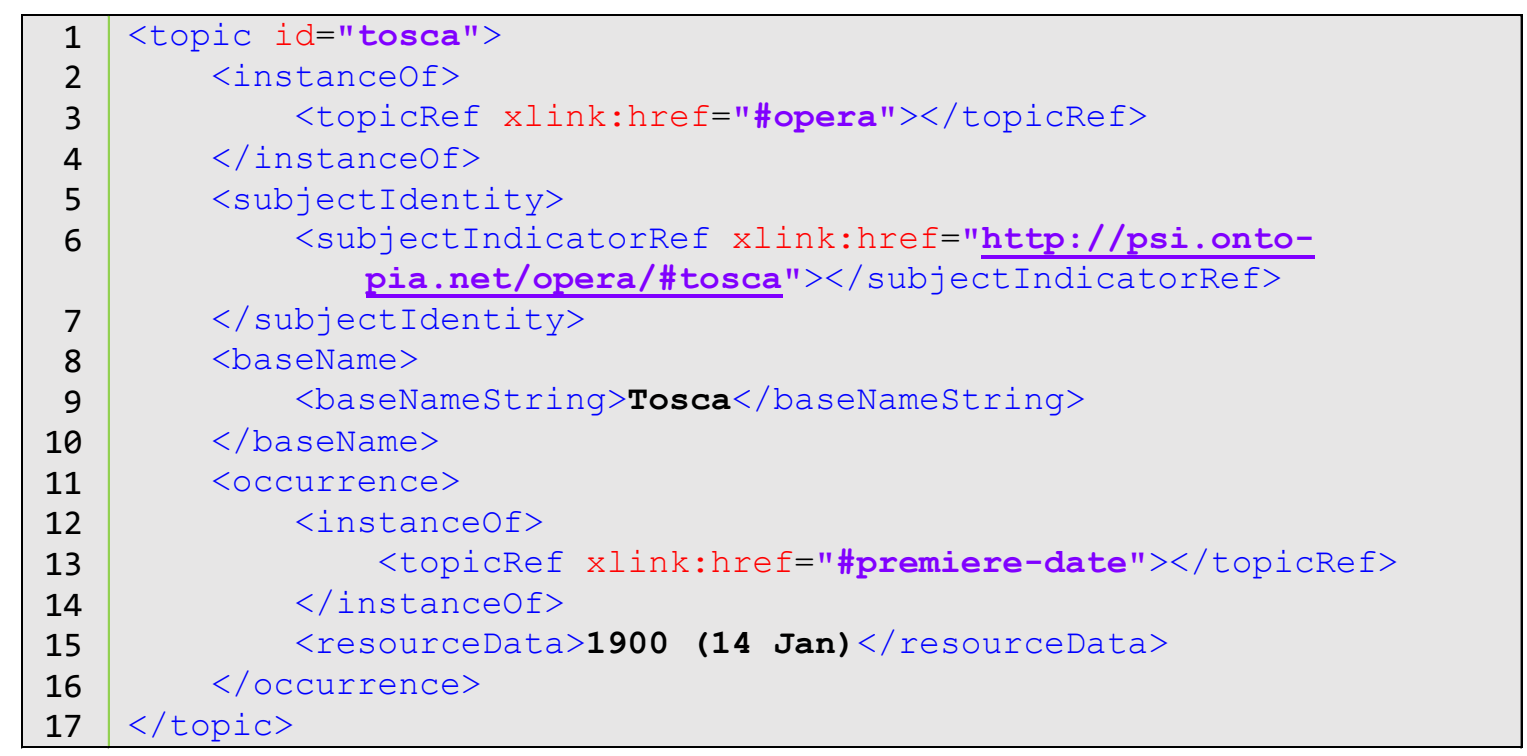

Fonte: adaptado de GESSA, 2005.

Cada Topic tem um código que o identifica dentre os outros e além dele possui um ou mais Names que podem ser utilizados para definir diferentes nomes para um único conceito, entre diferentes áreas do conhecimento ou idiomas. Para tal diferenciação os Names trabalham conjuntamente com outro elemento, o Scope. O Scope define o contexto do mapa, dentro de cada Topic, com um identificador. Esse Scope pode sinalizar uma área do conhecimento ou um idioma, por exemplo, e define sob qual situação a afirmação (nome ou relacionamento) é verdadeira.

No Código 9 é mostrado um exemplo de relacionamento com escopo definido. Nele se afirma que, sob o escopo da obra "La Bohème" a personagem "Rodolfo" tem como tipo de voz "Tenor", enquanto na obra "La Bohème 2" a mesma personagem tem como tipo de voz "Barítono". Ambas as afirmações são verdadeiras dentro de seu contexto e falsas fora dele. 
Código 9 - Exemplo de definição de escopo em XTM

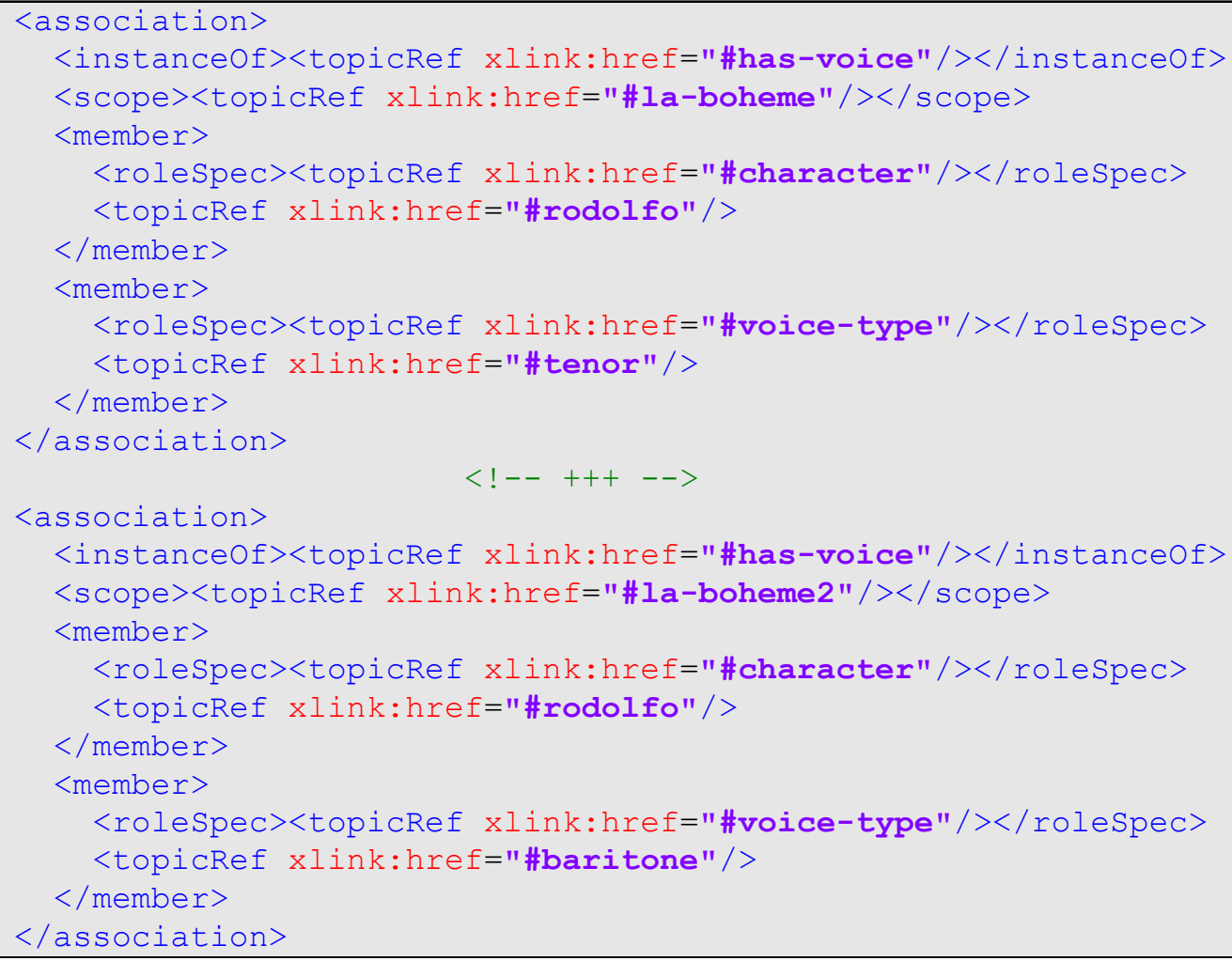

Fonte: adaptado de GESSA, 2005.

Dessa forma, é possível identificar, em um único grande Topic Map, quais Names são os mais adequados para uma área ou idioma e inclusive diferenciar as Associations e Ocurrences do Topic nos diferentes domínios de conhecimentos representados. É este elemento que permite definir diferentes contextos nos quais não apenas os termos utilizados para nomear os conceitos mudam, mas também as relações entre conceitos, o que possibilita a identificação mais precisa de conceitos.

\subsubsection{Semelhanças e diferenças entre RDF e Topic Maps: em busca da Web Pragmática}

Ao comparar o RDF e os TM, surgem naturalmente questionamentos sobre as semelhanças e diferenças entre essas tecnologias. Ambas buscam representar conceitos e suas propriedades e relacionamentos, mas as abordagens são fundamentalmente diferentes.

Enquanto o RDF se baseia na lógica formal e tem na simplicidade triádica sua principal força e flexibilidade, os TM utilizam como inspiração os índices remissivos de livros, assim como os glossários e tesauros, com estrutura consideravelmente mais 
complexa. Dessa forma, é possível afirmar que o RDF foi criado sob a perspectiva da programação para que os computadores entendessem as ontologias, enquanto os TM foram pensados sob o ponto de vista humano (PEPPER, 2002).

Outra diferença entre as duas tecnologias, apontada por Pepper (2002), é a forma com que cada uma delas identifica os recursos informacionais e os conceitos. Enquanto o RDF busca descrever algum recurso informacional, partindo dele para os conceitos, os TM iniciam sua representação a partir dos conceitos, e somente depois definem quais são os recursos que os abordam. Portanto, o RDF trilha um percurso semasiológico, enquanto os TM adotam a perspectiva onomasiológica.

Porém, a principal diferença, em termos práticos, é a existência de qualificadores, principalmente os Scopes presentes nos TM. Como dito anteriormente, esse elemento permite definir, dentro de uma única representação, quais relacionamentos e valores são adequados, ou que afirmações são consideradas verdadeiras, em diferentes situações (Código 7), o que permite que um conceito se relacione com diferentes recursos ou conceitos, de acordo com o contexto escolhido (PEPPER, 2000).

Porém, no RDF, essa característica não foi desenvolvida. Para realizar a indicação de contexto é necessário um retrabalho, um processo chamado de reificação, que envolve a criação de novas estruturas que aumentam a complexidade da representação e de programação. Com isso, compromete-se a simplicidade da sua concepção, além de realizar as indicações e restrições de contexto de forma limitada (GARSHOL, 2003).

A possibilidade de definição formal de contextos torna viável a Web Pragmática. A capacidade de definir, dentro dos recursos informacionais, não apenas o conceito, mas também o contexto de aplicação, permite a seleção e recuperação de informações que se adequem às diferentes necessidades e perfis de usuários.

O tamanho do código necessário também é diferente nas três situações. Em RDF simples, sem contexto, o código necessário para referenciar uma palavra chave para um determinado documento é curto e simples (Código 10). Esse mesmo relacionamento, entre obra, palavra-chave e autor, para ser expresso em RDF, é reificado, sendo necessário, além de maior investimento para criar as novas entidades e estruturas, o controle de entidades reificadas (Código 11). 
Código 10 - Exemplo de definição de palavras-chave em RDF

\begin{tabular}{|c|c|}
\hline 1 & $\begin{aligned} \text { <rdf: Description rdf:about="http://www.csc.ncsu.edu/faculty/mpsi- } \\
\text { ngh/papers/positions/nsf-02.pdf" }>\end{aligned}$ \\
\hline 2 & <dct:title>The Pragmatic Web: Preliminary Thoughts</dct:title> \\
\hline 3 & <dct:language rdf:resource="http://lexvo.org/id/iso639-3/eng"/> \\
\hline 4 & <dct:subject rdf:resource="http://dbpedia.org/page/Pragmatics"/> \\
\hline 5 & $\begin{array}{l}<\text { dct: subject rdf:resource=" } \overline{\text { http://dbpedia.org/page/Char- }} \\
\text { les W. Morris"/> }\end{array}$ \\
\hline 6 & $\begin{array}{l}\text { <dct: subject rdf:resource="http://bnb.data.bl.uk/id/con- } \\
\text { cept/ddc/e21/940.548673092"/> }\end{array}$ \\
\hline & $</$ rdf: Description $>$ \\
\hline
\end{tabular}

Fonte: adaptado de MOTA; KOBASHI, 2014.

Código 11 - Exemplo de reificação em RDF

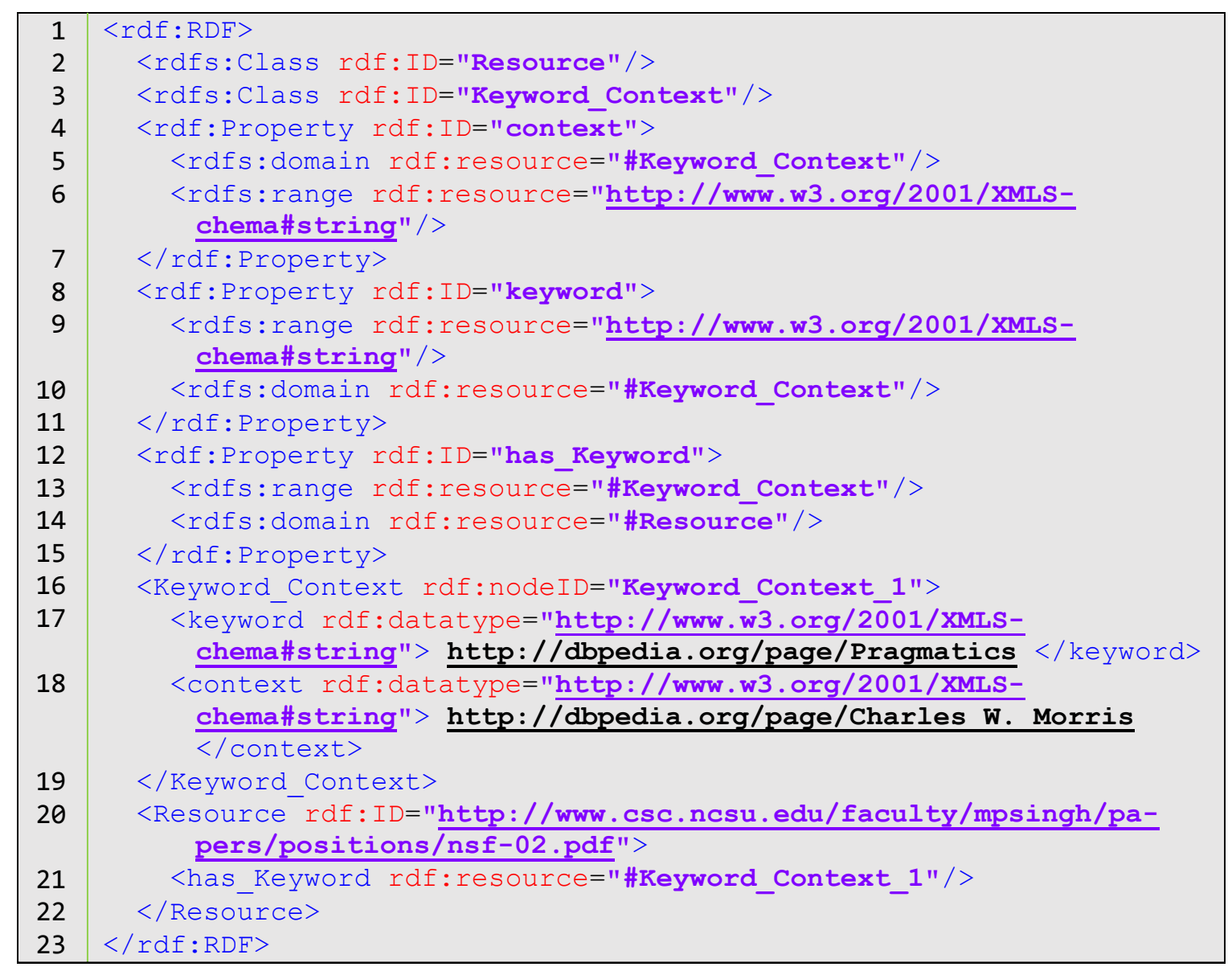

Fonte: adaptado de MOTA; KOBASHI, 2014.

Já em XTM, mesmo sendo criada uma estrutura, e ter quase tantas linhas de código quanto a reificação em RDF, a relação não necessita ser um objeto separado com um identificador único (que requer controle e gerenciamento paralelo, como em RDF), sendo também mais simples a estrutura necessária para identificar a relação entre os diferentes objetos (Código 12). 
Código 12 - Exemplo de associação em XTM

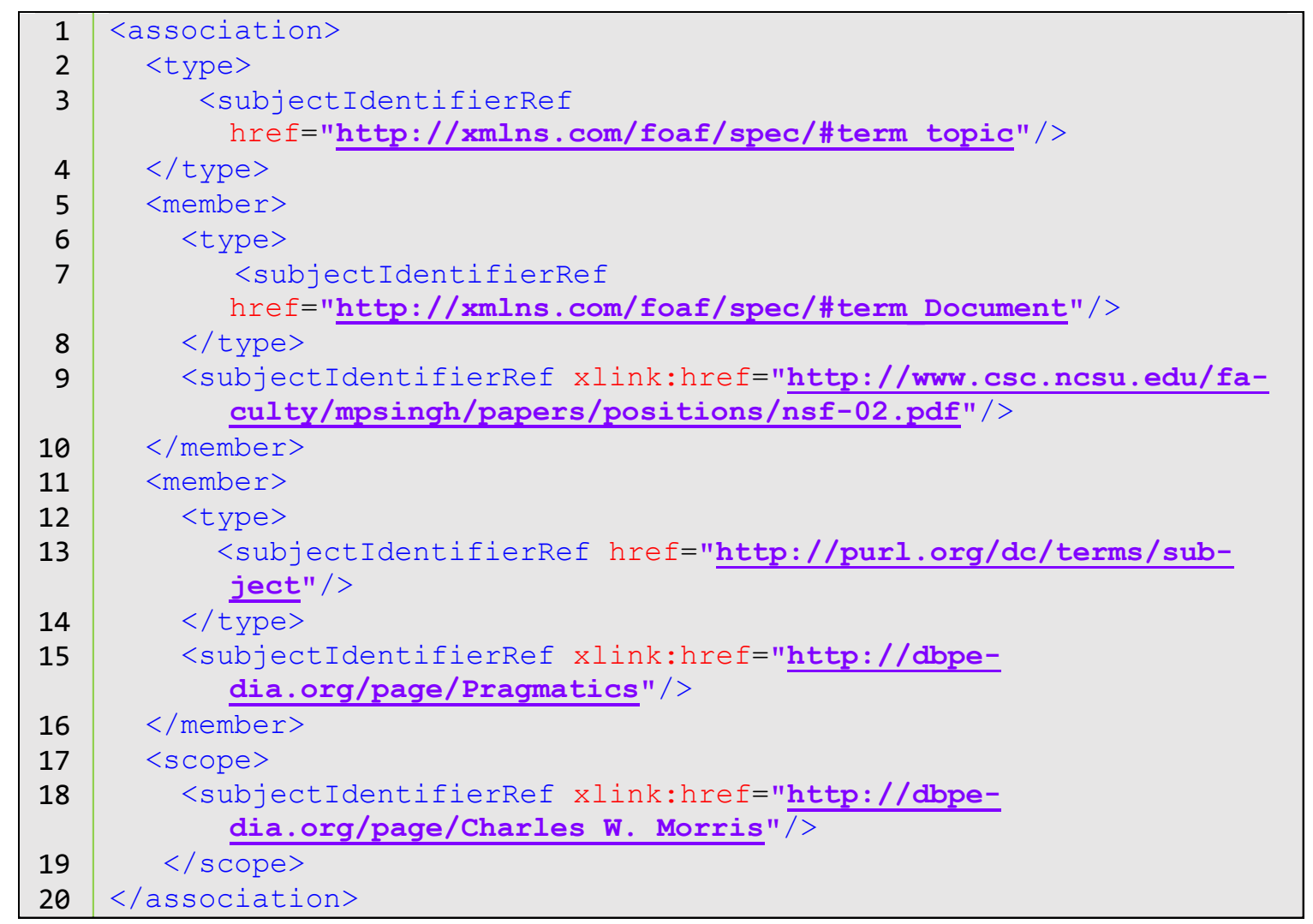

Fonte: adaptado de MOTA; KOBASHI, 2014.

Como pode ser visto, com os Topic Maps é possível representar as relações contextualizadas de forma mais elegante e com gerenciamento mais simples das entidades e relacionamentos. Esta possibilidade mostra-se interessante para modelar as formas de representação de informações com adição de contexto na Web Pragmática. 


\section{PERCURSO METOdOLÓGICO PARA A CONSTRUÇÃo DE UM MODELO DE REPRESENTAÇÃO E RECUPERAÇÃO DA INFORMAÇÃO PARA A WEB PRAGMÁTICA}

Neste capítulo serão descritos os passos realizados para alcançar os objetivos previamente estabelecidos. É importante ressaltar que a presente pesquisa tem cunho interdisciplinar por abordar problemas discutidos tanto na Ciência da Computação como na Ciência da Informação. Esta abordagem interdisciplinar ocorre, em primeiro lugar, porque o objeto de pesquisa, embora tenha origem na Ciência da Computação, requer as teorias e métodos da representação da informação estudados na Ciência da Informação para ser desenvolvido de forma adequada.

\section{1 Procedimentos Metodológicos da Pesquisa}

No percurso da pesquisa, foram inicialmente sistematizados os conceitos gerais que guiam a representação e a recuperação de informações e de conhecimentos. Nessa medida, foram analisados, na bibliografia especializada, os diferentes conceitos e abordagens sobre a representação e recuperação de informações, contrapondo-se ideias, de modo a esclarecer questões aparentemente conflitantes.

Os principais autores utilizados foram: Armengaud (2006), Benveniste (1976), Blair (2003, 2006), Bréal (1900), Cabré (1993, 1999), Case (2007), Cintra (1994), Cortina (2000), Dahlberg(1978), Eco (1984, 1987, 1988, 2000), Frege (2009), Greimas e Courtés (1983), Hjørland (2008, 2009, 2014), Ingwersen (1992), Ingwersen e Järvelin (2005), Julien, Heidi e Michels (2004), Kobashi (1994), Lancaster (2004), Lara (2004), Lopes (1999), Lyons (1975, 1979), Morris (1985), Palmer (1981), Peirce (1977), Saussure (2008), Tamba-Mecz (2006), Van Dijk (1977a, 1977b, 1992) e Wittgenstein $(1968,2009)$. Estes autores e obras fazem parte do referencial teórico da pesquisa.

Em seguida, foram sistematizados os conceitos fundamentais da Web Semântica e Web Pragmática. Nesta etapa foram identificadas e discutidas as teorias, métodos e técnicas que fundamentam e compõem as propostas da Web Semântica e da Web Pragmática. Foram discutidos os dois formatos de representação informacional para a web: RDF e Topic Maps, e comparados os pontos fortes e fracos de cada um deles para os fins da representação de contextos. 
Foram também discutidos os conceitos de Web Pragmática, Pragmática Virtual, Web 2.0 e Web 3.0, verificando-se suas semelhanças e diferenças.

Os principais autores discutidos nesta etapa foram: Arboit, Bufrem e Kobashi (2011), Berners-Lee (2005a, 2005b), Berners-Lee, Hendler e Lassila (2001), Bratt (2008), De Moor (2005), De Moor, Keeler e Richmond (2002), Di Maio (2008), Garshol (2003), González de Gomez e Gracioso (2007), González (2004), Gracioso (2010), Guarino (1998), Hjørland (2002, 2012), Kobashi e Santos (2006), O’ Reilly (2005), Pepper (2000, 2002), Pietarinen (2003a, 2003b), Rovira (2005), Schoop, De Moor e Dietz (2006), Singh (200x, 2002a, 2002b), Sowa (2000a, 2000b), Whitley (1974).

Foram apresentados e definidos, a seguir, os contextos passíveis de representação em acervos informacionais digitais e bases de periódicos científicos. Nesta perspectiva, foram analisados os possíveis contextos que interferem na interpretação de informações, principalmente com base nas contribuições de Eco (1984, 1987, 1988, 2000) Edmonds (1999) e Ingwersen e Järvelin (2005), usando como molde os trabalhos aplicados sobre contexto e interpretação de Allen e Kim (2001), Cortina (2000), Julien e Michels (2004) e Rothe (1987).

Nota-se que já foram sistematizados alguns elementos contextuais passíveis de representação com as atuais tecnologias, como a ontologia de citações CiTO $^{23}$, sendo, porém possível, e necessário, incluir outros contextos. Um contexto que pode posteriormente ser representado é o do pesquisador que realiza buscas, cujo perfil pode ser identificado nos dados informados no currículo Lattes ${ }^{24}$. Com a abertura dos dados dos pesquisadores, ali armazenados, e a possibilidade de exportação via XML, é possível utilizá-los com relativa facilidade. Neste trabalho, porém, não serão utilizados os dados da Plataforma Lattes para compor os perfis.

A etapa final da metodologia consiste em propor e testar uma modelagem que possibilite a adequada representação de contextos em acervos, para posterior uso na recuperação das informações.

\footnotetext{
${ }^{23} \mathrm{http}: / /$ www.essepuntato.it/lode/http://purl.org/spar/cito

${ }^{24}$ http://lattes.cnpq.br/
} 


\section{2 Modelagem Contextual}

Antes de apresentar os princípios e procedimentos da modelagem contextual proposta, será abordado, de forma breve, o conceito de modelo que orienta a presente pesquisa.

De acordo com Bunge (1974), a observação da realidade requer a sistematização do que se considera real. Sistematizar, aqui, tem o sentido de identificar traços comuns em objetos distintos. Os traços comuns permitem agrupar objetos em classes de equivalência que representam esquematicamente, um objeto da realidade. Semelhante sistematização permite construir o que Bunge (1974) denomina de objeto-modelo ou de modelo conceitual dos fenômenos ou objetos que estão sendo observados. Por ser modelo, são negligenciadas, intencionalmente, as características que individualizam os objetos. A criação de objetos-modelo significa, essencialmente, realizar operações de abstração para classificar objetos.

Não basta, porém, criar objetos- modelo. É necessário inseri-los em uma teoria ou modelo teórico, definido, em uma primeira abordagem, como um sistema hipotéticodedutivo que explica a realidade, por aproximação (BUNGE, 1974).

Considera-se, portanto, que a questão principal, na modelagem aqui proposta, é a explicitação de um modelo informacional e/ou conceitual que possa operar em contextos previamente definidos.

A aplicação da modelagem será avaliada por aplicação em um acervo específico, que opera com um objeto-modelo de registro bibliográfico tradicionalmente utilizado em bases de dados bibliográficos. Tendo em vista a quantidade expressiva de páginas disponíveis na Web e, para eliminar possíveis limitações de acesso aos artigos, será utilizada a Base de Dados de Periódicos em Ciência da Informação - BRAPCI ${ }^{25}$. Por ser um repositório que contém metadados de quase todos os artigos publicados em periódicos brasileiros de Ciência da Informação, esta base é ideal para realizar as verificações de viabilidade da modelagem em um ambiente real.

A modelagem de dados, principalmente no escopo dos sistemas de informação, funciona como a representação de um domínio do conhecimento. A modelagem DER (Diagrama Entidade-Relacionamento), composto de entidades, seus atributos e seus

\footnotetext{
${ }^{25}$ http://www.brapci.inf.br/
} 
relacionamentos, segundo o modelo proposto por Chen (1976), permite representar dados do mundo real para armazenamento em bases de dados relacionais.

Outras formas de representação foram avaliadas. Uma destas formas foi a Unified Modelling Language (UML), amplamente utilizada para representar dados no paradigma Orientado a Objetos (OO), que permite representar também herança, polimorfismo, comportamento e diagramas de sequência, entre outros. No entanto, exatamente por não ser necessária aqui a representação destes elementos, não foi utilizada.

Outra forma de representação possível de ser usada é em Resouce Description Framework Schema (RDFs). Este formato permite a representação de classes de objetos e designar restrições de valores: texto, número, data, entre outros. No entanto não elimina as limitações já presentes no RDF comum, e por isso, mesmo com as possibilidades que ela traz, não atende as necessidades de representação deste trabalho.

Por outro lado, há também a possibilidade de representar os contextos e o processo de interpretação mediante Ontologias de Alto Nível, ou de utilizá-las para avaliar a adequação dos modelos ER e/ou OO supracitados. Porém este processo é melhor utilizado para a elaboração de classes gerais, que descrevem características comuns de diversos objetos, mas de uma forma ampla, e que no caso deste trabalho não é necessário pois aborda objetos específicos (artigos, citações, contexto de interpretação), sendo a análise ER suficiente.

Na metodologia para a modelagem e representação de contextos foi utilizado, como ponto de partida, o diagrama entidade-relacionamento proposto para a BRAPCI, apresentado na Figura 12. 
Figura 12 - Diagrama Entidade-Relacionamento da BRAPCI

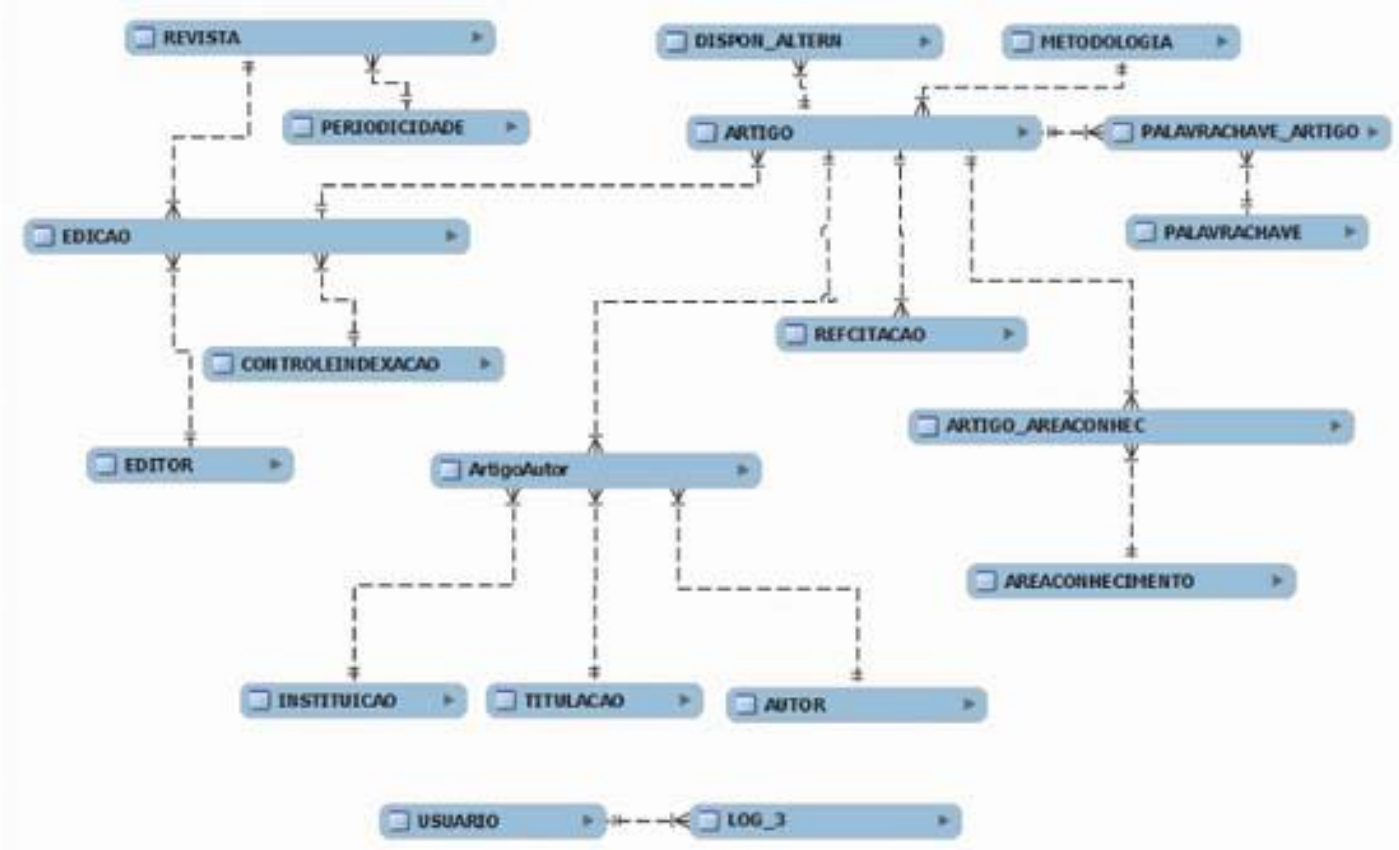

Fonte: BUFREM; COSTA; GABRIEL JUNIOR, 2005.

Como proposto no item 2.4, há diversas formas de avaliar ou perceber contextos. $\mathrm{Na}$ próxima seção são abordados os diversos contextos que podem ser considerados relevantes para a recuperação de informação, passíveis de representação por intermédio de DER e, posteriormente, por meio das tecnologias próprias para aplicação na Web Semântica e na Web Pragmática, tendo em vista diversos indicadores (KOBASHI; SANTOS, 2006) que podem ser utilizados também como contexto.

Partindo da noção de contexto de Ingwersen e Järvelin (2005): um conjunto de fatores que influenciam a relevância, assim como a ideia de "conjunto-contexto" de Armengaud (2006) e de "mundos possíveis" de Eco (2000): os contextos que, dentro do infinito grupo de contextos possíveis, são os mais prováveis de acontecer, selecionou-se alguns elementos contextuais. Os elementos são: Citações, Domínio-base do Documento, Área de Formação do Indivíduo, Domínio da Palavra-Chave, Área de Publicação da Revista, Áreas de Publicação do Indivíduo e Interesses do Indivíduo.

Cada um desses elementos está representado não apenas em DER, mas também em código adequado às propostas da Web Semântica e Web Pragmática. Os códigos apresentados no Capítulo 5 foram elaborados com base na documentação de cada tecnologia (ISO, 2003, 2006, 2013; W3C, 2006, 2014a, 2014b), e tiveram suas 
estruturas validadas usando o software Notepad $++{ }^{26}$ junto com o plugin XML Tools ${ }^{27}$. Eventuais inconsistências sintáticas de código, conhecidas, são devidas ao fato de que elas foram recortadas de um código maior, validado.

\footnotetext{
${ }^{26} \mathrm{http}: / /$ notepad-plus-plus.org/

${ }^{27}$ http://sourceforge.net/projects/npp-plugins/files/XML Tools/
} 


\section{MODELAGEM CONTEXTUAL: representação de contexto para a web pragmática}

Neste item é apresentada a metodologia desenvolvida para a representação de contextos, que compreende: avaliar os possíveis contextos que podem ser representados, destacando-se a relevância de cada um para a interpretação de informações; levantar um modelo que permita a adequada representação desses contextos; por último, apresentar exemplos de representações de contextos em ambientes informacionais digitais, com vistas à Web Pragmática. Na modelagem, serão considerados os contextos intratextual e extratextual

\subsection{Contextos Intratextuais}

Os contextos intratextuais são os dados identificados dentro do próprio texto, sem a necessidade de se ter conhecimentos externos para serem identificados. Esta é a classificação utilizada, por exemplo, por Cortina (2000) e Eco (1987), denominado de co-texto por este último. Alguns elementos de contexto que podem ser identificados de forma interna ao texto, relevantes para o processo de interpretação das mensagens ali expressas são apresentados a seguir.

\subsubsection{Citações}

Segundo a norma ABNT 10520 (2002, p. 1), uma citação é uma "menção de uma informação extraída de outra fonte", podendo ser direta, quando é uma transcrição textual do original, ou indireta, quando se cria um texto baseado na obra consultada. As citações são elementos textuais utilizados para reafirmar, negar ou referenciar informações dentro do texto, e "no universo do discurso científico, as influências teóricas e metodológicas se manifestam, via de regra, por meio de citações" (FRANCELIN, 2010, p. 120).

Com a possibilidade de identificar as diferentes influências exercidas sobre um trabalho, a adequada representação das citações desempenha importante papel na Web Pragmática: o contexto das citações é um elemento pragmático, de difícil identificação mediante análises puramente sintáticas e/ou semânticas. A possibilidade que se 
apresenta é realizar inferências mais complexas no que se refere às citações presentes no texto e, com isso, recuperar informação de forma mais precisa.

\subsubsection{Domínio de Origem do Documento}

O domínio, ou a área de conhecimento, onde ocorreu a criação ou publicação do documento pode ser considerada, simultaneamente, como contexto interno ou externo. Caso seja visto como identificável por meio da biblioteca ou website onde o documento foi encontrado, pode ser considerado como contexto externo. Por outro lado, se for identificada a área de conhecimento a partir da terminologia utilizada no texto, seguindo os moldes do proposto por Cabré (1993), ela será classificada como pertencente a um contexto interno.

Esse aspecto, facilmente reconhecido por sujeitos leitores (pela identificação do periódico ou biblioteca onde o texto foi encontrado), para o ambiente computacional, para que seja reconhecido e utilizado, é necessário introduzir representações explicitas e específicas que identifiquem o domínio da publicação, representando, de certa forma, o tema do documento (KOBASHI, 1994).

\subsubsection{Domínio da Palavra-Chave}

De forma semelhante ao apresentado anteriormente, o domínio de pertencimento das palavras-chave incorporadas aos artigos de periódicos pode ser derivado da terminologia utilizada no texto. Neste caso, pode ser considerado parte do contexto interno; quando atribuído por profissionais da informação para representar o documento em terminologia padronizada, será considerado como contexto externo.

Este contexto, assim como o anterior, também parte dos estudos de Cabré (1993), que afirma que os termos, e neste caso as palavras-chave, são unidades de linguagem utilizadas para designar os conceitos de um domínio de conhecimento específico, como já dito anteriormente na subseção 2.2.1. Desta forma, a escolha e representação das palavras-chave indicam, diretamente, qual o domínio abordado pelo documento.

Independentemente de como seja atribuída a palavra-chave ao texto, o domínio em que é utilizada, traz novas possibilidades de identificação de textos e verificação de 
relevância para as buscas, mediante a análise das relações entre os diferentes termos (LARA, 2004).

Neste caso, são necessárias também outras representações complementares, como a que permite ao usuário definir a área de interesse, por meio do sistema terminológico que deseja que seja considerada durante o processo de busca e recuperação de informações, ou que permitam aos SRI realizarem estas inferências de forma automatizada.

Estas representações complementares não serão abordadas de forma direta neste trabalho, pois são especificidades de cada SRI, usadas durante o processo de recuperação, enquanto este trabalho prioriza o processo de representação da informação. Uma representação contextual que pode ser utilizada para estes fins é abordada na subseção 5.1.2.1.

\subsection{Contextos Extratextuais}

Os contextos extratextuais, ou externos, que têm influência sobre a interpretação, são aqueles que necessitam de conhecimentos exteriores ao texto para serem identificados. Como no caso dos contextos internos, para a delimitação do que é um contexto extratextual, foram utilizados como fundamentos os trabalhos de Cortina (2000) e Eco (1987).

A seguir são apresentados alguns elementos de contexto que podem ser identificados de forma extratextual, que podem ser representadas para auxiliar na recuperação de informações.

\subsection{1 Áreas de Formação do Indivíduo}

Como abordado nos Subcapítulos 2.4 e 3.1.1, a formação do indivíduo e os grupos sociais em que este está inserido são elementos que moldam, como ocorre no domínio de criação do texto, a linguagem utilizada para a redação do texto, e a interpretação posterior desse texto. Este contexto é percebido, na literatura, nos textos de Teun Van Dijk (1977b) e Eco (1987, 2000), quando abordam os frames, e em Lyons (1975, p. 413) quando este define que uma parte dos elementos de interpretação é a própria “comunidade linguística a que o falante e o ouvinte pertencem". 
A adequada representação da área de formação, ou titulação, tanto dos autores quanto dos leitores, auxiliará a asserção da relevância durante o processo de recuperação de informações mediante a avaliação de equivalência ou proximidade das áreas de conhecimento em que autor e leitor têm titulações e, com isso, identificar se as terminologias utilizadas por ambos são iguais, semelhantes ou equivalentes.

\subsection{2 Áreas de Publicação do Indivíduo e da Revista}

De forma semelhante à área de formação, as áreas de publicação podem auxiliar a identificar áreas de convergência linguística, que podem criar situações de ambiguidade durante a leitura dos documentos. A representação das áreas em que o indivíduo publicou também indicará interesses que este tem, mesmo que não sejam representadas de outra forma.

Em relação às Revistas, as áreas de publicação reconhecidas para esta também indicam as áreas de convergência teórica e linguística, apontando indiretamente para as diferentes possibilidades de interpretação possíveis dentro do escopo das áreas percebidas.

Estes dois contextos são próximos dos frames expostos por Teun Van Dijk (1977b) e Eco $(1987,2000)$ no sentido que são representações de um conhecimento em um determinado momento ou situação, ao mesmo tempo que vai ao encontro do abordado por Rothe (1987) quando este afirma que não apenas o contexto de produção, mas também o de consumo da informação precisam ser considerados. As áreas de publicação tanto do indivíduo como da revista podem indicar esses contextos de produção e consumo.

\subsubsection{Interesses do Indivíduo}

As áreas de interesse ou de pesquisa de cada indivíduo definem, ou pelo menos sugerem, quais são os resultados mais relevantes para uma determinada busca, com base nas suas preferências de forma semelhante ao que Ingwersen e Järvelin (2005) e Allen e Kim (2001) definem como necessidade e tarefa, e é fundamental para o processo de interpretação, como definido por Lyons (1979) e Eco (1960). Sua adequada 
representação funciona como uma possibilidade de refinamento dos resultados, com base em inferências realizadas com outras representações.

A representação de interesses parece ser muito mais funcional se utilizada de forma complementar a outras representações ou processos de recuperação, sendo útil mesmo em ambientes informacionais digitais comuns.

Os interesses de cada indivíduo são variados e, por isso, essa representação não pode pré-determinar que os interesses sejam apenas referentes a áreas de conhecimento, palavras-chave ou algum tópico (assunto). Deve ser possível relacionar diversos elementos além destes, como um artigo específico, um autor, um conceito abstrato ou um objeto específico.

\subsection{Representações Contextual em Ambientes Informacionais Digitais}

Antes de representar as informações de forma adequada para o ambiente da Web, em direção a uma proposta de modelagem de contexto para a Web Pragmática, é necessário representá-las para um ambiente informacional digital. Esta representação, intermediária, permitirá visualizar a modelagem contextual em um ambiente informacional atual, de fácil verificação, que possibilita a posterior tradução para outros ambientes, se for necessário.

As entidades já presentes no DER da BRAPCI serão representadas mediante letras na cor preta, assim como os relacionamentos já existentes também serão representados na cor preta. As entidades e relacionamentos que fazem parte da sugestão de modelagem para representação contextual são aqueles cuja cor é vermelha.

\subsubsection{Citações}

As citações podem ser expressas mediante relacionamentos entre artigos. Esta entidade, [Artigo], já está representada no DER da BRAPCI (Figura 12) e não serão necessárias modificações para representá-las. Para adequadamente representar a relação de citação em um DER, uma das possibilidades é criar uma entidade [RefCitação] que receberá os códigos dos dois artigos: o <citante> e o <citado> (Figura 13). 
Figura 13 - Relacionamento de Citação entre Artigos

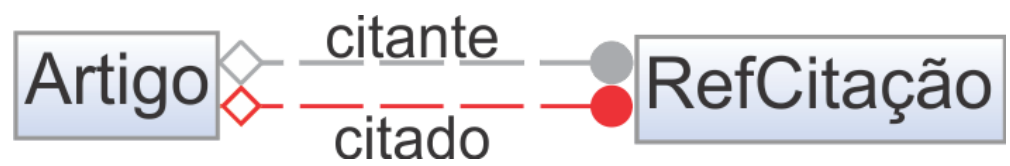

Fonte: Elaborado pelo autor, 2015.

Ou, no caso de obras que não façam parte da base, é possível criar uma outra entidade chamada [Obra], que manterá os registros de obras externas e elaborar as relações com esta entidade (Figura 14). De qualquer forma, a [RefCitação] será uma entidade intermediária que sinaliza a relação entre um objeto <citante> e um <citado>.

Figura 14 - Relacionamento de Citação entre Artigo e Obra

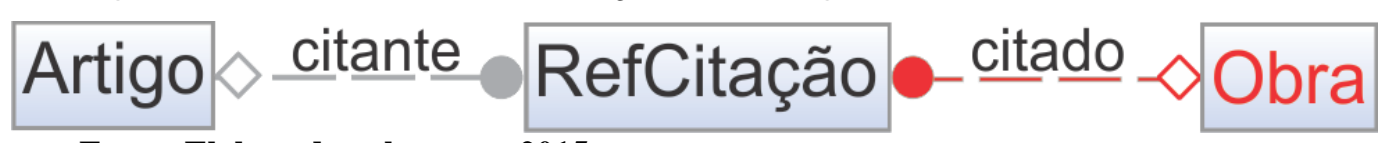

Fonte: Elaborado pelo autor, 2015.

Esta flexibilidade permitirá relacionar o artigo com qualquer obra que exista, esteja ela armazenada no próprio repositório, de forma interna (Figura 13), ou com alguma obra externa que tenha uma representação na base (Figura 14).

Outros elementos podem ser incluídos nesta representação são: tipo de citação (direta ou indireta), trecho extraído (no caso de citação direta), uso da citação (como fonte, concordando, discordando etc), entre outros. Estes elementos são, também, parte do contexto da citação, que direcionam a interpretação dos textos e podem ser representados na [RefCitação] por meio de propriedades, valores que qualificam a relação entre o [Artigo] e a [Obra].

Dentro do escopo da Web Semântica, já existe uma ontologia que disponibiliza uma notação para representar as citações e seus diferentes usos dentro do texto. A Citation Ontology, mais conhecida por seu acrônimo $\mathrm{CiTO}^{28}$, contém em sua definição diversas formas de representar um ato de citação. As distintas formas de citação são representadas por meio de propriedades do ato de citação, na ontologia, e podem assumir as formas ilustradas na Figura 15.

No entanto é importante ressaltar que a variedade de qualificações das citações proporcionadas pela CiTO pode ser confusa para o usuário: não é tão simples, por exemplo, diferenciar o qualificador "documento fonte" do "fonte de dados", ou diferenciar uma citação que "descreve" e a que "documenta". A documentação da CiTO

\footnotetext{
${ }^{28}$ http://www.essepuntato.it/lode/http://purl.org/spar/cito
} 
descreve cada um dos qualificadores, incluindo exemplos de cada, no entanto no dia-adia o seu uso para representação pode incorrer em descrições inadequadas.

Figura 15 - Tipos de Citação da Ontologia CiTO

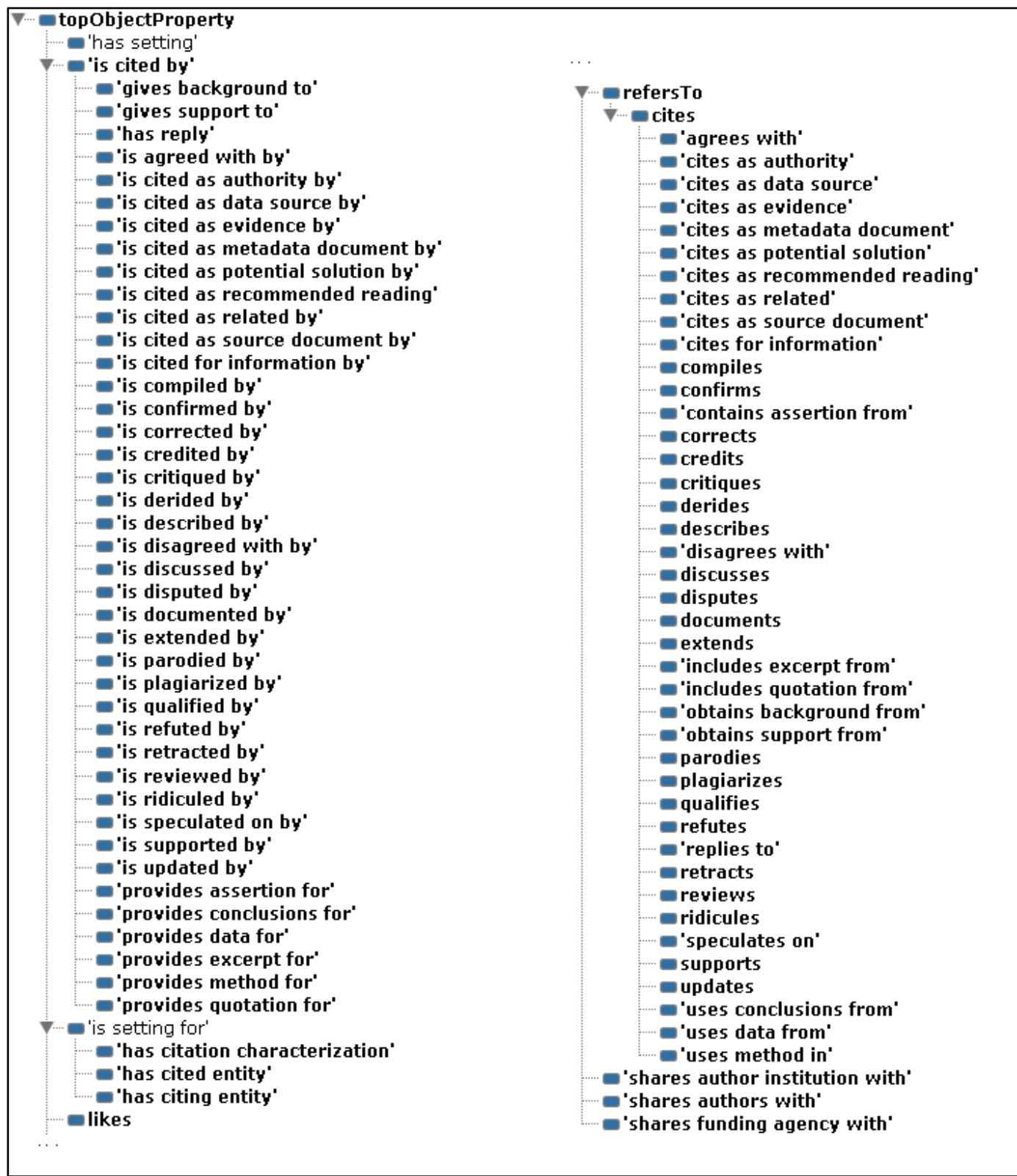

Fonte: adaptado de Shotton e Peroni (2014).

Os elementos da figura acima podem ser reaproveitados para a Web Pragmática, pois foram criados segundo a estrutura tripla proposta para a Web Semântica, e não necessitam da criação de um relacionamento n-ário entre as partes, pois é representada mediante OWL2, que não permite representação de relacionamentos n-ários. No entanto, a forma atual não permite melhor descrição da citação além do já expresso nas propriedades. A possibilidade de representar, também, o trecho citado ou o tipo de 
citação (direta/indireta) não seria permitida caso se utilize esta ontologia, ou as tecnologias atuais da Web Semântica.

\subsubsection{Domínios de Origem do Documento}

Os domínios de origem do documento também podem ser representados com elementos já presentes na BRAPCI. Neste caso, é necessário relacionar o [Artigo] e a [Área de Conhecimento], ambas entidades já presentes na base de dados, como pode ser visto na Figura 12 (pag. 84).

É de fácil percepção que um [Artigo] pode ser publicado em mais de uma [Área de Conhecimento], dependendo do assunto tratado e da abordagem utilizada. Devido a isto, é necessário criar uma nova entidade intermediária, aqui chamada de [Área_Artigo], para descrever as relações entre um [Artigo] e a(s) entidade(s) [Área de Conhecimento], aqui ilustrado na Figura 16.

Figura 16 - Relacionamento entre Área de Conhecimento e Artigo

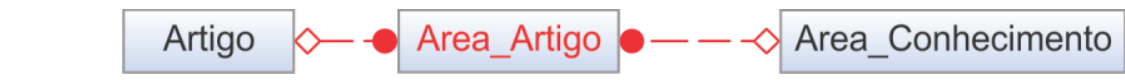

Fonte: Elaborado pelo autor, 2015.

Isto também permite representar um [Artigo] que contém dados e informações de uma [Área de Conhecimento] complementar à do periódico, ou que explore outros assuntos além daquele definido para o periódico.

\subsection{3 Áreas de Formação do Indivíduo}

No DER da BRAPCI (Figura 12, no Subcapítulo 4.1), é possível perceber a relação entre o [Autor] e sua [Titulação], que fica identificada na relação entre o [Autor] e a publicação, a entidade [Artigo]. Desta forma, é possível identificar, para cada entidade [Artigo], os autores e suas titulações. No entanto, mesmo existindo uma representação para a área de conhecimento, não há relação entre esta e a titulação do autor.

A sugestão aqui apresentada visa vincular as entidades [Área de Conhecimento] à [Titulação], o que permite aos SRI a identificação e recuperação de artigos cujo(s) autor(es) possuam titulação em algum(ns) domínio(s) de conhecimento(s) específico(s), 
e com isto melhorar a relevância dos resultados apresentados para o usuário. Esta representação necessita de uma entidade intermediária, chamada [Área_Título], em DER, apresentada na Figura 17.

Figura 17 - Área de Conhecimento e Titulação para o Autor

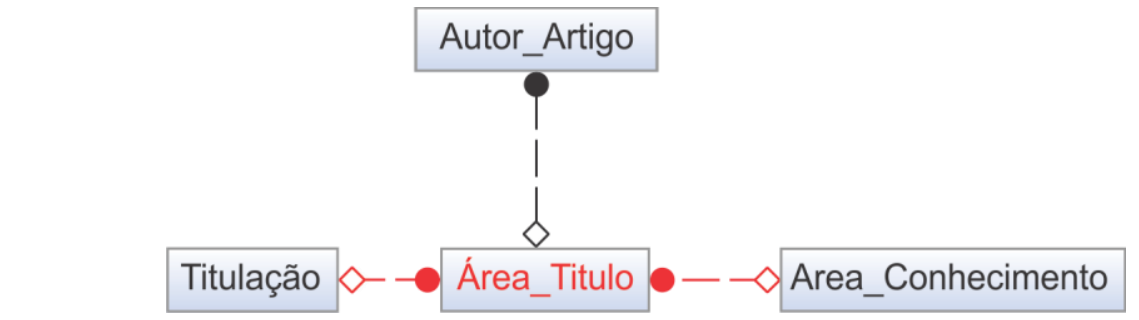

Fonte: Elaborado pelo autor, 2015.

Uma representação semelhante, apresentada na Figura 18, pode ser feita para os usuários que já existem na base na entidade [Usuário]. Esse recurso permite realizar inferências sobre a terminologia que o usuário domina ou conhece e, com isto, relacioná-lo às representações dos autores de forma automática e transparente, facilitando o uso dos SRI.

Figura 18 - Área de Conhecimento e Titulação para o Usuário

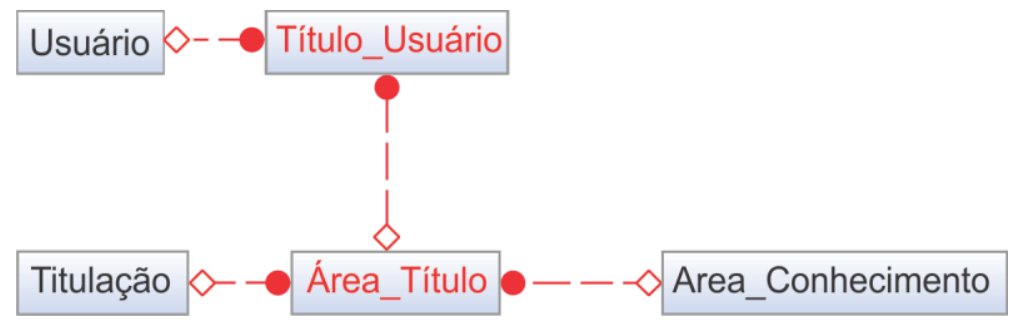

Fonte: Elaborado pelo autor, 2015.

\subsubsection{Domínio da Palavra-Chave}

A BRAPCI já considera que a palavra-chave não é um atributo puro e simples dos artigos e a trata como uma entidade separada, representada no DER como [PalavraChave]. No entanto não considera a relação destas com os diferentes domínios de conhecimento e seus vocabulários; a explicitação dessa relação possibilitaria eliminar (ou no mínimo diminuir) as ambiguidades, mesmo considerando que a palavra-chave seria uma entidade e não apenas a palavra em sua forma escrita. 
A sugestão é indicar a área de vinculação da palavra-chave, mediante a relação denominada de [Área_Palavra], que relaciona as entidades (já existentes) [PalavraChave] e [Área_Conhecimento]. É esta entidade [Área_Palavra], que faz a mediação entre as entidades [PalavraChave] e [Area_Conhecimento], que irá se relacionar com a entidade [Artigo] mediante a entidade-relação [PalavraChave_Artigo], como ilustra a Figura 19, em lugar da entidade [PalavraChave] no DER original (Figura 12).

Esta nova entidade permite a elaboração de vocabulários de diferentes áreas do conhecimento de forma a diferenciar, por exemplo, o termo "Vírus" da Medicina e Biologia do termo "Vírus" da Ciência da Computação.

Figura 19 - Tipos de Citação da Ontologia CiTO

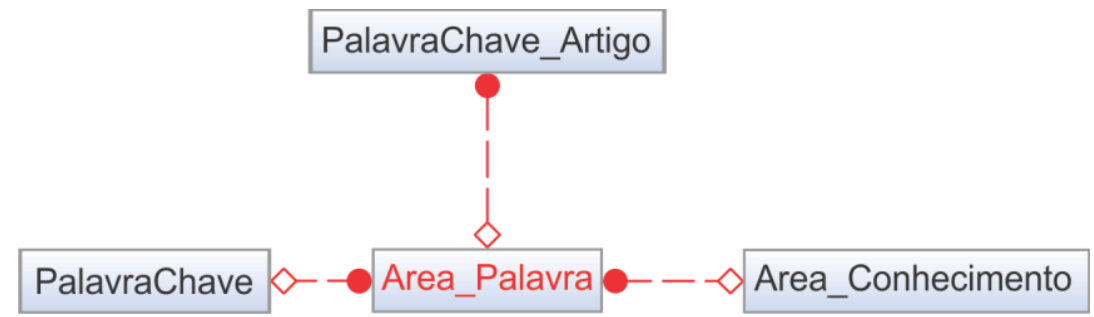

Fonte: Elaborado pelo autor, 2015.

Caso ocorra a inclusão de definições ou códigos sequenciais na entidade [Area_Palavra] é possível, também, incluir palavras que, dentro da mesma área de conhecimento, tenham significados distintos, porém especificar qual destes é utilizado dentro do artigo. Isto proporciona flexibilidade na descrição e eliminação (ou diminuição) de ambiguidade e/ou polissemia.

\subsection{5 Áreas de Publicação do Indivíduo}

De forma complementar à representação das áreas de formação do indivíduo, é possível visualizar a representação de áreas de publicação em que este atua com maior frequência. Esta representação envolve as entidades [Autor] e [Usuário], de um lado, e [Area_Conhecimento], de outro. É possível identificar as áreas de publicação do autor com as entidades já existentes no DER original, buscando nas relações detalhadas com as entidades expostas na Figura 20 (abaixo), mas isto apenas pode ser realizado com os artigos e autores presentes na base, e exige um comando de seleção complexo. 
Figura 20 - Áreas de Publicação do Autor na Base Atual

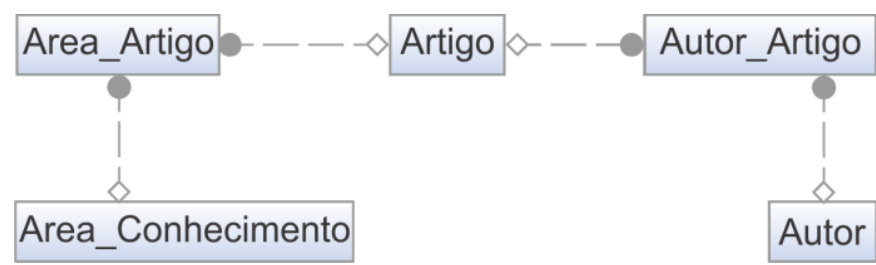

Fonte: Elaborado pelo autor, 2015.

Para obter dados complementares em relação às áreas de publicação, é necessário criar uma outra entidade, intermediária, que faça a ponte entre o [Autor], ou [Usuário] e a [Área de Conhecimento] em que este publica, aqui ilustrada na Figura 21.

Figura 21 - Áreas de Publicação do Autor Sugerida

Area_Conhecimento $\diamond-$ Area_Publicação_Autor $\bullet-\diamond$ Autor

Fonte: Elaborado pelo autor, 2015.

Este relacionamento pode ser realizado de forma semelhante para o [Usuário], com as devidas adequações, o que potencializa as possibilidades destas representações e permite a verificação de inferências entre autor e usuário, e em ambas direções.

\subsection{6 Área de Publicação da Revista}

A área de publicação da [Revista], como registrado no portal Qualis ${ }^{29}$ da Capes, também pode ser representado no DER da Brapci, porém expandindo para outras revistas não cadastradas no Qualis, ou áreas que não são ali consideradas, mas que foram identificadas por parte dos profissionais da informação, apenas com a adição de uma nova entidade.

Essa possibilidade de representação, ilustrada na Figura 22, mostra a nova entidade, chamada [Area_Revista], que une a [Revista] com [Area_Conhecimento], que possibilita a vinculação de uma Revista a diversas Áreas do Conhecimento, não restringindo as possibilidades de representação, e atendendo, especialmente, as Revistas de cunho interdisciplinar.

${ }^{29}$ http://qualis.capes.gov.br 
Figura 22 - Área de Publicação da Revista

$$
\text { Revista } \diamond-\checkmark \text { Revista_Area }-\checkmark \text { Area_Conhecimento }
$$

Fonte: Elaborado pelo autor, 2015.

\subsubsection{Interesses do Indivíduo}

Os interesses de cada indivíduo podem ser representados utilizando-se três entidades já existentes no DER da BRAPCI: [Usuário], [PalavraChave] e [Area_Conhecimento]. Porém para criar essa relação de forma adequada é necessário ter a entidade [Area_Palavra], sugerida no item 5.3.4, e a entidade [Interesse_Palavra], que une [Area_Palavra] ao [Usuário], como ilustrado na Figura 23.

Figura 23 - Áreas de Publicação do Autor Sugerida

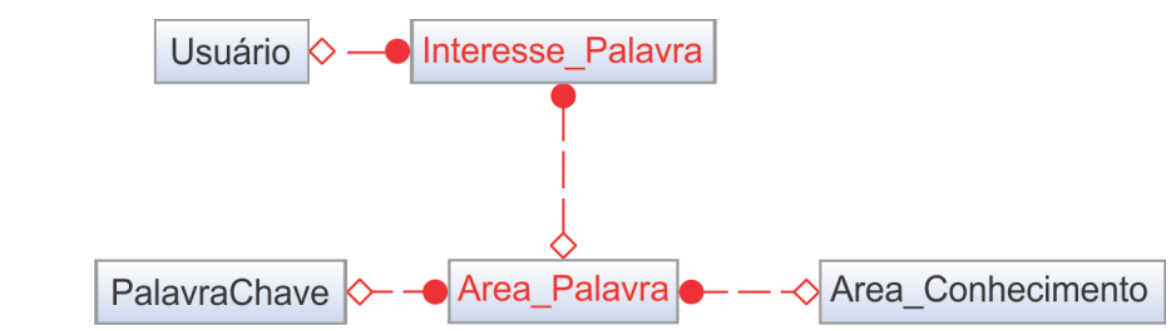

Fonte: Elaborado pelo autor, 2015.

A sugestão de criar a relação com [Area_Palavra] permite que o usuário indique as temáticas que mais o interessem, de forma controlada, relacionando o assunto e a área de conhecimento, como sugerido no item 5.3.4, que também possibilita realizar inferências e generalizações a partir dessas entidades.

\subsection{Representações Contextuais na Web Pragmática}

Nos ambientes informacionais digitais, principalmente no escopo da Web Semântica e/ou Web Pragmática, a representação das informações deve ser adequadamente traduzida para os padrões de disponibilização de dados definidos para esses ambientes. Nas representações de informações, como no caso dos contextos previamente abordados, tal representação pode ocorrer de diferentes formas, já explicadas no Subcapítulo 3.3.4: RDF simples, RDF reificado e XTM. 


\subsubsection{Citações}

A representação de citações com RDF pode ser feita utilizando-se a ontologia CiTO para qualificar o tipo de citação utilizado. Como mostrado no Código13 (abaixo), a ontologia permite fazer a asserção de quem é citado pelo documento e de que forma isso foi realizado. A limitação desta ontologia é no que tange à qualificação das palavras-chave. Mesmo sendo possível determinar quem foi citado, e de que forma, não é possível identificar a citação com palavras-chave, podendo ocorrer conflitos entre autores semelhantes que definem conceitos de formas distintas.

\section{Código 13 - Exemplo de citação em RDF}

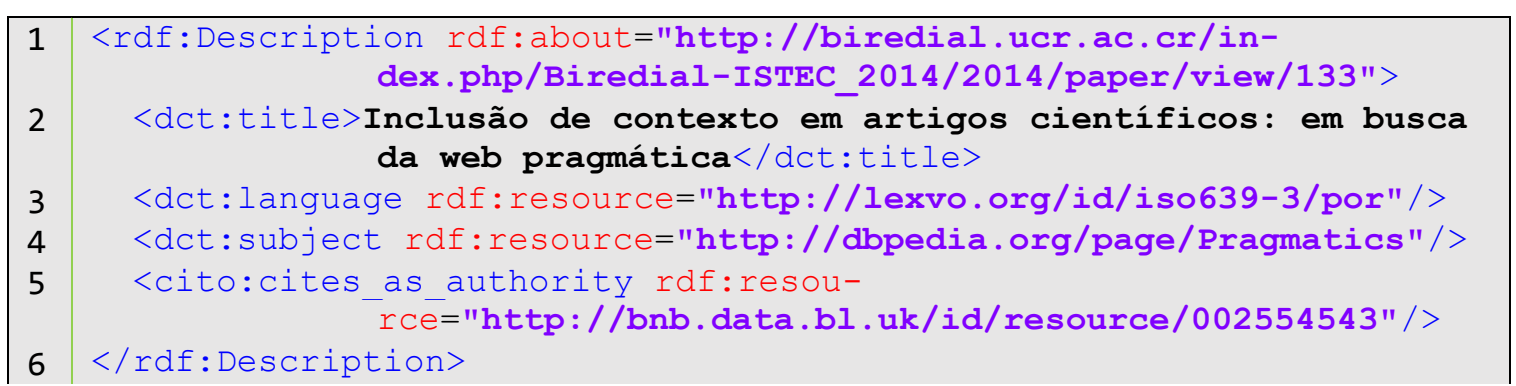

Fonte: Elaborado pelo autor, 2015.

A outra possibilidade é utilizar a reificação, a forma mais próxima dos padrões e tecnologias definidas e utilizadas para a Web Semântica. Nesta situação, cria-se uma classe intermediária, com RDFS, chamada neste exemplo de [Keyword_Context], cujos objetos realizam a relação entre a palavra-chave e o contexto de citação. O problema, neste modo, é que para cada palavra-chave ou autor utilizado é necessário criar um novo objeto da classe [Keyword_Context].

No exemplo ilustrado no Código 14, há apenas uma palavra-chave e autor, denominado "Keyword_Context_1", mas caso exista um número maior de palavraschave ou de autores para cada uma delas, novos objetos, com diferentes nomes (Keyword_Context_2, Keyword_Context_3, Keyword_Context_4, etc.), precisariam ser criados. 
Código 14 - Exemplo de citação com reificação em RDF

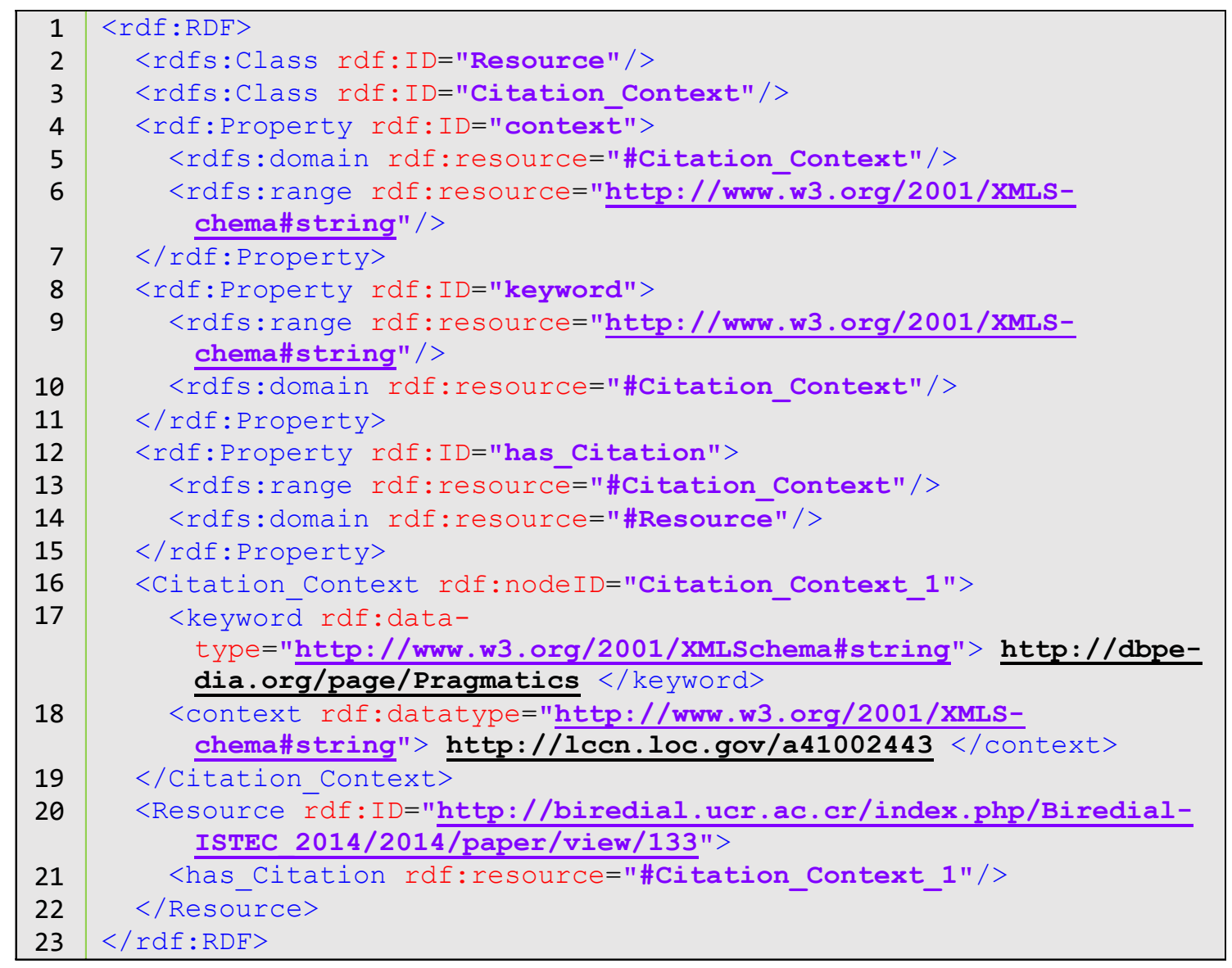

Fonte: Elaborado pelo autor, 2015.

Cada um desses objetos se relaciona com o documento, criando-se uma lista de relacionamentos entre o documento e diversos objetos [Keyword_Context]. Um exemplo de registros RDF reificados pode ser visto no Código 15, que contém uma lista de palavras-chave adequadamente contextualizadas para a descrição do documento. 
Código 15 - Exemplo de várias citações com reificação em RDF

\begin{tabular}{|c|c|}
\hline 1 & rdf:nodeID="Citation Context 1"> \\
\hline 2 & $\begin{array}{c}\text { <keyword rdf:datatype="http://www.w3.org/2001/XMLSchema\#string" } \\
\text { http://dbpedia.org/page/Pragmatics }</ \text { keyword }>\end{array}$ \\
\hline 3 & $\begin{array}{l}\text { <context rdf:datatype="http://www.w3.org/2001/xMLSchema\#string" } \\
\text { http://lccn.1oc.gov/a41002443</context> }\end{array}$ \\
\hline 4 & $</$ Citation Context $>$ \\
\hline 5 & <Citation_Context rdf:nodeID="Citation_Context_2"> \\
\hline 6 & 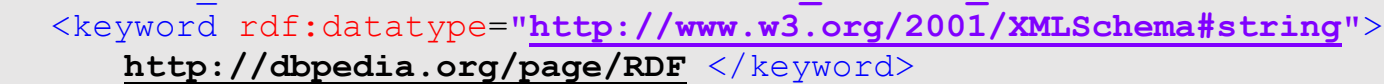 \\
\hline 7 & $\begin{array}{l}\text { <context rdf:datatype="http://www.w3.org/2001/XMLSchema\#string" }> \\
\text { http://w3.org/2001/sw/wiki/Special:URIResolver/RDF }</ \text { context }>\end{array}$ \\
\hline 8 & $</$ Citation Context $>$ \\
\hline 9 & <Citation_Context rdf:nodeID="Citation_Context_3"> \\
\hline 10 & $\begin{array}{c}\text { <keyword rdf:datatype="http://www.w3.org/2001/XMLSchema\#string" }> \\
\text { http://dbpedia.org/page/Knowledge Representation }</ \text { keyword }>\end{array}$ \\
\hline 11 & $\begin{array}{c}\text { <context rdf:datatype="http://www.w3.org/2001/XMLSchema\#string" } \\
\text { http://bnb.data.bl.uk/doc/resource/009418545 </context> }\end{array}$ \\
\hline 12 & $</$ Citation_Context $>$ \\
\hline 13 & $\begin{array}{c}\text { <Resource rdf:ID="http://biredial.ucr.ac.cr/index.php/Biredial-IS- } \\
\text { TEC 2014/2014/paper/view/133"> }\end{array}$ \\
\hline 14 & <has_Citation rdf:resource="\#Citation_Context_1"/> \\
\hline 15 & <has_Citation rdf:resource="\#Citation_Context_2" / > \\
\hline 16 & <has_Citation rdf:resource="\#Citation_Context_3" / > \\
\hline 17 & $</$ Resoürce $>$ \\
\hline
\end{tabular}

Fonte: Elaborado pelo autor, 2015.

Em Topic Maps, as associações entre os documentos e as palavras-chave seriam descritas de forma semelhante ao apresentado no Código 16. À medida que novas palavras-chave forem incluídas, novas relações serão expressas desta forma.

\section{Código 16 - Exemplo de citação em XTM}

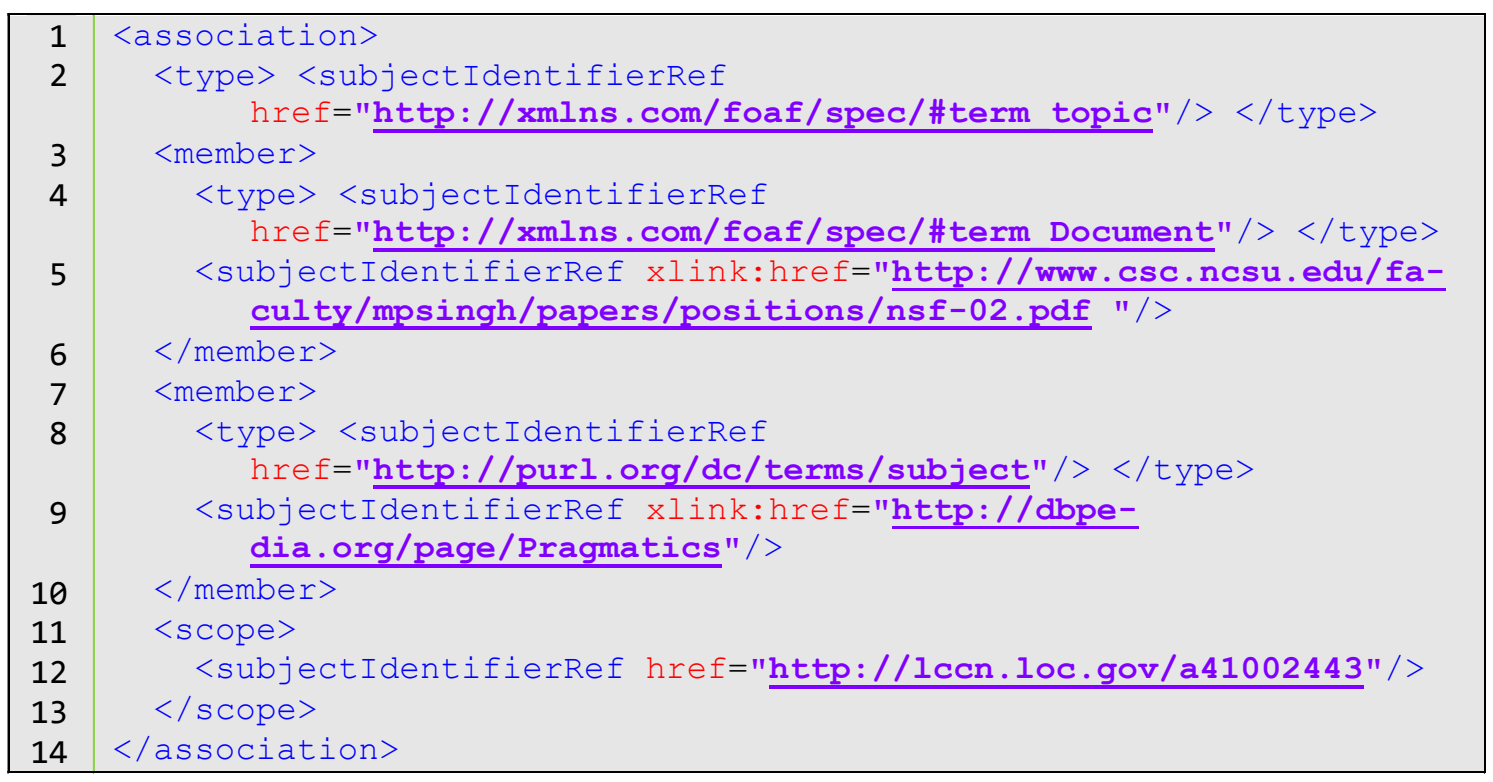

Fonte: Elaborado pelo autor, 2015. 
Esta forma de representação pode ser escolhida para evitar a criação e manutenção de diversos objetos de relacionamento entre palavra-chave e contexto, o que evita que, acidentalmente, se referencie no documento algum objeto [KeywordContext] inexistente ou existam objetos que não sejam referenciados por nenhum documento no repositório.

\subsubsection{Domínio-base do Documento}

Tomando como fundamentação a representação em DER, mas considerando que não há restrição como a existente nas bases de dados, a representação do domínio do documento, ou a área de conhecimento, pode ser realizada de forma direta, como um relacionamento "um para muitos" ou 1-N, simplificando a representação em RDF.

Como pode ser visto no Código 17, a chamada para a área de conhecimento se faz usando a propriedade knowledgeArea de uma ontologia, em construção, chamada aqui pelo prefixo bci. Neste exemplo, o artigo "Inclusão de Contexto em Artigos Científicos: em busca da web pragmática" está inserido em três áreas de estudo: Ciência da Informação, Ciência da Computação e Linguística.

\section{Código 17 - Domínio do Artigo em RDF}

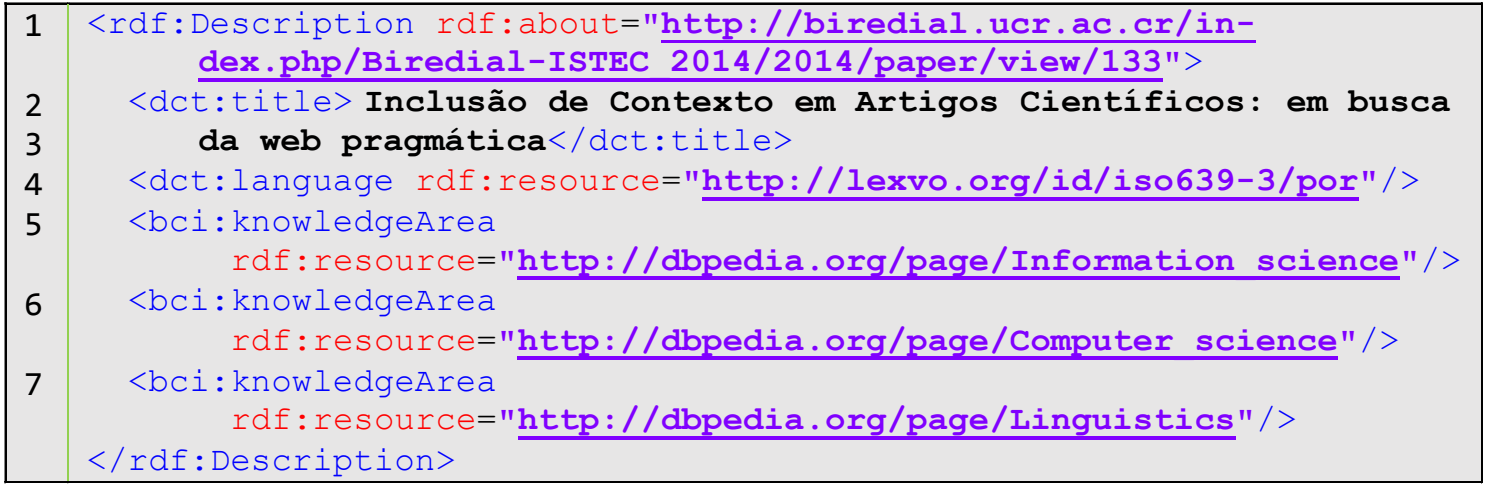

Fonte: Elaborado pelo Autor, 2015.

Em TopicMaps a relação precisa ser criada para cada área de conhecimento; dessa forma, seguindo o exemplo exposto no Código 17, seriam necessárias três representações semelhantes à exposta no Código 18, que retrata a relação entre o domínio Ciência da Informação e o mesmo artigo do exemplo anterior.

O código necessário para XTM, neste caso, seria de 39 linhas, o triplo do exposto no Código 18, enquanto em RDF foram necessárias apenas sete. No entanto, as 
representações têm a mesma validade para os SRI. Nesta situação, que não necessita de qualificadores intermediários, a simplificada do RDF mostra-se mais adequada.

\section{Código 18 - Domínio do Artigo em XTM}

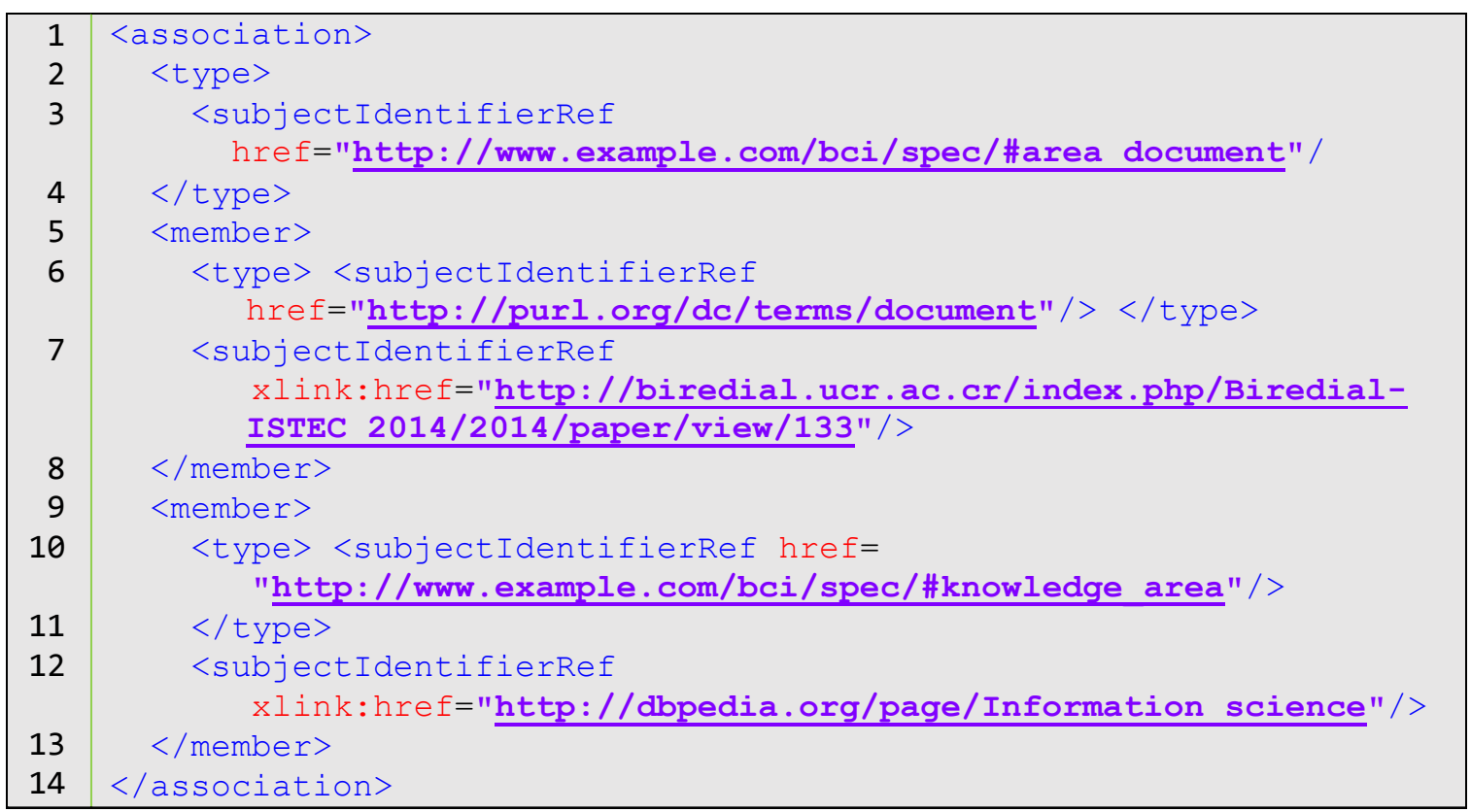

Fonte: Elaborado pelo autor, 2014.

\subsection{3 Área de Formação do Indivíduo}

Da mesma forma que a área de conhecimento do artigo, a área de formação do indivíduo também utiliza a mesma propriedade exposta nos Códigos 18 e 19: knowledgeArea. Porém, neste caso, há um qualificador para a área: a titulação, e por isso, este não é um relacionamento "um para muitos" ou 1-N, mas um "muito para muitos" ou N-N, como o caso da citação. No Código 19 é possível ver como seria no caso de relações diretas, sem qualificador da titulação, onde o indivíduo se relaciona com duas áreas de formação.

\section{Código 19 - Área de Formação em RDF}

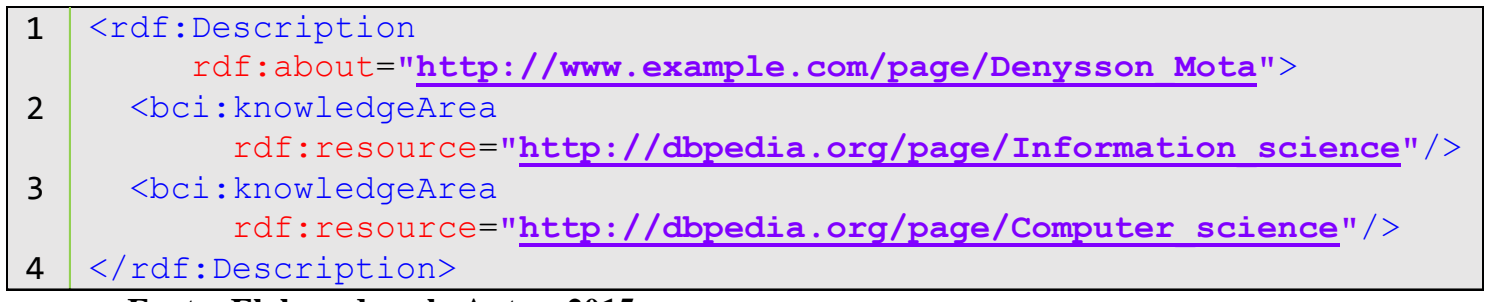

Fonte: Elaborado pelo Autor, 2015. 
Para uma relação qualificada em RDF é necessário reificar a referência, assim como foi feito para as citações. No entanto, é necessário decidir o que é considerado contexto no caso de uma titulação: o título ou a área. Para este trabalho, e os exemplos aqui mostrados, a contextualização se dá pela relação entre o autor e sua titulação; a agregação da área de conhecimento tem a função de qualificar tal relação. Outras opções podem ser avaliadas para avaliar a forma mais adequada de representação. $\mathrm{O}$ exemplo de representação reificada em RDF é aqui ilustrada no Código 20.

\section{Código 20 - Área de Formação com reificação em RDF}

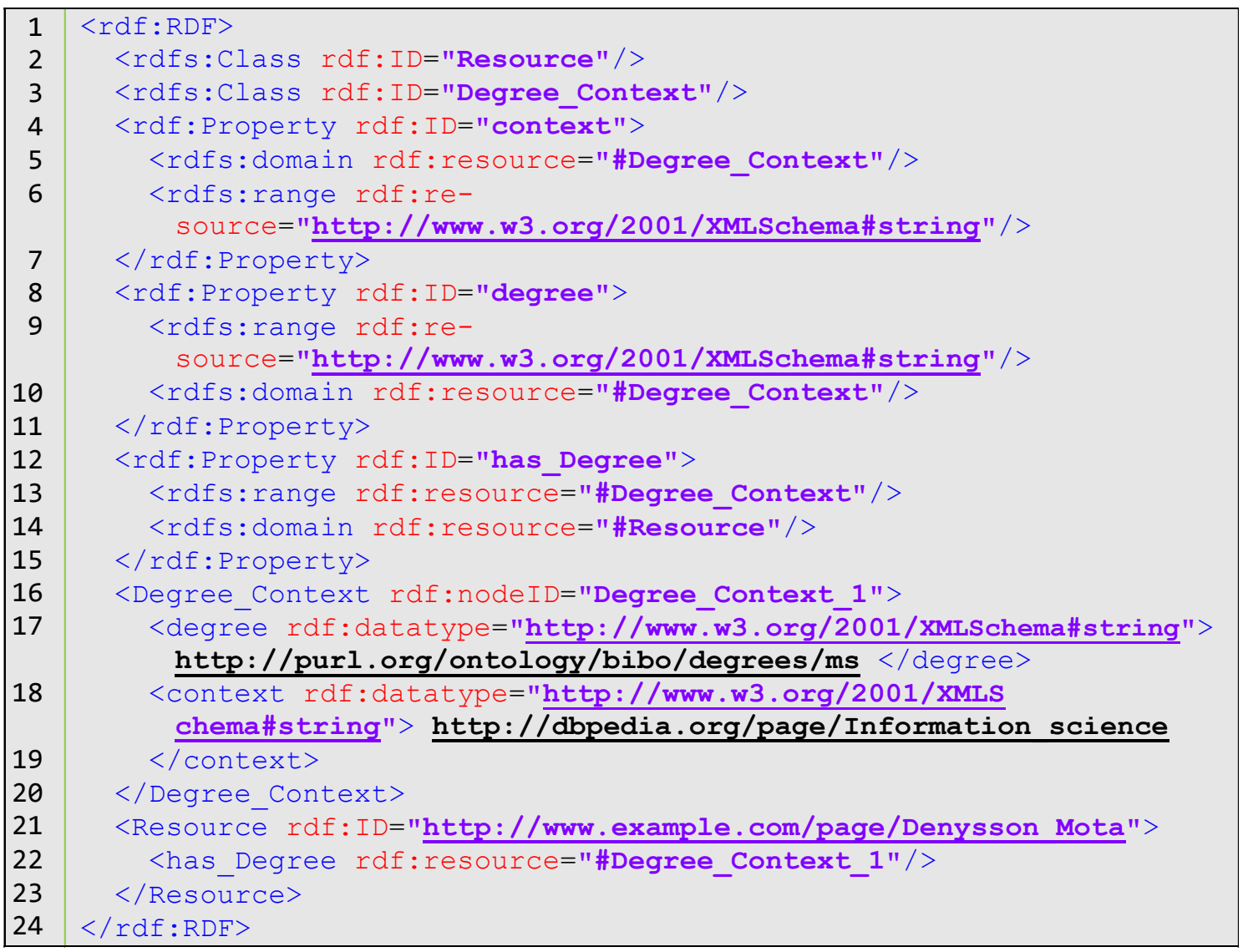

Fonte: Elaborado pelo autor, 2015.

Em TopicMaps, assim como ano caso anterior, a relação precisa ser criada para cada área de conhecimento. Mas, com a possibilidade de delimitação de escopo, se simplifica a forma de destacar a titulação. A diferença da quantidade de código necessário para XTM, neste caso, é semelhante ao caso das citações, sendo menor que a reificação, mas maior que a ligação direta em RDF simples. O Código 21 ilustra como é possível representar a área de formação do indivíduo, com qualificador, em XTM. 
Código 21 - Área de Formação em XTM

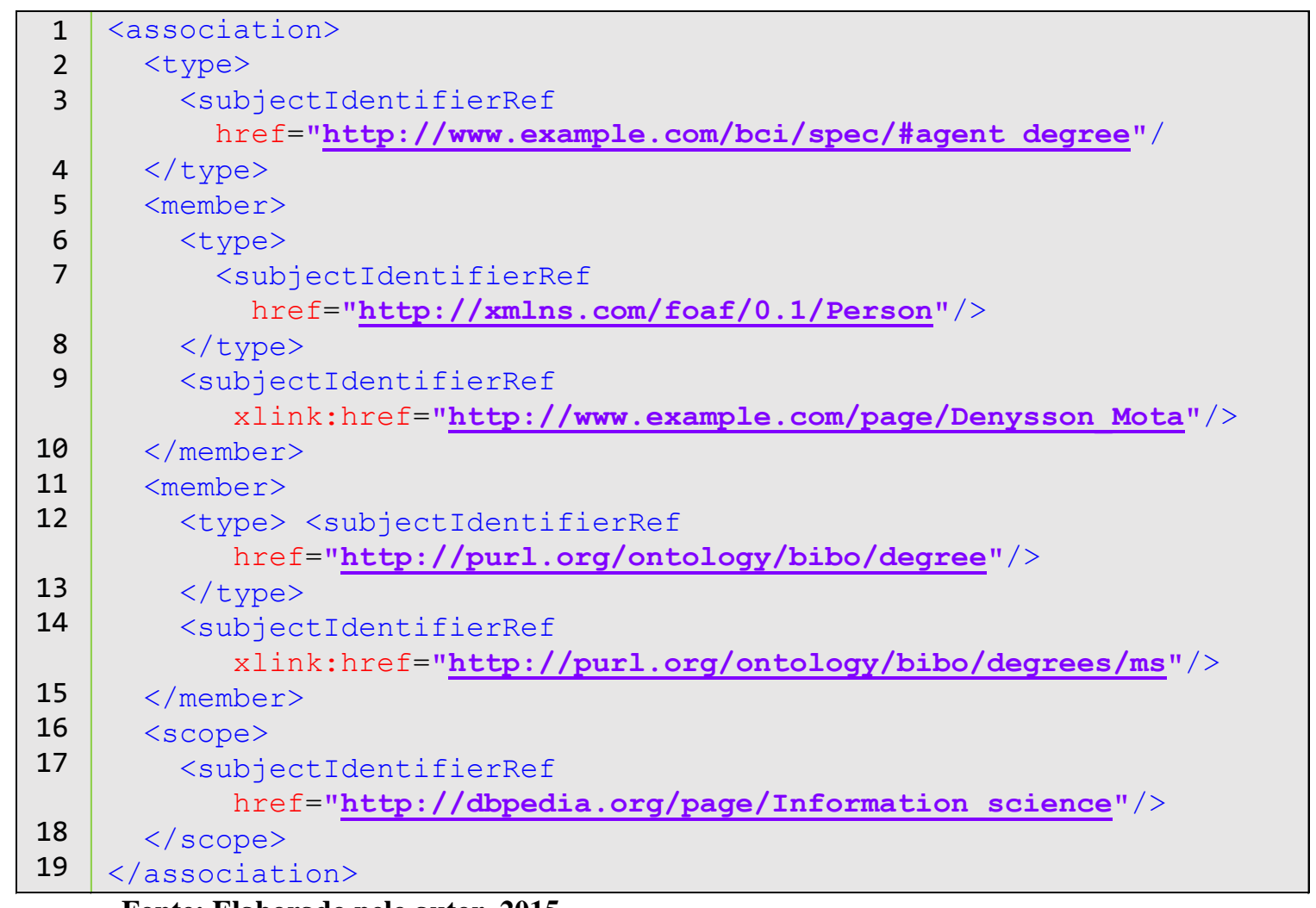

Fonte: Elaborado pelo autor, 2015.

\subsubsection{Domínio da Palavra-Chave}

De forma semelhante à citação, não é possível definir em que contexto é citada a palavra-chave, ou de qual domínio ela vem, de forma binária. Para expressar esta relação, é necessário criar um código que permita a representação de relação n-ária: RDF reificado e XTM. O exemplo de código em RDF está aqui ilustrado no Código 22. 
Código 22 - Domínio Terminológico em RDF Reificado

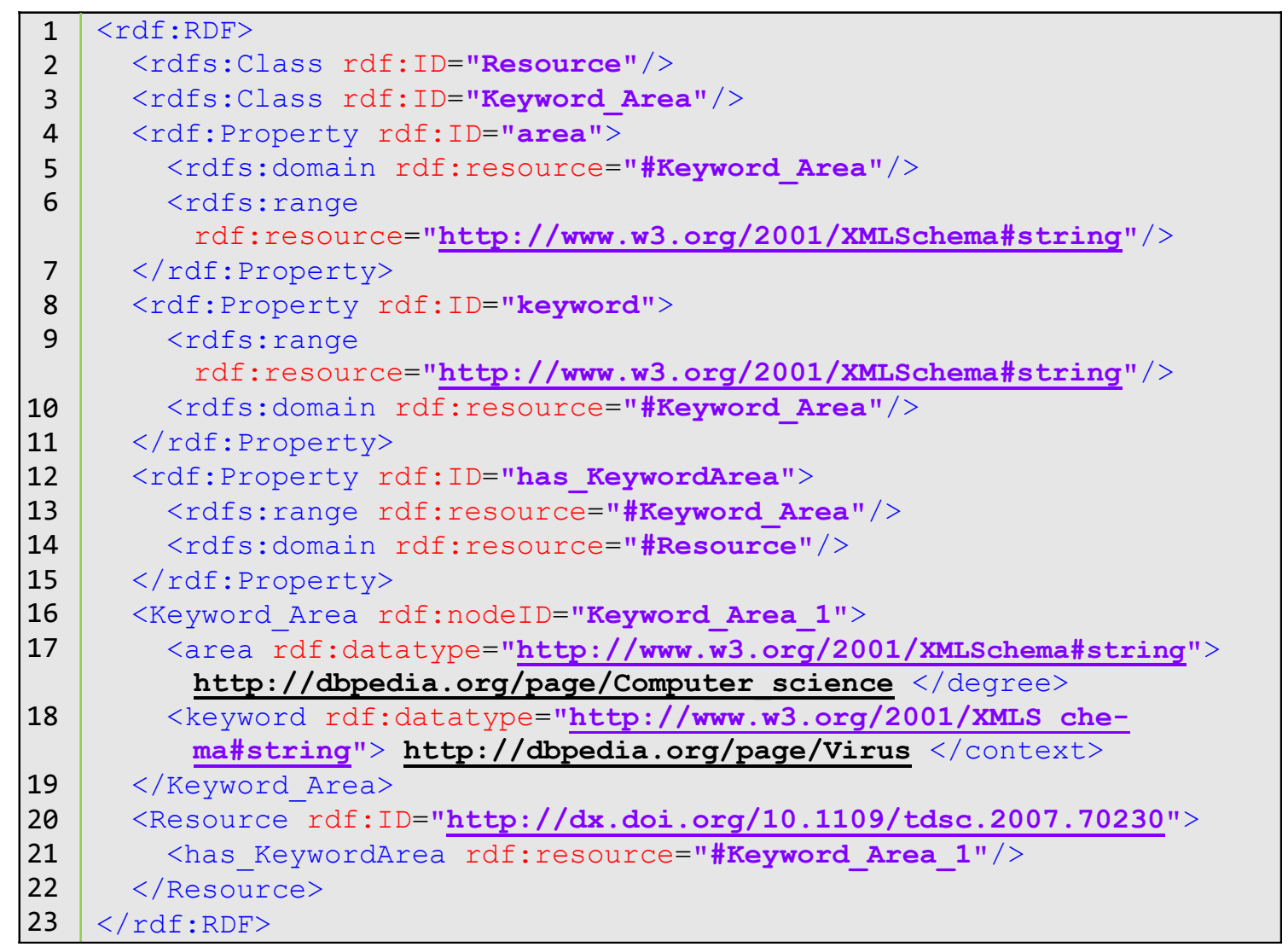

Fonte: Elaborado pelo autor, 2015.

Em TopicMaps, assim como na representação da Área de Titulação, a relação precisa ser criada para cada área de conhecimento, mas com a possibilidade de delimitação de escopo simplifica-se a forma de destacar a titulação. No entanto é necessário decidir o que é considerado contexto no caso de uma titulação: o título ou a área.

A diferença da quantidade de código necessário para XTM, neste caso, é semelhante ao caso das citações, sendo menor que a reificação, mas maior que a ligação direta 1-N. O Código 21 ilustra como é possível representar a área de formação do indivíduo, com qualificador, em XTM. 


\section{Código 23 - Domínio Terminológico em XTM}

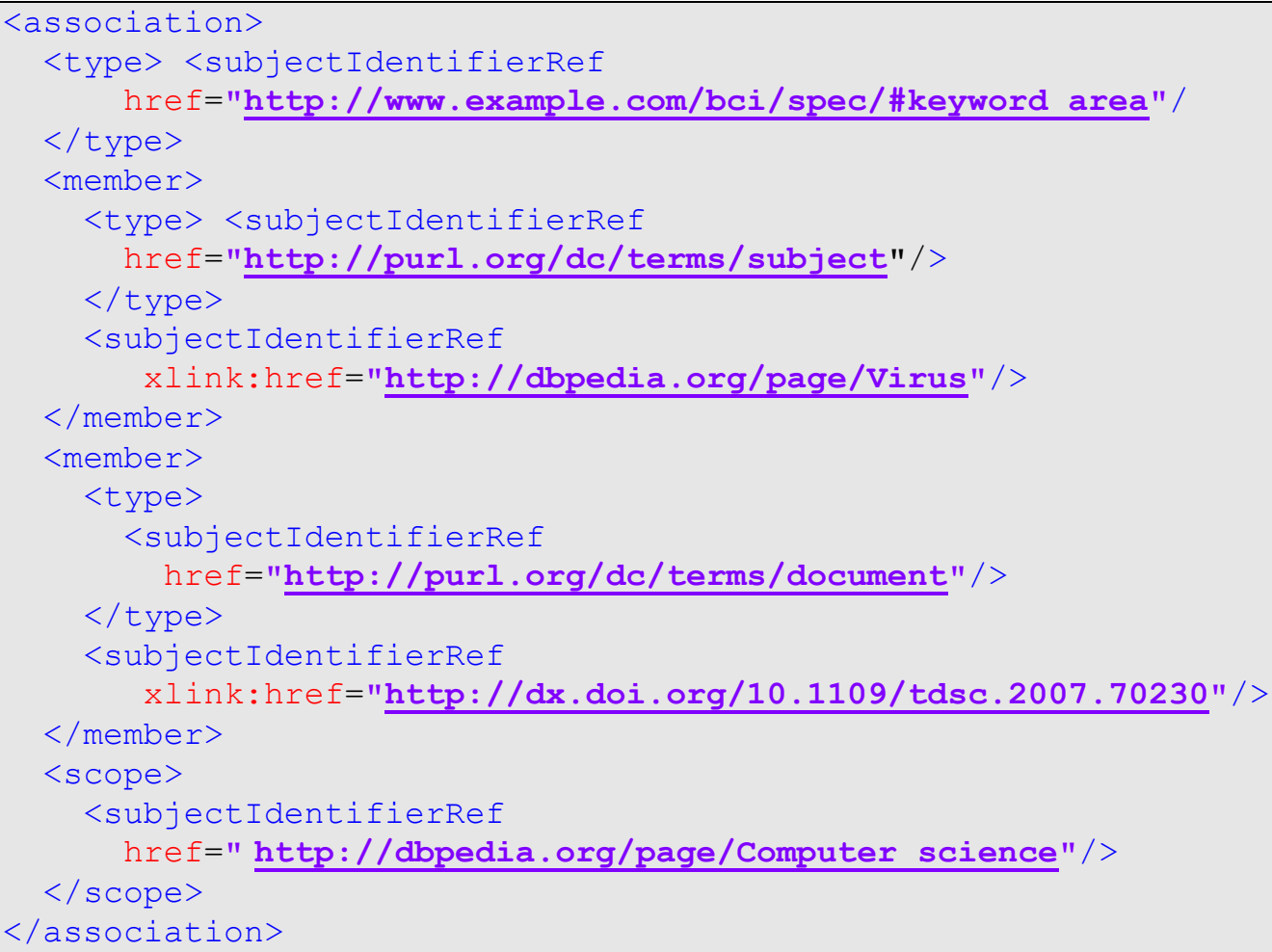

Fonte: Elaborado pelo autor, 2014.

\subsection{5 Área de Publicação da Revista}

A área de publicação da revista pode ser representada de forma semelhante à área de formação do indivíduo, tanto em RDF como em XTM. Uma representação simples, 1-N, em que cada registro da revista indica quais as áreas, de forma ampla ou geral, que cobre em suas publicações. O exemplo do Código 24 mostra um exemplo de como pode ser representada a área de publicação da revista "Incid".

\section{Código 24 - Áreas de Publicação da Revista em RDF Simples}

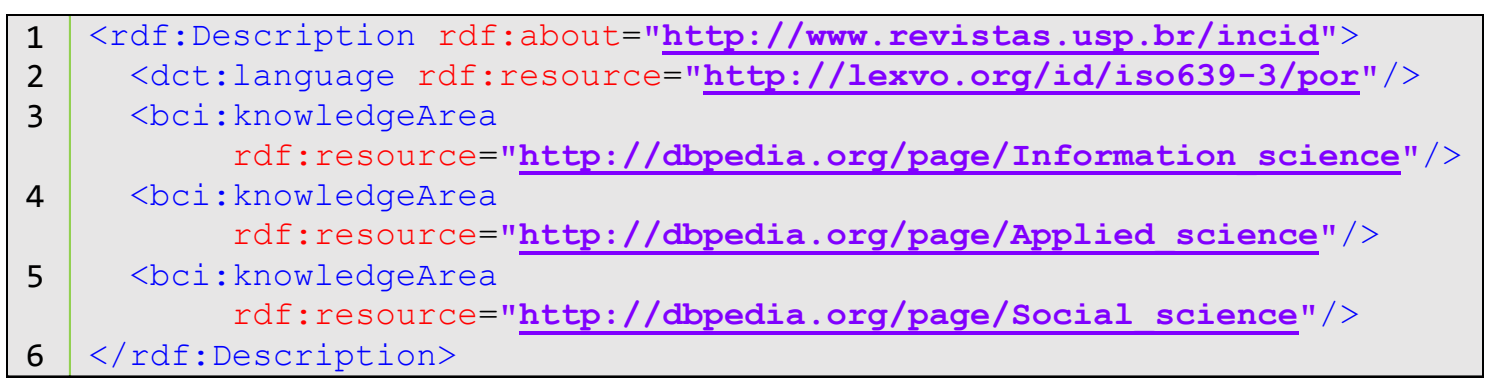

Fonte: Elaborado pelo Autor, 2015. 
De forma semelhante, o Código 25 ilustra um exemplo de representação desta relação em XTM.

\section{Código 25 - Áreas de Publicação da Revista em XTM}

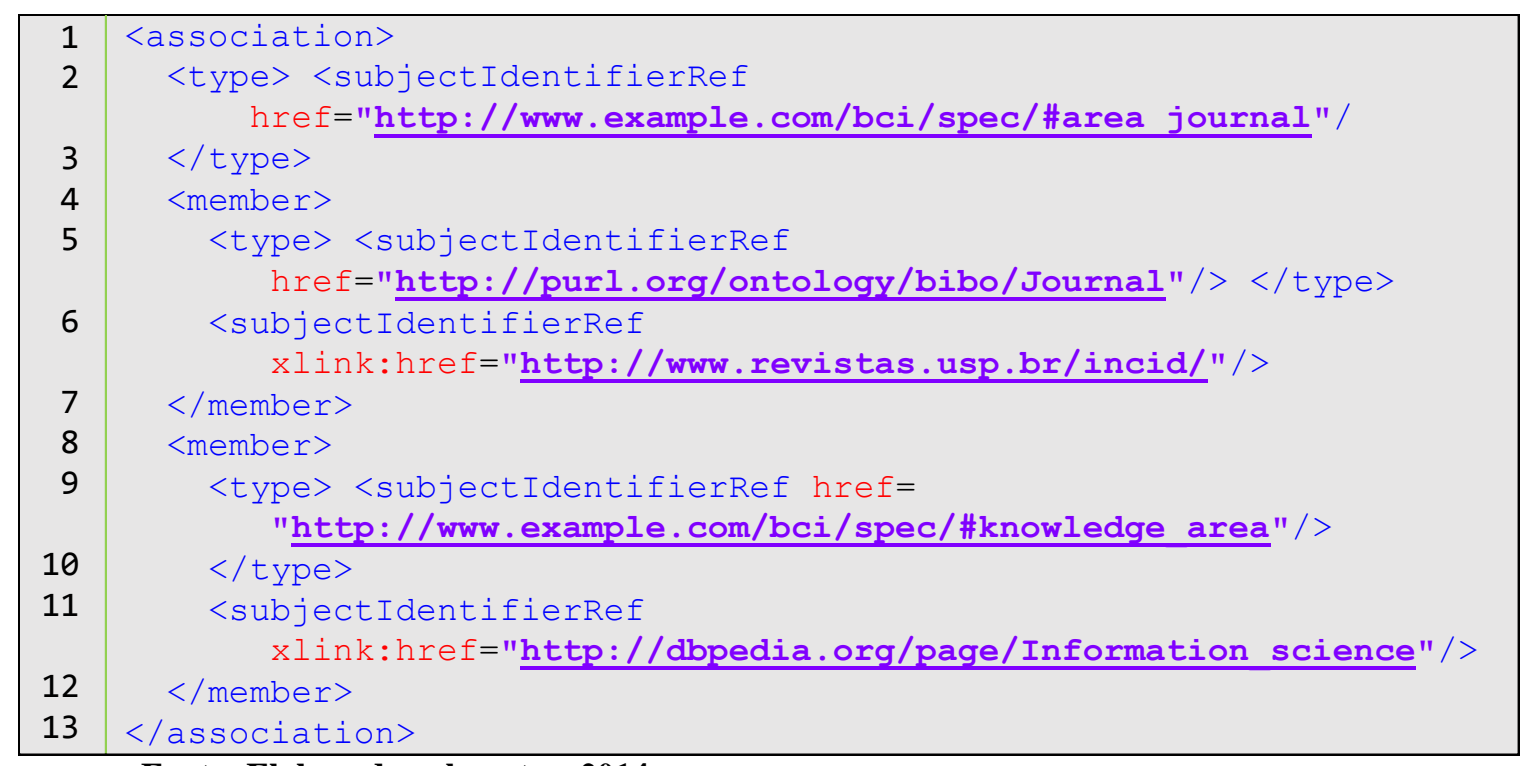

Fonte: Elaborado pelo autor, 2014.

\subsection{6 Áreas de Publicação do Indivíduo}

É possível identificar e extrair as áreas de publicação do autor internamente na Brapci, mas, no caso dos usuários, é necessário criar uma nova representação, que também permita complementar as áreas de publicação dos autores da base. Esta representação é realizada de forma simples, sem a necessidade de reificação em RDF, como pode ser visto no Código 26.

Código 26 - Áreas de Publicação do Indivíduo em RDF

\begin{tabular}{|c|c|}
\hline 1 & $\begin{aligned}<r d f: & \text { Description } \\
& \text { rdf:about="http://www.example.com/page/Denysson Mota" }>\end{aligned}$ \\
\hline 2 & $\begin{array}{l}<\text { bci:publicationArea } \\
\text { rdf:resource="http://dbpedia.org/page/Information science"/> }\end{array}$ \\
\hline 3 & $\begin{array}{l}\text { <bci:publicationArea } \\
\text { rdf:resource="http://dbpedia.org/page/Computer science" / > } \\
\text { </rdf:Description> }\end{array}$ \\
\hline
\end{tabular}

Fonte: Elaborado pelo Autor, 2015.

O Código 27 ilustra um exemplo de representação desta relação em XTM. 
Código 27 - Áreas de Publicação do Indivíduo em XTM

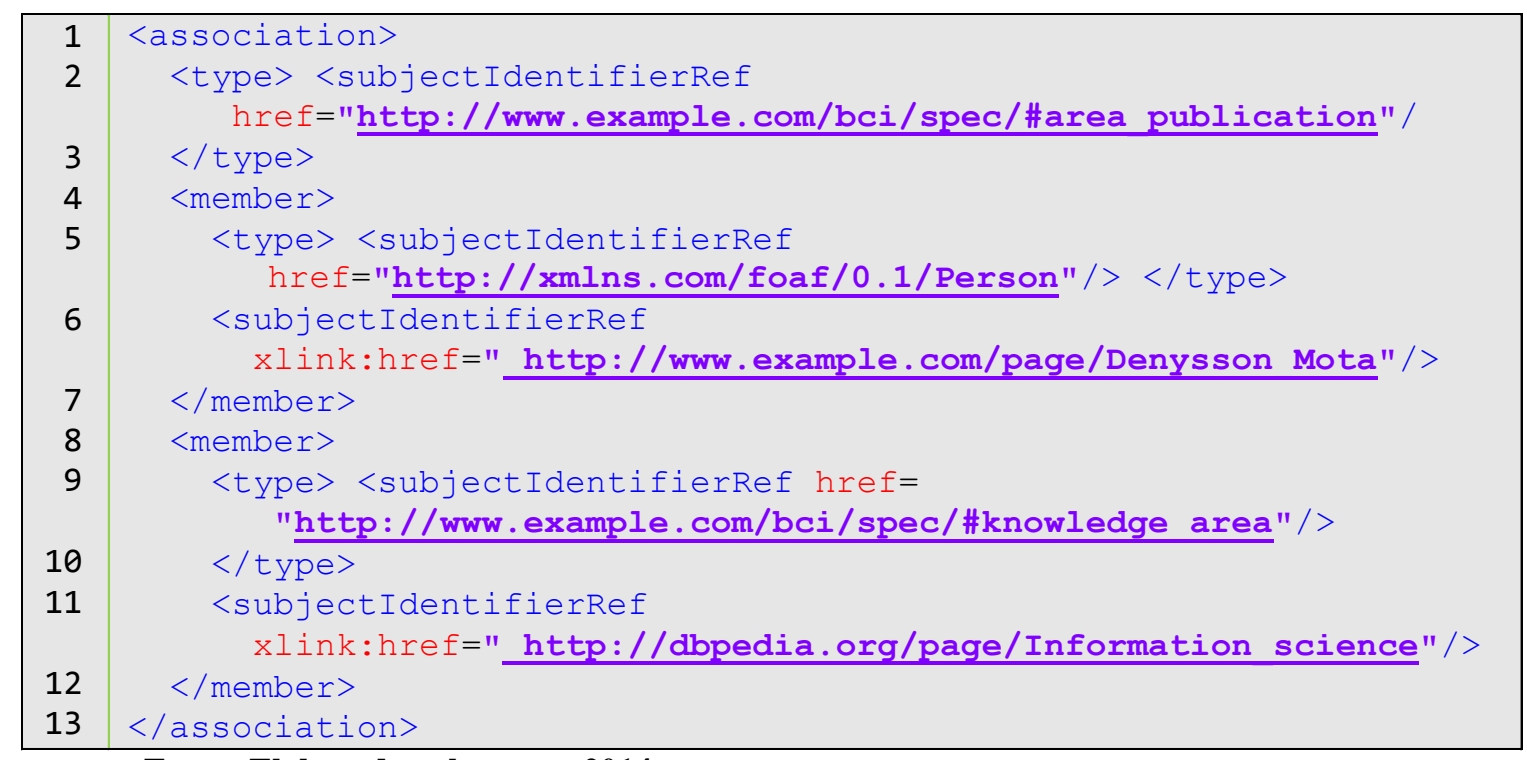

Fonte: Elaborado pelo autor, 2014.

\subsubsection{Interesses do Indivíduo}

No âmbito da Web Semântica já existe a possibilidade de representar os interesses de um indivíduo. Em 2007 foi publicada a versão 0.9 do vocabulário Friend of a Friend ${ }^{30}$, mais conhecido por seu acrônimo FOAF. O objetivo deste vocabulário é criar um repositório de indivíduos, seus dados e suas relações com outros indivíduos.

Com o vocabulário FOAF é possível identificar diversas características dos indivíduos, ilustradas na Figura 24, onde é possível ver as suas propriedades, tais como: e-mail, telefone, publicações e interesses. É este último elemento que permite a representação de interesses também no âmbito da Web Pragmática.

\footnotetext{
${ }^{30}$ http://xmlns.com/foaf/spec/20070524.html
} 
Figura 24 - Propriedades do Vocabulário FOAF

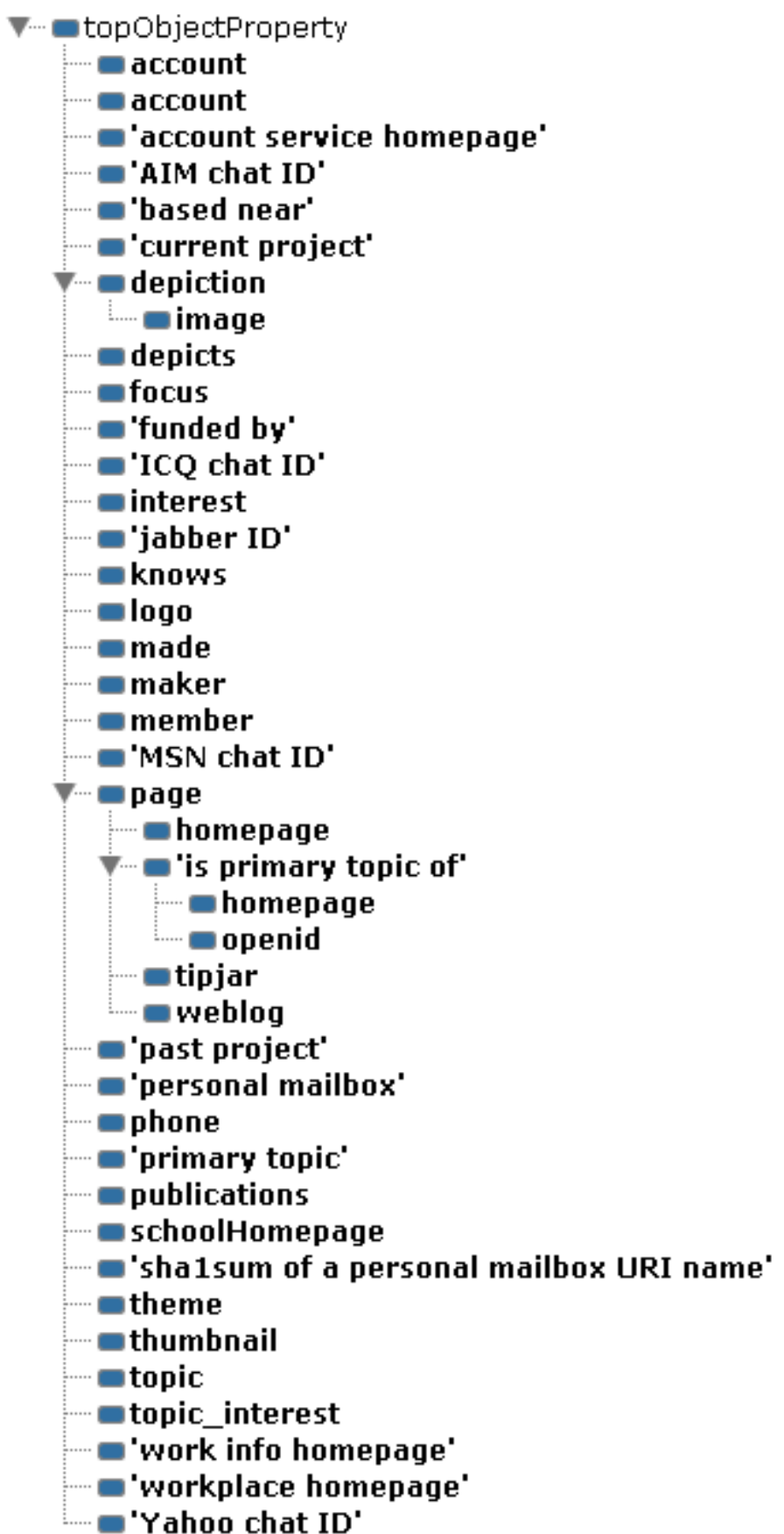

Fonte: BRICKLEY; MILLER, 2007. Adaptado pelo autor, 2015.

A propriedade interest pode ser reutilizada aqui para indicar não apenas um documento, como foi originalmente criada, mas apontar para uma área de conhecimento, ampla ou específica, de interesse dos indivíduos. Desta forma, simplifica-se o modo de realizar as relações e inferências com outros contextos aqui representados, tais como: Domínio Base do Documento, Domínio da Palavra-Chave e Área de Publicação da Revista, por exemplo. 
No Código 28 é ilustrado um exemplo, em RDF simples, de como poderia ser representado este contexto.

\section{Código 28 - Interesse do Indivíduo em RDF}

\begin{tabular}{|c|c|}
\hline 1 & <rdf:Description \\
& rdf:about=" http://www.example.com/page/Denysson Mota" \\
2 & <foaf:interest \\
& rdf:resource="http://dbpedia.org/page/Information science" $/>$ \\
3 & <foaf:interest \\
& rdf:resource="http://dbpedia.org/page/Information retrieval" $/>$ \\
4 & </rdf:Description $>$
\end{tabular}

Fonte: Elaborado pelo Autor, 2015.

O Código 29 ilustra um exemplo de representação desta relação em XTM.

\section{Código 29 - Interesse do Indivíduo em XTM}

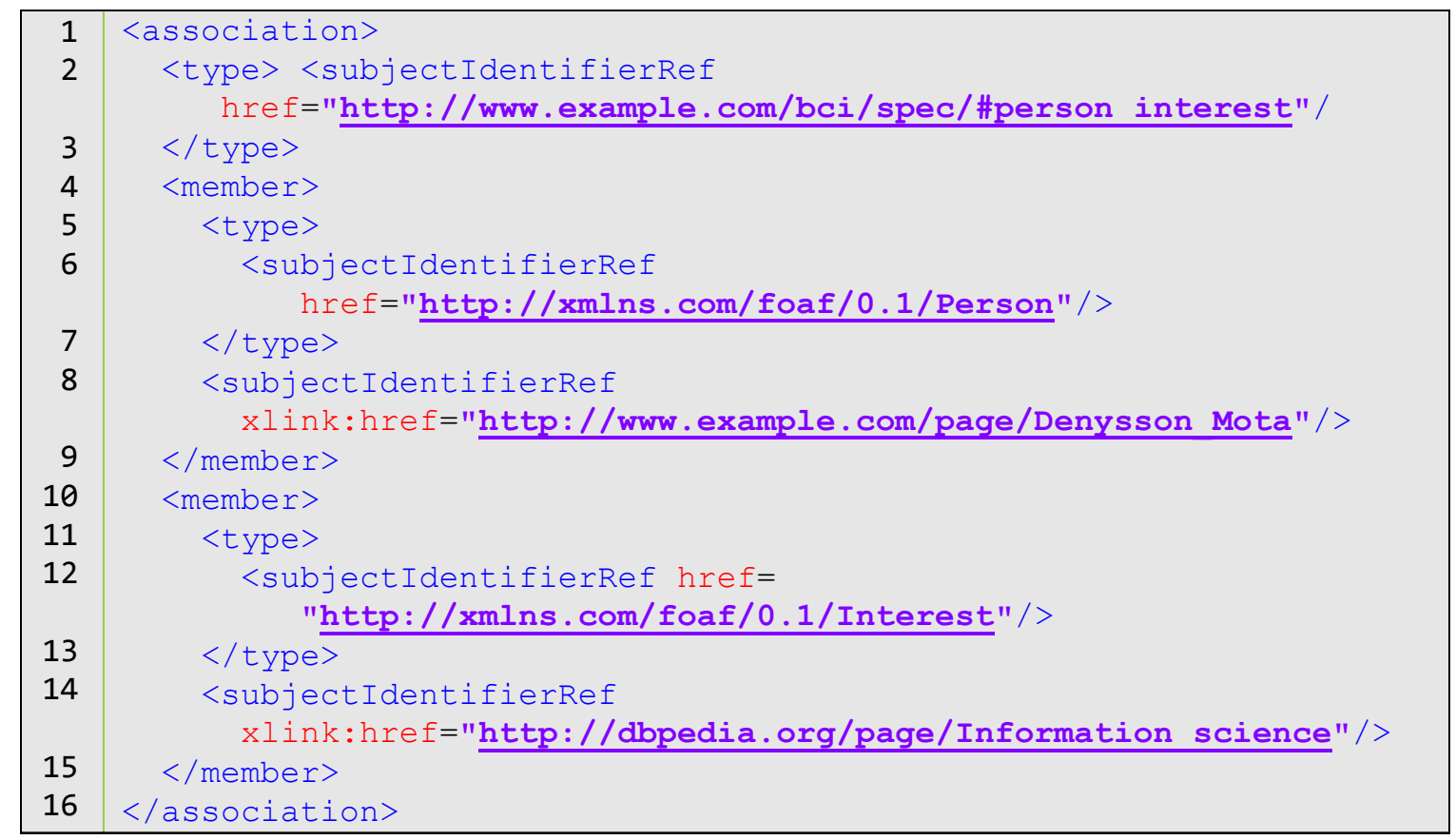

\section{Fonte: Elaborado pelo autor, 2014.}

Estes são apenas alguns exemplos de como é possível modelar e representar um possível contexto na representação da informação de um documento. Outras formas de representação podem ser avaliadas para obter a forma mais adequada e simples de contextualizar as informações atualmente armazenadas em repositórios digitais, que poderão ser disponibilizadas abertamente para a Web, no escopo da Web Semântica, aproximando esta última de uma Web Pragmática.

Os contextos analisados neste capítulo são diversos. Devido à extensão dos contextos analisados e discutidos, poderá ser difícil acompanhar todos os exemplos. 
Para tornar mais clara a proposta, apresenta-se, no Quadro 5, uma sistematização dos contextos apresentados no Capítulo 5 e os principais textos, apresentados no Capítulo 4, utilizados para levantar e discutir os elementos que o compõem, que originaram as representações em DER e, posteriormente, em RDF e XTM.

Quadro 6 - Contextos Representados e Autores Utilizados

\begin{tabular}{|l|l|}
\hline \multicolumn{1}{|c|}{ Contexto } & \multicolumn{1}{|c|}{ Autor } \\
\hline 1. Contexto Intratextual & Armengaud (2006) \\
& Cortina (2000) \\
& Eco (1987) \\
& Greimas e Courtés (1983) \\
\hline 1.1 Citações & ABNT 10520 (2002) \\
& Francelin (2010) \\
\hline 1.2 Domínio de Origem do Documento & Cabré (1993) \\
& Kobashi (1994) \\
\hline 1.3 Domínio da Palavra-Chave & Edmonds (1999) \\
& Cabré (1993) \\
& Van Dijk (1992) \\
& Lara (2004) \\
\hline 2. Contextos Extratextuais & Armengaud (2006) \\
& Cortina (2000) \\
& Eco (1987) \\
& Greimas e Courtés (1983) \\
\hline 2.1 Áreas de Formação do Indivíduo & Cabré (1993) \\
\hline 2.2 Ấreas de Publicação do Indivíduo & Teun Van Dijk (1977b) \\
& Lyons (1979) \\
& Eco (1987) \\
& Eco (2000) \\
\hline 2.3 Áreas de Publicação da Revista & Teun Van Dijk (1977b) \\
& Lyons (1979) \\
Eco (1987) \\
& Eco (2000) \\
& Rothe (1987) \\
\hline & Ingwersen e Järvelin (2005) \\
& Allen e Kim (2001) \\
& Lyons (1979) \\
Eco (1960) \\
\hline
\end{tabular}

Fonte: Elaborado pelo Autor (2015) 


\section{CONSIDERAÇÕES FINAIS}

A presente pesquisa cujo objeto foi a representação e a recuperação de informações em acervos digitais, nos contextos da Web semântica e Web pragmática, caminhou em perspectiva interdisciplinar por abordar problemas discutidos tanto na Ciência da Computação como na Ciência da Informação. A abordagem interdisciplinar ocorreu, em primeiro lugar, porque o objeto de pesquisa, embora tenha origem na Ciência da Computação, requer as teorias e métodos da representação de informações, estudados na Ciência da Informação, para ser desenvolvido de forma adequada e pertinente.

As pesquisas para representar contextos de interpretação para verificação e asserção de relevância, por parte dos SRI, remontam à década de 1970, em diversos estudos de recuperação de informações desenvolvidos no paradigma cognitivo (INGWERSEN, 1992). A importância dessas iniciativas se expressa na realização de um evento, criado em 1996, dedicado exclusivamente a essa temática (VAKKARI; SAVOLAINEN; DERVIN, 1997).

A representação de contextos, por sua vez, é um amplo campo de estudos, com diversos caminhos de pesquisa que não se excluem, mas se complementam. Ganharam maior evidência a partir dos experimentos que vêm sendo realizados para a implementação da Web Semântica e, de modo mais recente, com as ideias de criação da Web Pragmática.

Este trabalho trilhou um desses caminhos. Não se teve como objetivo abordar todos eles ou esgotar as possibilidades de estudos sobre a temática, mas traçar um caminho que permitisse pensar em alternativas para chegar a resultados aplicáveis. Este caminho atribuiu importância decisiva aos estudos realizados nas áreas que se dedicam a pensar a linguagem. Nesse sentido, foram analisadas noções como sintaxe, semântica, pragmática, termo, conceito, contexto e relevância, entre outros. Deve-se ressaltar que as reflexões sobre a importância da linguagem nos processos de representação e busca de informações não são recentes. Na perspectiva linguística, os indivíduos não são seres isolados; ao contrário, eles estão inseridos em grupos sociais que compartilham experiências, linguagem, conhecimentos e cultura.

No contexto científico, utilizam-se linguagens de especialidade para produzir e comunicar conhecimentos. Nessas linguagens, os termos tendem a ser definidos de forma mais precisa do que na linguagem natural. Nessa medida, ao realizar buscas em 
sistemas especializados, os usuários utilizam termos especializados e não apenas palavras da linguagem natural. Dito de outro modo, os usuários recorrem a termos integrados à construção social de conceitos. Pode-se afirmar, portanto, que um contexto social adequadamente representado por meio de conceitos compartilhados é essencial para promover recuperação mais produtiva de informações.

Os contextos específicos abordados nesta pesquisa foram os da Web Semântica e Web Pragmática. Para isso, foram apresentados e discutidos os conceitos fundamentais, pretensões e tecnologias tanto da Web Semântica quanto da Web Pragmática. Como proposto nas hipóteses de trabalho, na Introdução desta tese, partiu-se da ideia que, apesar dos avanços já alcançados nas pesquisas sobre a Web Semântica, é possível criar sistemas mais potentes ao serem incorporadas as questões pragmáticas aos ambientes digitais.

A possibilidade de representação de informação pragmática através de Topic Maps e Ontologias foi outra hipótese levantada na pesquisa. Considerou-se que estes poderiam ser pensados como instrumentos de modelagem de dados contextuais em acervos de ambientes digitais.

Para a operacionalização da proposta, foram identificados os diversos contextos passíveis de serem representados no ambiente da web. Tratou-se, portanto, de criar objetos-modelo relativos aos contextos a serem representados. Esses objetos-modelo foram integrados a uma teoria, como propõe Bunge (1974), no caso, as teorias da linguagem que incorporam aspectos pragmáticos. Contribuíram para isso os estudos de Eco $(1984,1987,2000)$ e Van Djik (1977a, 1977b, 1992), que definem o conceito de frames, juntos com os de Cortina (2000), Lyons, (1975) e Greimas e Courtés (1983). Dos diferentes contextos identificados, foram escolhidos para a representação nos moldes dos SRI atuais e da Web Semântica e Web Pragmática os seguintes elementos: Citações, Domínio-base do Documento, Área de Formação do Indivíduo, Domínio da Palavra-Chave, Área de Publicação da Revista, Áreas de Publicação do Indivíduo e Interesses do Indivíduo.

Para a discussão das formas de operacionalização, optou-se por contrastar três formas de representação: DER, RDF e XTM. O primeiro visa expressar a ideia nos moldes dos SRI atuais que possibilitam a "tradução" para outros modelos de representação de forma relativamente simples. O segundo, o RDF, foi escolhido por ser o padrão tecnológico atual para a representação de recursos informacionais no ambiente 
da Web Semântica, apesar de suas limitações para representação contextual. Já o XTM foi escolhido por ser uma alternativa ao RDF. Com efeito, o XTM incorpora, de forma nativa, a possibilidade de representar contextos por meio dos chamados scopes, que qualificam as relações entre os dados representados. Embora a representação de dados de contexto por meio da linguagem XTM requeira maior número de linhas de código do que em RDF, é uma alternativa interessante e factível para ser utilizada na construção de SRIs, como apresentado na tese.

As possibilidades contextuais aqui expostas objetivam abrir caminhos para a representação de contextos nos ambientes informacionais contemporâneos. Novas pesquisas podem surgir a partir do presente trabalho, dentre as quais podem ser vislumbradas: a criação de ontologias para o trabalho científico; a exploração de contextos adicionais que, em conjunto, permitam identificar a relevância dos textos recuperados; o desenvolvimento de SRIs baseado nos conceitos e metadados elaborados nesta pesquisa.

Constatou-se, por fim, que as propostas da Web Semântica e da Web Pragmática estão longe de incorporar, de forma ampla, a semântica e a pragmática, tal como são definidas na esfera da Linguística e nos estudos semióticos. As limitações impostas pelas tecnologias da informação permitiram constatar que o que de fato é possível adicionar aos sistemas de recuperação de informações, na atualidade, é maior quantidade de dados de natureza sintática aos já existentes nos metadados das páginas web. Com isso, mesmo que seja possível simular operações semânticas em computadores, com o uso de proposições simples, ou operações pragmáticas de adição de elementos contextuais, não se pode afirmar que os conceitos e propostas da Web Semântica e da Web Pragmática incorporam, de fato, a significação.

Consideradas essas limitações, os exemplos aqui apresentados podem ser vistos como operações de adição de dados sintáticos, tanto na representação em RDF quanto em XTM. No entanto as diferenças tecnológicas e práticas entre essas linguagens, como apresentado na tese, trazem impactos importantes nas formas de representação e posterior uso na recuperação.

O RDF tem como objetivo ser simples e de fácil representação, no entanto essa simplicidade traz problemas quando se deseja representar contextos, porque solicita a inclusão de novos objetos e uma camada de complexidade que vai de encontro à simplicidade proposta inicialmente. Por outro lado, o XTM já considera, em sua 
estrutura básica, a possibilidade de representar contextos, chamados especificamente de escopo, que facilitam a representação.

A principal dificuldade encontrada na elaboração desta tese foi definir as formas de representação de contextos considerando as tecnologias da Web Semântica e da Web Pragmática, pois tanto em RDF quanto em XTM não há aplicativos que realmente facilitem ou simplifiquem a construção das representações contextuais, sendo necessário escrever toda a codificação de forma manual. A utilização de programas só é útil para verificar a integridade dos dados. Há plug-ins que permitem adicionar funcionalidades a frameworks de programação para a criação e verificação de códigos em RDF (ex.: $\operatorname{dotNetRDF}^{31}$ e Jena ${ }^{32}$ ), mas exige a instalação de outros programas e sua posterior inclusão e configuração, processos que tornam ainda mais complexa a tarefa de criação de estruturas de dados. Há também ferramentas que permitem criar representações completas em XTM (ex.: Ontopia ${ }^{33}$ ) mas, devido à sua amplitude e complexidade, seu uso é inadequado para a representação de contextos expostas nesta pesquisa. O mesmo ocorre com os programas para criar estruturas em RDF (ex.: RDF Editor in Java ${ }^{34}$ ), cujo uso apresenta alta complexidade.

Em síntese, a compreensão de que há limites para introduzir contextos em sistemas de informação foi o maior aprendizado obtido no desenvolvimento desta pesquisa. Foi possível compreender, também, que termos como semântica e pragmática, requerem abordagem crítica. De fato, a operacionalização de conceitos semânticos e pragmáticos ainda está longe de ser realidade nos sistemas de informação contemporâneos.

A experiência adquirida com esta pesquisa permite pensar em estudos futuros. Como próximo passo, pode-se pensar em definir um vocabulário formal e específico para a representação de contextos, no ambiente da Web Semântica, como um possível caminho a ser percorrido em direção a uma Web Pragmática, nos moldes do que foi utilizado nos Códigos 13 a 29, expostos no Capítulo 5.

Este vocabulário, expansível, poderá partir das seguintes noções: "contexto" de Ingwersen e Järvelin (2005): um conjunto de fatores que influenciam a relevância;

\footnotetext{
${ }^{31}$ https://bitbucket.org/dotnetrdf

32 https://jena.apache.org

${ }^{33} \mathrm{http}: / / w w w . o n t o p i a . n e t$

${ }^{34} \mathrm{http}: / /$ sourceforge.net/projects/rdfeditor
} 
“conjunto-contexto" de Armengaud (2006) e de "mundos possíveis" de Eco (2000): os contextos que, dentro do infinito grupo de contextos possíveis, são os mais prováveis de acontecer; "frames" de Van Dijk (1977b) e Eco (1987): conjunto de conhecimentos de mundo que permite diferentes interpretações das sentenças. O vocabulário deverá incluir os contextos aqui representados e outros que, ao longo do tempo, serão identificados e representados adequadamente para este novo contexto: a Web Pragmática. 


\section{REFERÊNCIAS}

ABBAGNANO, N. Dicionário de Filosofia. São Paulo: Martins Fontes, 1998.

ABBAGNANO, N. Dicionário de Filosofia. 5. ed. rev. e amp. São Paulo: Martins Fontes, 2007.

ALLEN, B.; KIM, K.-S.; Person and context in information seeking: Interactions between cognitive and task variables. The New Review of Information Behaviour Research, v. 2, p. 1-16, 2001.

ALMEIDA, M.; SOUZA, R.; FONSECA, F. Semantics in the Semantic Web: A Critical Evaluation. Knowledge Organization, Berlin, v. 38, No.3, pp. 187 - 203, maio/jun. 2011.

ARBOIT, A. E.; BUFREM, L. S.; KOBASHI, N. Y. A Institucionalização da Ciência da Informação no Brasil sob a Ótica da Evolução Quantitativa dos Cursos de Graduação na Área. Informação \& Sociedade: Estudos, João Pessoa, v.21, n.1, p. 145-158, jan./abr. 2011.

ARISTÓTELES. Órganon. Bauru - SP: Edipro, 2005.

ARMENGAUD, F. A Pragmática. São Paulo: Parábola Editorial, 2006.

ASSOCIAÇÃO BRASILEIRA DE NORMAS TÉCNICAS (ABNT). NBR 10520: Informação e documentação - Citações em documentos - Apresentação. Rio de Janeiro: ABNT, 2002.

BENVENISTE, É. Problemas de linguística geral. São Paulo: Ed. Nacional; EDUSP, 1976. Volume I.

BERNERS-LEE, T. Semantic Web Concepts. 2005a. Disponível em: <http://www.w3.org/2005/Talks/0517-boit-tbl>. Acesso em: 25 set. 2014

BERNERS-LEE, T. Web for real people. 2005b. Disponível em <http://www.w3.org/2005/Talks/0511-keynote-tbl/ >. Acesso em: 25 set. 2014.

BERNERS-LEE, T.; CAILliAU, R. WorldWideWeb: Proposal for a HyperText Project. 1990. Disponível em: < http://www.w3.org/Proposal.html >. Acesso em: 13 out. 2014.

BERNERS-LEE, T.; HENDLER, J.; LASSILA, O. The semantic web: a new form of web content that is meaningful to computers will unleash a revolution of new possibilities. New York: Scientific American, 2001. Disponível em: <http://www.sciam.com/2001/050lissue/0501berners-lee.html>. Acesso em: 13 out. 2014.

BLAIR, D. C. Information Retrieval and the Philosophy of Language. Annual Review of Information Science and Tecchnology, v. 37, pp. 3-50, Medford, 2003. 
BLAIR, D. C. Wittgenstein, Language and Information: Back to the Rough Ground! Dordrecht: Springer, 2006.

BONFIM, M. E. Recuperação de Documentos Texto Usando Um Modelo Probabilístico Estendido. Piracicaba: UNIMEP, 2006. 131 f. Dissertação (Mestrado em Ciência da Computação). Mestrado em Ciência da Computação. Universidade Metodista de Piracicaba, 2006.

BORLUND, P. The Concept of Relevance in IR. Journal of the American Society for Information Science and Technology, v.54, p. 913-925, 2003.

BORST, W. N. Construction of engineering ontologies. Tese (Doutorado em Information and Knowledge Systems). University of Tweenty - Centre for Telematica and Information Technology, Enschede, Nederland, 1997.

BOUNDLESS. Boundless Psychology. 201X. Disponível em < https://www.boundless.com/psychology/textbooks/boundless-psychology-textbook/ > Acesso em: 13 ago. 2014.

BRATT, S. Semantic Web, and Other Technologies to Watch. 2008. Disponível em < http://www.w3.org/2008/Talks/1009-bratt-W3CSemTech/Overview.html > Acesso em: 13 ago. 2014.

BRÉAL, M. Semantics: studies in the science of meaning. New York: Henry Holt \& Company, 1900.

BRICKLEY, D.; MILLER, L. FOAF Vocabulary Specification 0.9. 2007. Disponível em < http://xmlns.com/foaf/spec/20070524.html > Acesso em: 17 maio 2015.

BRITISH LIBRARY. Sample Data. Disponível em <http://www.bl.uk/bibliographic/ datasamples.html>. Acesso em: 12 dez. 2014.

BRUYNE, P. de, HERMAN, J., SCHOUTHEETE, M. de. Dinâmica da pesquisa em ciências sociais. Rio de Janeiro: Francisco Alves, 1977.

BUFREM, L. S, et al. Modelizando práticas para a socialização de informações- a construção de saberes no ensino superior. Perspectivas em Ciência da Informação, Belo Horizonte, v.15, n.2, p.22-41, maio/ago. 2010.

BUNGE, M. Teoria e realidade. São Paulo, Perspectiva, 1974.

CABRÉ, M. T. La terminologia: representación y comunicación: elementos para una teoría de base comunicativa y otros artículos. Barcelona: IULA/Universitat Pompeu Fabra, 1999.

CABRÉ, M. T. La terminología: teoría, metodología, aplicaciones. Barcelona: Antártida/Empúries, 1993. 
CANÇADO, M. Manual de Semântica: noções básicas e exercícios. Belo Horizonte: UFMG, 2008.

CAPURRO, R. What is information science for? A philosophical reflection. in: Pertti Vakkari, Blaise Cronin Eds.: Conceptions of Library and Information Science. Historical, empirical and theoretical perspectives, London: Taylor Graham 1992, pp. 8298.

CARDOSO, O. N. P. Recuperação de Informação. Infocomp, Lavras, v. 2, n. 1, p. 33$38,2000$.

CARSTAIRS-MCCARTHY, A. Origins of Language. In: ARONOFF, M.; RESSMILLER, J. The Handbook of Linguistics. Oxford: Blackwell Publishers Ltd, 2008. p. $1-18$.

CASE, D. O. Looking for Information: A Survey of Research on Information Seeking, Needs, and Behavior. London: Academic Press, 2007.

CHEN, P. P-S. The Entity-Relationship Model-Toward a Unified View of Data. ACM Transactions on Database Systems, v.1, n.1, p. 9-36, 1976. Disponível em: <http://www.csc.lsu.edu/news/erd.pdf>. Acesso em 23 mar. 2014.

CINTRA, A. et al. Para Entender as Linguagens Documentárias. São Paulo: Polis, 1994.

CORTINA, A. O Príncipe de Maquiavel e seus leitores: uma investigação sobre o processo de leitura. São Paulo: Editora UNESP, 2000.

DAHLBERG, I. Teoria do conceito. Ciência da Informação, Rio de Janeiro, v. 7, n. 2, p. 101-107, 1978. Disponível em: <http://revista.ibict.br/index.php/ciinf/article/view/ 1680/1286>. Acesso em 23 mar. 2014.

DE MOOR, A. Patterns for the Pragmatic Web, In: DAU, F.; MUGNIER, M.-L.; STUMME, G. International Conference on Conceptual Structures. Lecture Notes in Computer Science, v. 3596, p. 1-18, 2005.

DE MOOR, A.; KEELER, M.; RICHMOND, G. Towards a pragmatic web, In: UTA, Priss et al. Conceptual Structures: Integration and Interfaces. Lecture Notes in Computer Science, v. 2393, p. 235-249, 2002. Disponível em < http://www.cspeirce.com/menu/library/aboutcsp/richmond/web.pdf >. Acesso em 23 mar. 2014.

DI MAIO, P. The Missing Pragmatic Link in the Semantic Web. Business Intelligence Advisory Service Executive Update. v. 8, n. 7, 2008.

ECO, U. Lector in Fabula: la cooperación interpretativa en el texto narrativo. Barcelona: Lumen, 1987

ECO, U. O conceito de texto. São Paulo: T. A. Q. /EDUSP, 1984. 
ECO, U. Obra aberta: forma e indeterminação nas poéticas contemporâneas. São Paulo: Perspectiva, 1988.

ECO, U. Os limites da interpretação. São Paulo: Pioneira, 2000.

EDMONDS, B. The Pragmatic Roots of Context. In: PROC. OF THE 2ND INTERNATIONAL AND INTERDISCIPLINARY CONFERENCE ON MODELING AND USING CONTEXT. Berlin; Heidelberg; New York, v. 1688, 1999. Anais... v. 1688, p. 119-132, 1999.

FLORIDI, L. On the intrinsic value of information objects and the infosphere. Ethics and Information Technology, v. 4, n. 4, p 287-304, 2002.

FRANCELIN, M. M. Ordem dos conceitos na organização da informação e do conhecimento. Tese (Doutorado em Ciência da Informação). Universidade de São Paulo - PPGCI, São Paulo, 2010.

FREGE, G. Lógica e Filosofia da Linguagem. São Paulo: EDUSP, 2009.

GARSHOL, L. M. Living with topic maps and RDF. 2003. Disponível em <http://www.ontopia.net/topicmaps/materials/tmrdf.html> Acesso em: 08 abr. 2014.

GESSA, N. Test Cases for RDF/TM Interoperability. 2005. Disponível em <http://tesi.fabio.web.cs.unibo.it/view/RDFTM/TestCases>. Acesso em 14 dez. 2014.

GERSTING, J. L. Fundamentos Matemáticos para a Ciência da Computação. Rio de Janeiro: LTC, 1995.

GONZÁLEZ DE GOMEZ, M. N.; GRACIOSO, L. de S. Ciência da informação e a ação comunicativa no cenário Web. In: ENCONTRO NACIONAL DE PESQUISA EM CIÊNCIA DA INFORMAÇÃO, v.8, 2007, Salvador. Anais..., v.8, 2007.

GONZÁLEZ, J. A. M. et al. De los tesauros a los topic maps: nuevo estándar para la representación y la organización de la información. Enc. Bibli: R. Eletr. Bibliotecon. Ci. Inf., Florianópolis, n.18, $2^{\circ}$ sem. 2004.

GRACIOSO, L. de S. Justificação e a ação de informação no contexto da pragmática virtual. Liinc em Revista, Rio de Janeiro, v.6, n.2, p. 286- 300, set. 2010.

GREIMAS, A. J., COURTÉS, J. Dicionário de semiótica. São Paulo: Cultrix, 1983.

GRUBER, T. A translation approach to portable ontologies. Knowledge Acquisition, v.5, n.2, p. 199-220, 1993.

GRUBER, T. SKRB Mailing List, 1994.

GUARINO, N. Formal Ontology in Information Systems. 1998. Disponível em: $<$ http://citeseerx.ist.psu.edu/viewdoc/download?doi=10.1.1.29.1776\&rep=rep1\&type=p df>. Acesso em 23 mar. 2014. 
HJØRLAND, B. Concept theory. Journal of the American Society for Information Science and Technology, v.60, n.8, p.1519-1536, 2009.

HJØRLAND, B. Domain analysis in information science: eleven approaches traditional as well as innovative. Journal of Documentation, v.58, n.4, 2002, p. 422-462, 2002.

HJØRLAND, B. Is classification necessary after google? Journal of Documentation. 2012, 68(3), 299-317.

HJØRLAND, B. The phrase "information storage and retrieval" (IS\&R): A historical note. Journal of the Association for Information Science and Technology. 2014. Disponível em: <http://www.curis.ku.dk/ws/files/94411548/IS_R_Final.docx>. Acesso em: 14 dez. 2014.

HJØRLAND, B. What is Knowledge Organization (KO)? Knowledge Organization, v.35, n.2/3, p.86-101, 2008.

INGWERSEN, P. Information Retrieval Interaction. London: Taylor Graham, 1992.

INGWERSEN, P.; JÄRVELIN, K. The turn: integration of information seeking and retrieval in context. Dordrecht, The Netherlands: Springer, 2005.

INTERNATIONAL ORGANIZATION FOR STANDARDIZATION (ISO). ISO/IEC 13250:2003: Information technology -- SGML applications -- Topic maps. Genebra, 2003.

INTERNATIONAL ORGANIZATION FOR STANDARDIZATION (ISO). ISO/IEC 13250-2:2006: Information technology -- Topic Maps -- Part 2: Data model. Genebra, 2006.

INTERNATIONAL ORGANIZATION FOR STANDARDIZATION (ISO). ISO/IEC 13250-3:2013: Information technology -- Topic Maps -- Part 3: XML syntax. Genebra, 2013.

JAPIASSÚ, H.; MARCONDES, D. Dicionário Básico de Filosofia. Rio de Janeiro: Zahar, 2006.

JÄRVELIN, K.; VAKKARI, P. The Evolution of Library and Information Science 1965-85: A Content Analysis of Journal Articles. In: VAKKARI, P.; CRONIN, B., Conceptions of Library and Information Science: Historical, empirical and theoretical perspectives. London, UK: Taylor Graham, 1992. p. 109-125.

JULIEN, H.; MICHELS, D. Intra-individual information behaviour in daily life. Information Processing and Management, v. 40, p. 547-562, 2004.

KEMP, D. A. Relevance, Pertinence and Information System Development. Information Storage and Retrieval, V. 10, N. 2, pp. 37-47, 1974. 
KOBASHI, N. Y. A elaboração de informações documentárias: em busca de uma metodologia. Tese (Doutorado em Ciências da Comunicação). Universidade de São Paulo - Programa de Pós Graduação em Comunicação, São Paulo, 1994.

KOBASHI, N. Y.; SANTOS, R. N. M. dos. Institucionalização da pesquisa científica no Brasil: cartografia temática e de redes sociais por meio de técnicas bibliométricas. Transinformação. Campinas, v. 18, p. 27-36, 2006.

KUHN, T. S. The Structure of Scientific Revolutions. 2. ed. Chicago: University of Chicago Press, 1970.

LANCASTER, F. W. Indexação e resumos: teoria e prática. 2. ed. Brasília: Briquet de Lemos, 2004.

LARA, M. L. G. de. Diferenças conceituais sobre termos e definições e implicações na organização da linguagem documentária. Ciência da Informação. Brasília, v.33, n.2, p.91-96, maio/ago. 2004. Disponível em: <http://revista.ibict.br/index.php/ciinf/ article/download/266/23>. Acesso em: 28 fev. 2014.

LOPES, E. Fundamentos da linguística contemporânea. São Paulo: Cultrix, 1999.

LYONS, J. Introdução à Linguística teórica. São Paulo: Nacional, Edusp, 1979.

LYONS, J. Introduction to Theoretical Linguistics. Cambridge: Cambridge University Press, 1975.

MANNING, C. D.; RAGHAVAN, P.; SCHÜTZE, H. Introduction to Information Retrieval. Cambridge: Cambridge UP, 2008.

MARTINS, G. K. Institucionalização cognitiva e social da Organização e Representação do Conhecimento na Ciência da Informação no Brasil. Tese (Doutorado em Ciência da Informação). Universidade Estadual Paulista - PPGCI, Marília, 2014.

MARTINS, G. K. Mapa conceitual de uma ontologia de domínio do Patrimônio Imaterial Brasileiro: um percurso pelos caminhos de Peirce, Dahlberg e Novak. João Pessoa: UFPB, 2010. 131 f. Dissertação (Mestrado em Ciência da Informação). Programa de Pós-Graduação em Ciência da Informação (PPGCI). Universidade Federal da Paraíba, 2010.

MOOERS, C. N. Zatocoding applied to mechanical organization of knowledge. American Documentation, 2, 20-32, 1951

MORRIS, C. Fundamentos de la teoría de los signos. Barcelona: Paidós, 1985.

MOTA, D.; KOBASHI, N. Y. Inclusão de contexto em artigos científicos: em busca da web pragmática. 2014. Disponível em <http://biredial.ucr.ac.cr/index.php/BiredialISTEC_2014/2014/paper/view/133>. Acesso em 14 dez. 2014. 
O' REILLY, T. What is Web 2.0. Disponível em: <http://www.oreillynet.com/pub/a/oreilly/tim/news/2005/09/30/what-is-web-20.html>. Acesso em 14 dez. 2014.

PALMER, F. R. Semantics: a new outline. Cambridge: Cambridge University Press, 1981.

PEIRCE, C. S. Semiótica. São Paulo: Perspectiva, 1977.

PEPPER, S. Ten Theses on Topic Maps and RDF. 2002. Disponível em <http://www.ontopia.net/topicmaps/materials/rdf.html>. Acesso em: 08 abr. 2014.

PEPPER, S. The TAO of Topic Maps. 2000. Disponível em <http://www.ontopia.net/topicmaps/materials/tao.html >. Acesso em: 08 abr. 2014.

PIETARINEN, A. The Semantic + Pragmatic Web = The Semiotic Web. 2003. Disponível em <http://www.helsinki.fi/ pietarin/publications/The Semiotic WebPietarinen.pdf $>$. Acesso em: 08 abr. 2014.

RAMALHO, R. A. S.; VIDOTTI, S. A. B. G.; FUJITA, M. S. L. Web semântica: uma investigação sob o olhar da Ciência da Informação. Datagramazero. Rio de Janeiro, v. 8, p. 1-16, 2007.

ROTHE, A. El papel del lector en la crítica alemana contemporânea. In: MAYORAL, José Antonio (Org.). Estetica de la recepción. Madrid: ARCO/LIBROS S. A. 1987, pp. $13-30$

ROVIRA, C. DigiDocMap conceptual maps editor and Topic Maps norms. 2005. Disponível em: <http://www.upf.edu/hipertextnet/en/...3/digidocmap.html>. Acesso em: 20 set. 2014.

SARACEVIC, T. Relevance: A Review of and a Framework for Thinking on the Notion in Information Science. Journal of the American Society for Information Science, nov./dez. 1975. pp. 321-343.

SARACEVIC, T. Relevance: A Review of the Literature and a Framework for Thinking on the Notion in Information Science. Part II: Nature and Manifestations of Relevance. Journal of the American Society for Information Science and Technology, v. 58, n. 13, pp. 1915-1933, 2007.

SAUSSURE, F. de. Natureza do signo lingüístico. In: Curso de Linguística geral. São Paulo: Cultrix, 2008.

SCHOOP, M.; DE MOOR, A.; DIETZ, J. L.G. The Pragmatic Web: A Manifesto. Communications of the ACM: two decades of the language-action perspective, v. 49, n. 5, maio, p. 75-76, 2006.

SCHUTZ, A. Reflections on the Problem of Relevance. New Haven: Yale University Press, 1970. 
SHEN, X.; TAN, B.; ZHAI, C. Context-sensitive information retrieval using implicit feedback. 2005. Disponível em: < http://sifaka.cs.uiuc.edu/czhai/pub/sigir05-if.pdf >. Acesso em: 20 set. 2014.

SHOTTON. D.; PERONI, S. CiTO, the Citation Typing Ontology. Disponível em <http://purl.org/spar/cito/>. Acesso em: 14 dez. 2014.

SINGH, M. P. The Pragmatic Web. IEEE Internet Computing, v. 6, n. 3, May/June, p. 4-5, 2002a.

SINGH, M. P. The Pragmatic Web: Preliminary thoughts. 2002b. Disponível em: <http://lsdis.cs.uga.edu/SemNSF/Singh-Position.pdf>. Acesso em: 14 dez. 2014.

SINGH, M. P. Tools for Pragmatics: Metadata for Nothing; Ontologies for Free? 200X. Disponível em: <http://www.csc.ncsu.edu/faculty/mpsingh/papers/positions/ Singh-meaning.pdf $>$. Acesso em: 14 dez. 2014.

SOWA, J. F. Knowledge Representation: Logical, Philosophical, and. Computational Foundations. Pacific Grove: Brooks/Cole., 2000a.

SOWA, J. F. Ontology, Metadata and Semiotics. In: GANTER, B; MINEAU, W. Conceptual Structures: Logical, Linguistic, and Computational Issues, Lecture Notes in AI \#1867, Berlin: Springer-Verlag, 2000b, p. 55-81.

SOWA, J. F. Top-Level Categories. 2001. Disponível em < http://www.jfsowa.com/ontology/ toplevel.htm>. Acesso em: 22 mar. 2015.

STRAWSON, P. F. On referring. Mind: New Series, v. 59, n. 235, p. 320-344, 1950.

TAMBA-MECZ, I. A Semântica. São Paulo: Parábola Editorial, 2006.

USCHOLD, M.; GRÜNINGER, M. Ontologies: Principles, Methods and Applications. Knowledge Engineering Review, vol. 11, $\mathrm{n}^{\circ}$ 2, 1996, pp. 93-155. Disponível em: <http://www.aiai.ed.ac.uk/project/ftp/documents/1996/96-kerintro-ontologies.ps>.

Acesso em: 22 mar. 2015.

VAKKARI, P.; SAVOLAINEN, R.; DERVIN, B. Information Seeking in Context. Proceedings of an International Conference on Research in Information Needs, Seeking and Use in Different Contexts, $\mathrm{n}^{\mathbf{0}}$ 1, 1996. Tampere, Finlândia, Anais... Londres: Taylor Graham, 1997.

VALLET, D. et al. Personalized Information Retrieval in Context. 2006. Disponível em < http://ir.ii.uam.es/ acemedia/publications/mrc06.pdf >. Acesso em 20 set. 2014.

VAN DIJK, T. A. Cognição, discurso e interação. São Paulo: Contexto, 1992.

VAN DIJK, T. A. Context and cognition: Knowledge frames and speech act comprehension. Journal of Pragmatics, v. 1, p. 211-232, 1977a. 
VAN DIJK, T. A. Text and Context: Exploration in the semantics and pragmatics of discourse. London: Longman, 1977b.

WHITLEY, R. Cognitive and social institucionalization of scientific specialities and research areas. In: WHITLEY, R. Social processes of scientific development. London: Routledge and Kegan, 1974. p. 69-95.

WITTGENSTEIN, L. Investigações Filosóficas. Petrópolis: Editora Vozes, 2009.

WITTGENSTEIN, L. Tractatus Logico-Philosophicus. São Paulo: Companhia Editora Nacional/EDUSP, 1968.

WORLD WIDE WEB CONSORTIUM (W3C). Defining N-ary Relations on the Semantic Web. 2006. Disponível em < http://www.w3.org/TR/swbp-n-aryRelations/ >. Acesso em 20 abr. 2014.

WORLD WIDE WEB CONSORTIUM (W3C). OWL 2 Web Ontology Language Document Overview. 2.ed. 2012a. Disponível em: <http://www.w3.org/TR/2012/RECowl2-overview-20121211/>. Acesso em: 12 dez. 2014.

WORLD WIDE WEB CONSORTIUM (W3C). OWL 2 Web Ontology Language Primer. 2.ed. 2012b. Disponível em: <http://www.w3.org/TR/2012/REC-owl2-primer20121211/>. Acesso em: 12 dez. 2014.

WORLD WIDE WEB CONSORTIUM (W3C). RDF 1.1 Concepts and Abstract Syntax. 2014a. Disponível em < http://www.w3.org/TR/2014/REC-rdf11-concepts20140225/ >. Acesso em 20 abr. 2014.

WORLD WIDE WEB CONSORTIUM (W3C). Resource Description Framework (RDF). 2014b. Disponível em < http://www.w3.org/RDF/ >. Acesso em < 20 abr. 2014>. 